\title{
A CRITIQUE OF THE
}

\section{THEORY OF EVOLUTION}

THOMAS HUNT MORGAN 

Jonathan wittenberg 



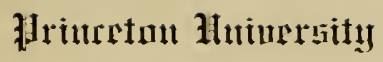

THE LOUIS CLARK VANUXEM FOUNDATION LECTURES FOR 1915-1916 


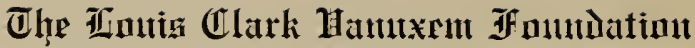

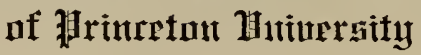

was established in 1912 with a bequest of $\$ 25,000$ under the will of Louis Clark $I$ anuxem, of the Class of 18\%9. By direction of the executors of Mr. Vanuxem's estate, the income of the founclation is to be used for a series of public lectures delivered in Princeton ammally, at least one half of which shall be on subjects of current scientific interest. The lectures are to be published and distributed among schools and libraries generally.

The following lectures have already been published or are in press:

1912-13 The Theory of Permutable Functions, by Vito Volterra

1913-14 Lectures delivered in connection with the dedication of the Graduate College of Princeton University by Emile Boutroux, Alois Riehl, A. D. Godley, and Arthur Shipley

1914-15 Romance, by Sir Walter Raleigh

1915-16 $\triangle$ Critique of the Theory of Evolution, by Thomas Hunt Morgan 


\title{
A CRITIQUE
}

OF THE

\section{THEORY OF EVOLUTION}

\author{
BY \\ THOMAS HUNT MORGAN
}

PROFESSOR OF EXPERTMENTAL ZOOLOGY IN

COLUMBIA UNIVERSITY

LECTURES DELIVERED AT PRINCETON UNIVERSITY

FEBRUARY 24, MARCH 1, 8, 15, 1916

PRINCETON UNIVERSITY PRESS

PRINCETON

LONDON : HUMPHREY MILFORD

OAFORD UNIVERSITY PRESS

1916 
Copyright, 1916, by

Princeton Univerity Press

Publisled October. 1916

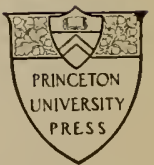




\section{PREFACE}

Occasionally one hears today the statement that we have come to realize that we know nothing about evolution. 'This point of riew is a liealthy reaction to the orer-conficlent belief that we knew everything about evolution. 'There are even those rash enough to think that in the last few years we have learned more about evolution than we might have hoped to know a few years ago. A critique therefore not only becomes a criticism of the older evidence but an appreciation of the new eridence.

In the first lecture an attempt is made to put a new raluation on the traditional evidence for erolution. In the second lecture the most recent work on heredity is dealt with, for only characters that are inherited can become a part 
of the evolutionary process. In the third lecture the physical basis of heredity and the composition of the germ plasm stream are examined in the light of new observations; while in the fourth lecture the thesis is developed that chance variation combined with a property of living things to manifold themselves is the key note of modern erolutionary thought.

$$
\text { T. H. MORGaN }
$$

July, 1916 


\section{'TABLE OF CON'TEN'TS}

CHAPTER I

A REVALUATION OF THE EVIDENCE ON WHICH THE THEORY OF EVOLUTION WAS BASED

PAGE

Preface $\ldots \ldots \ldots \ldots \ldots \ldots \ldots \ldots \ldots \ldots \ldots$

1. Three Kinds of Evolution ........... 1- 7

2 The Evidence for Organic Evolution..... 7-27

a. The Evidence from Comparative Anatomy 7-1t

b. The Evidence from Embryology..... 1t-23

c. The Evidence from Paleontology.... 24-27

3. Tile Four Great Historical Speculations. .27-39

a. The Environment.............27-31

Geoffroy St. Hilaire

b. L'se and Disuse.............. 31-31

From Lamarck to Weismann

c. The Lnfolding Principle........... 3t-36

Yägeli and Bateson

d. Natural Selection.............36-39

Darwin 


\section{CHAPTER II}

THE BEARING OF IIENDEL'S DISCOVERY ON THE ORIGIN OF HEREDITY CHARACTERS

1. Mendel's First Discorery-Segregation......1-52

2. Mendel's Second Discovery-Independent As-

sortment $\ldots \ldots \ldots \ldots \ldots \ldots \ldots \ldots 2-59$

3. The Characters of IVild Animals and Plants Follow the Same Laws of Inheritance as do the Characters of Domesticated Animals and Plants ................... . . . . .

a. Sexual Dimorphism ...........61-6t

Eosin eye color of Drosophila....61-62

Color of the Clover Butterfly. Colias philodice .............62-63

Color of Papilio turnus.........63

Color pattern of Papilio polytes.....63-6 $\mathrm{t}$

b. Duplication of parts..........65-66

Thorax of Drosophila...........65

Legs of Drosophila...........65-66

c. Loss of characters............66-68

"Eyeless" of Drosophila.........66-67

Vestigial wings of Drosophila.....67

Bar eye of Drosophila.........67-68

d. Simall changes of characters........68-70

"Speck" .................68

Bristles of "club" ...........70

e. Manifold effects of same factor......71

f. Constant but trivial effects may be the product of factors laving other vital aspects ................ 73 
g. Sex-linked inheritance . . . . . . . . 75-80

in Drosophila ampelophila . . . . . . 75-76

in the wild species D. repleta......76

in $\operatorname{man} \ldots \ldots \ldots \ldots \ldots \ldots \ldots$

in domesticated Fowls..........77-78

in the wild moth, Abraxas........78-80

h. Inltiple allelomorphs...... ....81-8t

in the wild Grouse Locust.......... 81-83

in domesticated mice and rabbits....83

in I) rosophila ampelophila ... ....8.

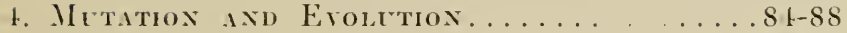

\section{CHAPTER III}

THE FACTORIAL THEORY OF HEREDITY AND THE COMPOSITION OF THE

GERM PLASM

1. The Cellethir Basis of Organic Frolition ANd Heredity. . . . . . . . . . . . . . 89-93

2. The Mechinjsa of Mexdelia Heredity

Discovered IN THE Behlitior of the

Chrovosones . . . . . . . . . . . .98-10?

3. The Forr Great Linkage Grotps of Dros-

OPHILA ANPELOPHILA .......... 103-118

a. Group I. . . . . . . . . . 10t-109

b. Group II. . . . . . . . . . . 109-119

c. Group III. . . . . . . . . . 112-115

d. Group IV. . . . . . . . . . 115-118

4. Iochlizhtion of Fictors in the Chronosontes . . . . . . . . . . . . . 118-112

a. The Fvidence from Sex Ininked

Inleritance. . . . . . . . . . 118-137 
b. The Evidence from Interference. .137-138

c. The Evidence from Non-Dis-

junction. . . . . . . . 139-142

5. How Maxy Genetic Factors are there in the Germ-Plasm of A Single INdiVIDUAL? . . . . . . . . . . . 1 1 $12-1+3$

6. Conclusions ................ 1 .

CHAPTER IV

\section{SELECTION AND EYOLUTION}

1. The Theory of Natural Selection..... 145-161

2. How has Selection in Domesticated ANi-

Mals aNd Plants Brovght about its

Results?.................161-165

3. Are Factors Changed through Selection? 165-187

4. How does Natural Selection Infleence

The colrse of Evolution?........187-193

5. Conclisions . . . . . . . . . . . . 193-194

IXDEX . . . . . . . . . . . . . . 195-197 


\section{CHAP'TER I}

\section{A REVALUATION OF THE EVIDENCE ON WHICH THE THEORY OF EVOLUTION \\ WAS BASED}

We use the word evolution in many ways - to include many different kinds of changes. There is hardly any other scientific term that is used so carelessly-to imply so much, to mean so little.

\section{Thref Kintos of Evolution}

We speak of the evolution of the stars, of the evolution of the horse, of the evolution of the steam engine, as though they were all part of the same process. What have they in common? Only this, that each concerns itself with the history of something. When the astronomer thinks of the crolution of the earth, the moon, the sun and the stars, he has a picture of diffuse matter that has slowly condensed. With condensation came heat; with heat, action and 
reaction within the mass until the chemical substances that we know today were produced. 'This is the nebular hypothesis of the astrononer. The astronomer explains, or tries to explain, how this evolution took place, by an appeal to the physical processes that have been worked out in the laboratory, processes which he thinks have existed through all the eons during which this evolution was going on and which were its inmediate causes.

When the biologist thinks of the evolution of animals and plants, a different picture presents itself. He thinks of series of animals that have lived in the past, whose bones (fig. 1) and shells have been preserved in the rocks. Ie thinks of these animals as having in the past given birth, through an unbroken succession of individuals, to the living inhabitants of the earth today. He thinks that the old, simpler types of the past have in part changed over into the more complex forms of today.

He is thinking as the historian thinks, but he sometimes gets confused and thinks that he is explaining evolution when he is only describing it. 


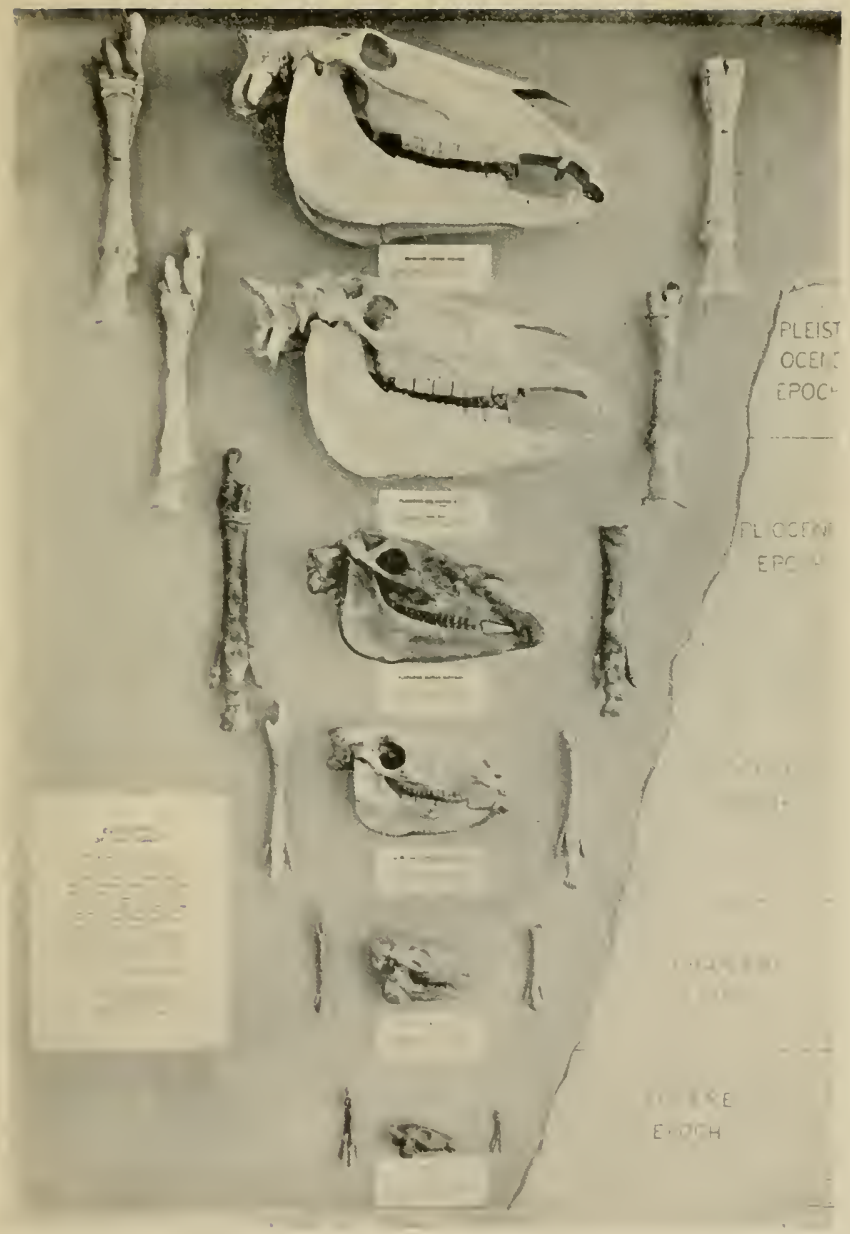

Iir. 1. A series of skulls and feet. Eohippus, Menohipmus, Meryhippus, Hipparion and kquus. (American Muem of Natural Mistory. Ifter Matthews.) 
A third kind of evolution is one for which man himself is responsible, in the sense that he has brought it about, often with a definite end in view.

His mind has worked slowly from stage to stage. We can often trace the history of the stages through which his psychic processes have passed. 'The evolution of the stean-boat, the steam engine, paintings, clothing, instruments of agriculture, of manufacture, or of warfare (fig. 2) illustrates the history of human progress. There is an obvious and striking similarity between the evolution of man's inventions and the evolution of the shells of molluses and of the bones of mammals, yet in neither case does a knowledge of the order in which these things arose explain them. If we appeal to the psychologist he will probably tell us that human inventions are either the result of happy accidents, that have led to an unforeseen, but discovered use; or else the use of the invention was foreseen. It is to the latter process more especially that the idea of purpose is applied. When we come to review the four great lines of evolutionary thought we 


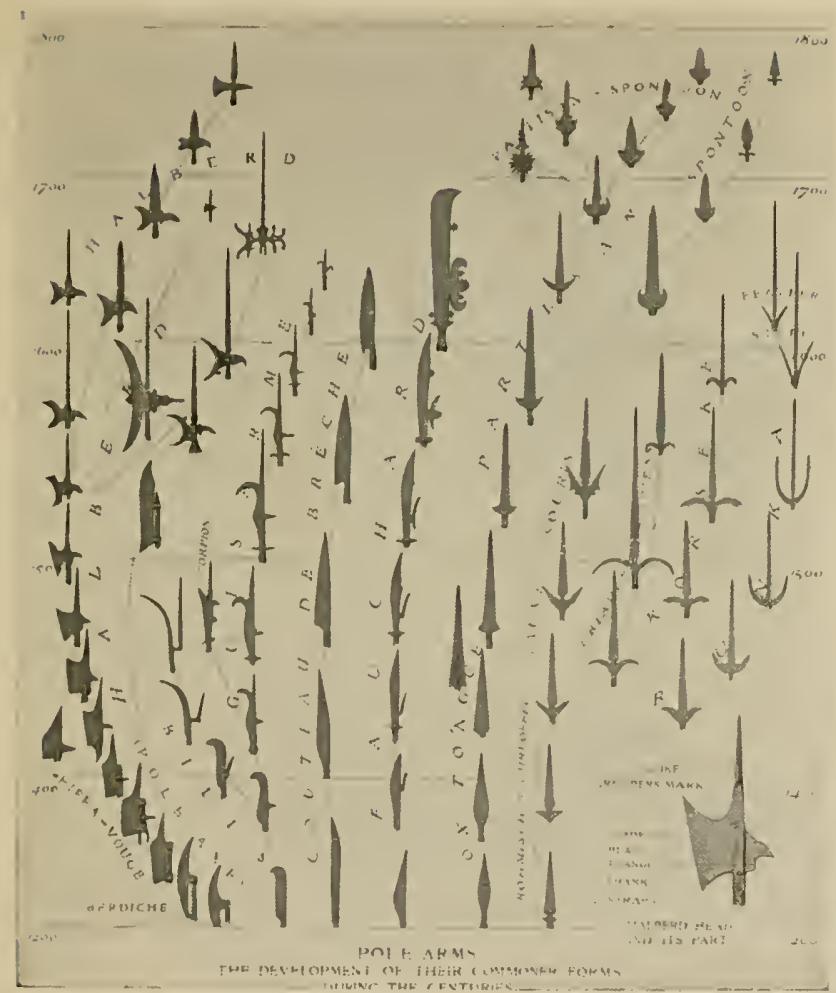

Fig. 2. Evolution of pole arms. (Metropolitan Museum. After Dean.)

shall see that this human idea of purpose recurs in many forms, suggesting that man has often tried to explain how organic evolntion has taken place by an appeal to the method which 
he believes he makes use of himself in the inorganic world.

What has the evolution of the stars, of the horse and of human inventions in common! Only this, that in each case from a simple beginning through a series of changes something more complex, or at least different, has come into being. 'To lump all these kinds of changes into one and call them evolution is no more than asserting that you believe in consecutive series of events (which is history) causally connected (which is science); that is, that you believe in history and that you believe in science. But let us not forget that we may have complete faith in both without therely offering any explanation of either. It is the business of science to find out specifically what kinds of erents were inrolved when the stars evolved in the sky, when the horse evolved on the earth, and the steam engine was evolved from the mind of man.

Is it not rather an empty generalization to say that any kind of change is a process of erolution! At most it means little more than that you want to intimate that miraculous interven- 
tion is not necessary to aceount for such kinds of histories.

IVe are concerned here more particularly with the biologists' ideas of evolution. My intention is to review the evidence on which the old theory rested its case, in the light of some of the newer evidence of recent years.

Four great branches of study have furnished the evidence of organic evolution. 'They are:

Comparative anatomy.

Enbryology.

Paleontology.

Experimental Breeding or Geneties.

The Eivdenee from Comparative Anatomy

When we study animals and plants we find that they can be arranged in groups according to their resemblances. 'This is the basis of comparative anatomy, which is only an accurate study of facts that are superficially obvious to everyone.

'The groups are based not on a single difference. but on a very large number of resemblances. Let us take for example the group of vertebrates. 
'The hand and the arm of man are similar to the hand and arm of the ape. $\mathrm{We}$ find the same plan in the forefoot of the rat, the elephant, the horse and the opossum. We can identify the same parts in the forefoot of the lizard, the frog (fig. 3), and even, though less

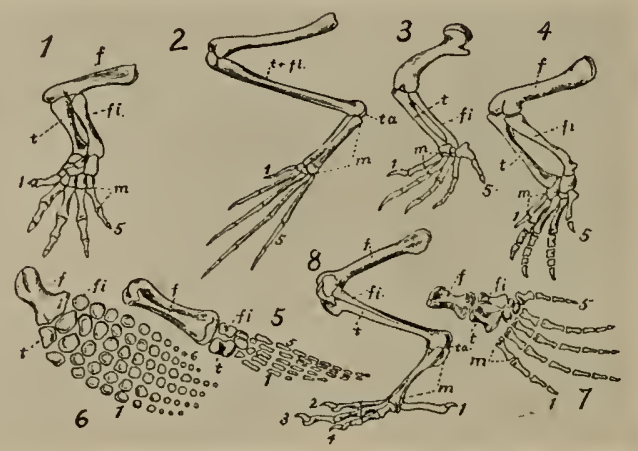

FIg. 3. Limb skeletons of extinct and living animals, showing the homologous bones: 1, salamander; $\mathcal{2}$, frog; 3, turtle; 4, Metosaurus; 5, Pleisiosaurus; 6, Ichthyosaurus; 7, Mesosaurus; 8, duck. (After Jordan and Kellogg.)

certainly, in the pectoral fins of fishes. Comparison does not end here. We find similarities in the skull and back bones of these same animals; in the brain; in the digestive system; in the heart and blood ressels; in the muscles.

Each of these systems is very complex, but 
the same general arrangement is found in all. Anyone familial with the evidence will, I think, probably reach the conclusion either that these animals have been created on some preconceived plan, or else that they have some other bond that unites them; for we find it difficult to believe that such complex, yet similar things could have arisen independently. But we try to convince our students of the truth of the theory of erolution not so much by calling their attention to this relation as by tracing each organ from a simple to a complex structure.

I have never known such a course to fail in its intention. In fact, I know that the student often becomes so thoroughly convinced that he resents any such attempt as that which I am about to make to point out that the evidence for his conviction is not above criticism.

Because we can often arrange the series of structures in a line extending from the rery simple to the more complex, we are apt to become unduly impressed by this fact and conclude that if we found the complete series we should find all the intermediate steps and that they have arisen in the order of their complex- 
ity. 'This conclusion is not necessarily correct. Let me give some examples that have come under my own observation. We have bred for five years the wild fruit fly Drosophila ampelophila (fig. 4) and we have found over a hum-
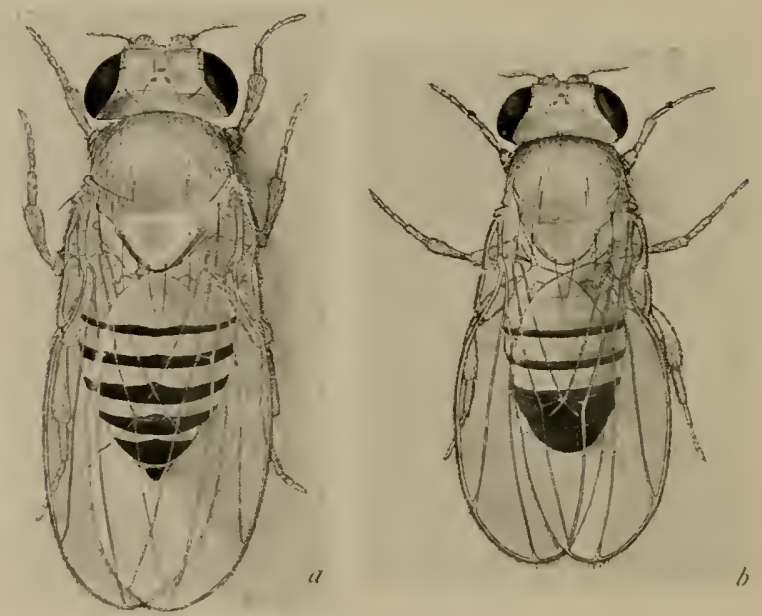

Fig. 1. Drosophila ampelophila. a, Female and b, male.

dred and twenty-five new types that breed true. Each has arisen independently and suddenly. Every part of the body has been affected by one or another of these mutations. For instance many different kinds of changes have 
taken place in the wings and several of these involve the size of the wings. If we arrange the latter arbitrarily in the order of their size there will be an almost complete series beginning with the normal wings and ending with those of apterous flies. Sereral of these types are represented in figure 5. 'The order in which these mutations occurred bears no relation to

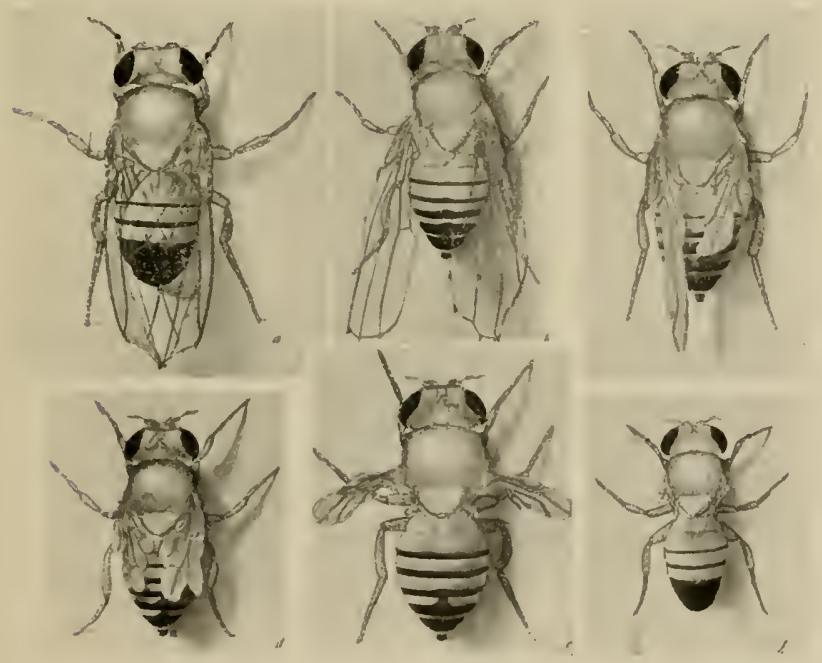

Fu. 5. Ilutants of Drosophila ampelophila arranged in order of bize of wings: (a) cut; (1) hearled; (c) stumpy; (d) another individual of stmmp; (f) restigial $(g)$ apterous. 
their size; each originated independently from the wild type.

The wings of the wild fly are straight (fig. 4). Several types have arisen in which the wings are bent upwards and in the most extreme type the wings are curled orer the back, as seen in figure $54(\mathrm{~g})$, yet there is no historical connection between these stages.

Mutations have occurred involving the pigmentation of the body and wings. The head and thorax of the wild Drosophila ampelophila are grayish yellow, the abdomen is banded with yellow and black, and the wings are gray. 'There have appeared in our cultures several kinds of darker types ranging to almost black flies (fig. 20) and to lighter types that are quite yellow. If put in line a series may be made from the darkest flies at one end to the light yellow flies at the other. 'Ihese types, with the fluctuations that occur within each type, furnish a complete series of gradations; ret historically they have arisen independently of each other.

Many changes in eye color have appeared. As many as thirty or more races differing in eye 
color are now maintained in our cultures. Some of them are so similar that they can scarcely be separated from each other. It is easily possible begimning with the darkest eye color, sepia, which is deep brown, to pick out a perfectly graded series ending with pure white eyes. But such a serial arrangement would give a totally false idea of the way the different types have arisen; and any conclusion based on the existence of such a series might rery well be entirely erroneous, for the fact that such a series exists bears no relation to the order in which its members have appeared.

Suppose that erolution "in the open" had taken place in the same way, by means of discontinuous variation. What value then would the evidence from comparative anatomy have in so far as it is based on a continuous series of variants of any organ?

No one familiar with the entire evidence will doubt for a moment that these 12.5 races of Drosophila ampelophila belong to the same species and have had a common origin, for while they may differ mainly in one thing they are extremely alike in a humdred other things. and 
in the general relation of the parts to each other.

It is in this sense that the evidence from comparative anatomy can be used I think as an argument for evolution. It is the resemblances that the animals or plants in any group have in common that is the basis for such a conclusion; it is not because we can arrange in a continuous series any particular variations. In other words, our inference concerning the common descent of two or more species is based on the totality of such resemblances that still remain in large part after each change has taken place. In this sense the argument from comparative anatomy, while not a demonstration, carries with it, I think, a high degree of probability.

\section{The Euidence from Embryology}

In passing from the egg to the adult the individual goes through a series of changes. In the course of this development we see not only the beginnings of the organs that gradually enlarge and change into those of the adult animal, but also see that organs appear and 
later disappear before the aldult stage is reached. We find, moreorer, that the young sometimes resemble in a most striking way the adult stage of groups that we place lower in the scale of evolution.

Many years before Darwin adranced his theory of evolution through natural selection, the resemblance of the young of higher animals to the adults of lower animals had attracted the attention of zoölogists and various views, often very naïve, had been adranced to account for the resemblance. Among these speculations there ras one practically identical with that adopted by Darwin and the post-Darwinians, namely that the higher animals repeat in their development the adult stages of lower animals. Later this riew became one of the cornerstones of the theory of organic evolution. It reached its climax in the writings of Haeckel, and I think I may add without exaggeration that for twenty-five years it furnished the chief inspiration of the school of descriptive embryology. 'Today it is taught in practically all textbooks of biology. Haeckel called this interpretation the Biogenetic Law. 
It was recognized, of course, that many embryonic stages could not possibly represent ancestral animals. A young fish with a huge yolk sac attached (fig. 6) could scarcely ever have led a happy, free life as an adult individ-

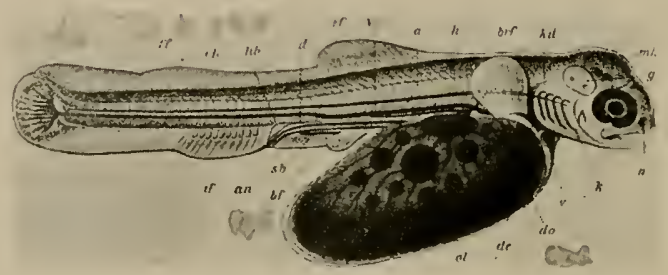

Fig. 6. Young trout (Trutta fario) six days after hatching. (After Ziegler.)

ual. Such stages were interpreted, howerer, as embryonic additions to the original ancestral type. 'The embryo had done something on its own account.

In some animals the young have structures that attach them to the mother, as does the placenta of the mammals. In other cases the young derelop membranes about themselveslike the amnion of the chick (fig. 7) and mammal-that would have shut off an adult animal from all intercourse with the outside 
world. Hundreds of such embryonic adaptations are known to embryologists. 'These were explained as adaptations and as falsifications of the ancestral records.

At the end of the last century Weismamm in-

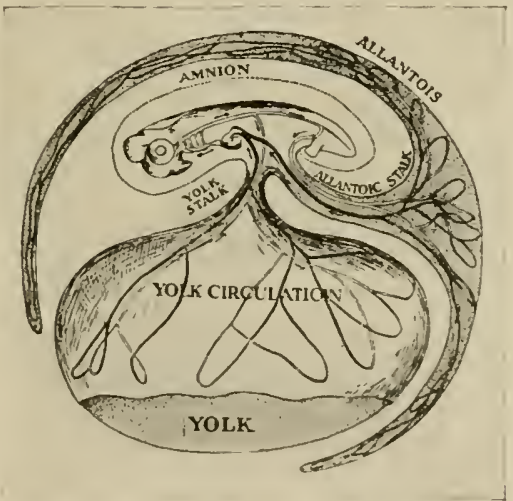

Fig. i. Diagram of chick showing relations of amnion, allantois and yolk. (\fter Lillie.)

jected a new idea into our views concerning the origin of variations. He urged that variations are germinal, i.e. they first appear in the egg and the sperm as changes that later bring about modifications in the individual. 'The idea has been fruitful and is generally aceepted by most biologists today. It means that the 
offspring of a pair of animals are not affected by the structure or the activities of their parents, but the germ plasm is the ummodified stream from which both the parent and the young have arisen. Hence their resemblance. Now, it has been found that a rariation arising in the germ plasm, no matter what its cause, may affect any stage in the development of the next individuals that arise from it. 'There is no reason to suppose that such a change produces a new character that always sticks itself, as it were, on to the end of the old series. 'This idea of germinal variation therefore carried with it the death of the older conception of erolution by superposition.

In more recent times another idea has become current, mainly due to the work of Bateson and of de Vries - the idea that variations are discontinuous. Such a conception does not fall easily into line with the statement of the biogenetic "law"; for actual experience with discontinuous rariation has taught us that new characters that arise do not add themselves to the end of the line of already existing characters but if they affect the adult characters 
they change them without, as it were, passing through and heyond them.

I renture to think that these new ideas and
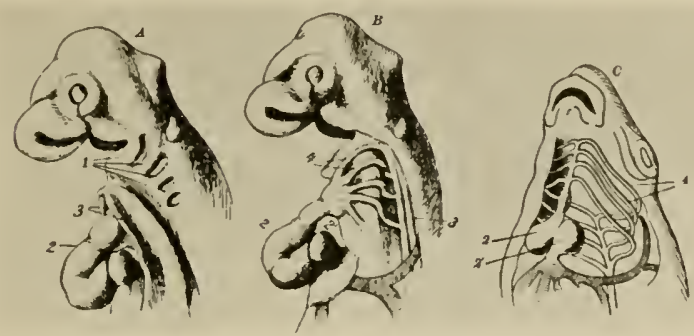

Frg. 8. Diagram of head of chick I and B, showing gill slits, and aortic arches; and head of fish $C$ showing aortic arches. (Atter Hesse.)

this new eridence have played havoe with the biogenetic "law". Nevertheless, there is an interpretation of the facts that is entirely com-

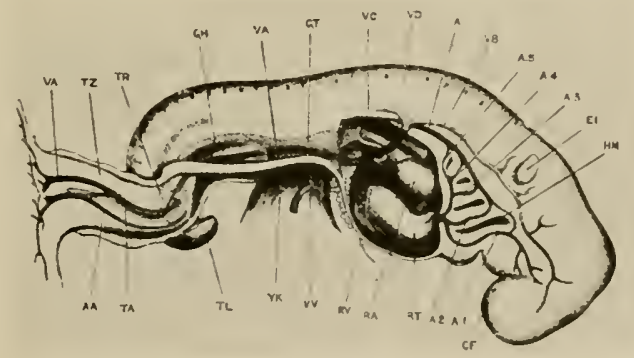

Fic. 9. Human embryo showing gill sits and aortic arches. (. fter His; from Marmalt.) 
patible with the theory of evolution. Let me illustrate this by an example.

'The embryos of the chick (fig. 8) and of man (fig. 9) possess at an early stage in their development gill-slits on the sides of the neck like those of fishes. No one familiar with the

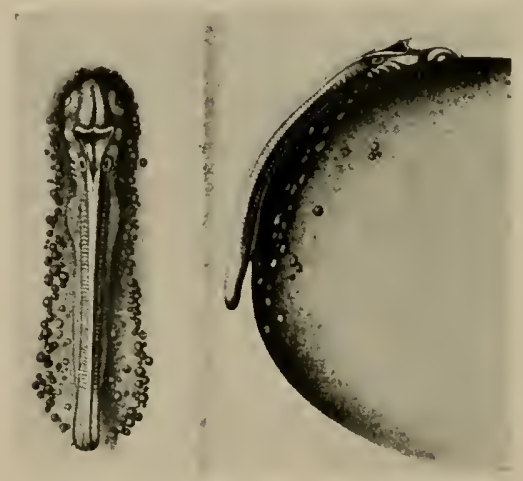

Fig. 10. Young fish, dorsal view, and side view, showing gill slits. (Aftel Kopsch.)

relations of the parts will for a moment doubt that the gill slits of these embryos and of the fish represent the same structures. When we look further into the matter we find that young fish also possess gill slits (fig. 10 and 11 ) - even in young stages in their development. Is it not 
then more probable that the mammal and bird possess this stage in their derelopment simply because it has never been lost? Is not this a more reasonable view than to suppose that the gill slits of the embryos of the higher forms represent the adult gill slits of the fish
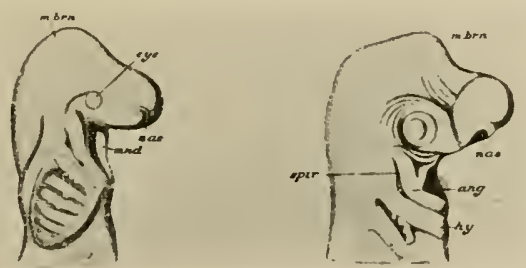

Fig. 11. Side riews of head of embryo sharks, showing gill slits.

that in some mysterious way have been pushed back into the embryo of the bird?

I conld give many similar examples. All can be interpreted as embryonic survirals rather than as phyletic contractions. Not one of them calls for the latter interpretation.

'The study of the cleavage pattern of the segmenting egg furnishes the most convincing evidence that a different explanation from the one stated in the biogenetic law is the more probable explanation. 
It has been found that the cleavage pattern las the same general arrangement in the early stages of flat worms, annelids and molluses (fig. 12). Obviously these stages have never
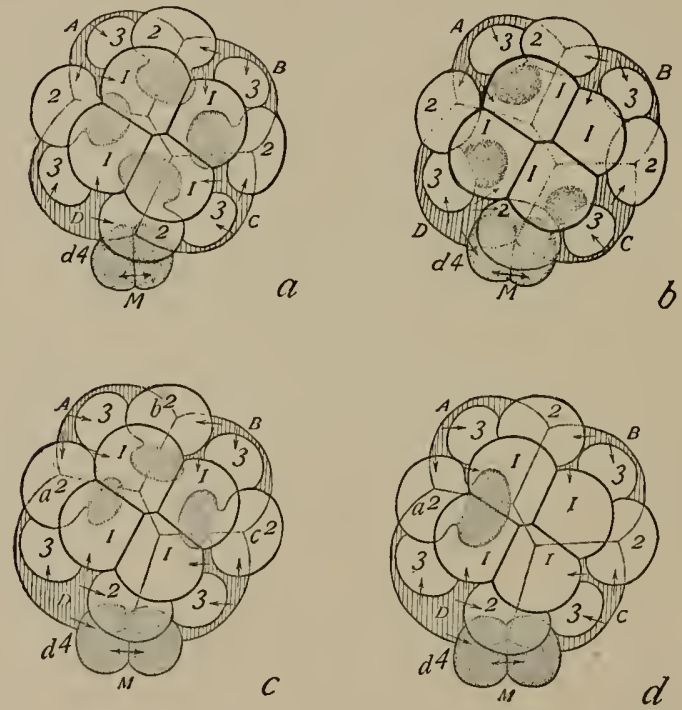

Fig. 12. Cleavage stages of four types of eggs, showing the origin of the mesenchyme cells (stippled) and mesodem cells (darker); a, Planarian; b, Innelid (Podarke); c, Mollusc (Crepidula), c, Mollusc (Unio).

been adult ancestors, and obviously if their resemblance has any meaning at all, it is that each group has retained the same general plan 
of clearage, possessed by their common ancestor.

Accepting this view, let us ask, does the evidence from embryology favor the theory of erolution? I think that it does very strongly. 'The embryos of the mammal, bird, and lizard have gill slits today because gill slits were present in the embryos of their ancestors. 'There is no other view that explains so well their presence in the higher forms.

Perhaps someone will say, Well! is not this all that we have contended for! Have you not reached the old conchusion in a roundabout way? I think not. 'To my mind there is a wide difference between the old statement that the higher animals living today have the original adult stages telescoped into their embryos, and the statement that the resemblance between certain characters in the embryos of higher animals and corresponding stages in the embryos of lower animals is most plausibly explained by the assumption that they have descended from the same ancestors, and that their common structures are embryonic survivals. 


\section{The Evidence from Paleontology}

'The direct evidence furnished by fossil remains is by all odds the strongest evidence that we have in faror of organic evolution. Paleontology holds the incomparable position of being able to point directly to the evidence showing that the animals and plants living in past times are connected with those living at the present time, often through an unbroken series of stages. Paleontology has triumphed over the weakness of the evidence, which Darwin admitted was serious, by filling in many of the missing links.

Paleontology has been criticised on the ground that she camnot pretend to show the actual ancestors of living forms because, if in the past genera and species were as abundant and as diverse as we find them at present, it is very improbable that the bones of any individual that happened to be preserved are the bones of just that species that took part in the evolution. Paleontologists will freely admit that in many cases this is probably true, but even then the evidence is, I think, still just as raluable and 
in exactly the same sense as is the evidence from comparative anatomy. It suffices to know that there lived in the past a particular "group" of animals that had many points in common with those that preceded them and with those that came later. Whether these are the actual ancestor's or not does not so much matter, for the view that from such a group of species the later species have been derived is far more probable than any other view that has been proposed.

With this unrivalled material and splendid series of gradations, paleontology has constructed many stages in the past history of the globe. But paleontologists have sometimes gone beyond this descriptive phase of the subject and have attempted to formulate the "causes", "laws" and "principles" that have led to the development of their series. It has even been claimed that paleontologists are in an incomparably better position than zoölogists to discover such principles, because they know both the beginning and the end of the evolutionary series. The retort is obvious. In his sweeping and poetic rision the paleontologist may fail completely to find out the nature of 
the pigments that have gone into the painting of his picture, and he may confuse a familiarity with the different views he has enjoyed of the canvas with a knowledge of how the painting is being done.

My good friend the paleontologist is in greater danger than he realizes, when he leaves descriptions and attempts explanation. He has no way to check up his speculations and it is notorious that the human mind without control has a bad habit of wandering.

When the modern student of variation and heredity - the geneticist-looks orer the different "continuous" series, from which certain "laws" and "principles" have been deduced, he is struck by two facts: that the gaps, in some cases, are enormous as compared with the single changes with which he is familiar, and (what is more important) that they involve numerous parts in many ways. The geneticist says to the paleontologist, since you do not know, and from the nature of your case can never know, whether your differences are due to one change or to a thousand, you can not with certainty tell us anything about the hereditary units 
which have made the process of evolution possible. And without this knowledge there can be no understanding of the causes of evolution.

\section{THE FOUR GREAT HISTORICAL SPECULATIONS}

Looking backward over the history of the evolution theory we recognize that during the hundred and odd years that have elapsed since Buffon, there have been four main lines of speculation concerning evolution. We might call them the four great cosmogonies or the four modern epics of erolution.

\section{The Extironment \\ Geoffroy St. Hilaire}

About the beginning of the last century Geoffroy St. Hilaire, protégé, and in some respects a disciple of Buffon, was interested as to how living species are related to the animals and plants that had preceded them. He was familiar with the kind of change that takes place in the embryo if it is put into new or changed surroundings, and from this knowledge he concluded that as the surface of the 
earth slowly changed-as the carbon dioxide contents in the air altered-as land appearedand as marine animals left the water to inhabit it, they or their embryos responded to the new conditions and those that responded favorably gave rise to new creations. As the environment changed the fauna and flora changedchange for change. Here we have a picture of progressive evolution that carries with it an idea of mechanical necessity. If there is anything mystical or even improbable in St. Hiliare's argument it does not appear on the surface; for he did not assume that the response to the new enviromment was always a favorable one or, as we say, an adaptation. He expressly stated that if the response was unfavorable the individual or the race died out. He assumed that sometimes the change might be favorable, i.e., that certain species, entire groups, would respond in a direction favorable to their existence in a new environment and these would come to inherit the earth. In this sense he anticipated certain phases of the natural selection theory of Darwin, but only in part; for his picture is not one of strife within and without 
the species, but rather the escape of the species from the old into a new world.

If then we recognize the intimate bond in chemical constitution of living things and of the world in which they derelop, what is there improbable in St. Hilaire's hypothesis? Why, in a word is not more credit given to St. Milaire in modern evolutionary thought? 'The reasons are to be found, I think, first, in that the evidence to which he appealed was meagre and inconchusive; and, second, in that much of his special evidence does not seem to us to be applicable. For example the monstrous forms that development often assumes in a strange enviromment, and with which every embryologist is only too familiar, rarely if ever furnish combinations, as he supposed, that are capable of living. On the contrary, they lead rather to the final catastrophe of the organism. And lastly, St. Hilaire's appeal to sudden and great transformations, such as a crocodile's egg hatching into a bird, has exposed his view to too easy ridicule.

But when all is said, St. Hilaire's conception of evolution contains elements that form the 
background of our thinking to-day, for taken broadly, the interaction between the organism and its environment was a mechanistic conception of evolution even though the details of the theory were inadequate to establish his contention.

In our own time the French metaphysician Bergson in his Evolution Creatrice has proposed in mystical form a thought that has at least a superficial resemblance to St. Hilaire's conception. The response of living things is no longer hit in one species and miss in another; it is precise, exact; yet not mechanical in the sense at least in which we usually employ the word mechanical. For Bergson claims that the one chief feature of living material is that it responds favorably to the situation in which it finds itself; at least so far as lies within the possible physical limitations of its organization. Evolution has followed no preordained plan; it has had no creator; it has brought about its own creation by responding adaptively to each situation as it arose.

But note: the man of science believes that the organism responds today as it does, because at 
present it has a chemical and physical constitution that gives this response. We find a specific chemical composition and generally a specific physical structure already existing. We have no reason to suppose that such particular reactions would take place until a specific chemical configuration had been acquired. Where did this constitution come from? 'This is the question that the scientist asks himself. I suppose Bergson would have to reply that it came into existence at the moment that the first specific stimulus was applied. But if this is the answer we have passed at once from the realm of observation to the realm of fancy-to a reahm that is foreign to our experience; for such a view assumes that chemical and physical reactions are guided by the needs of the organism when the reactions take place inside living beings.

\section{Use And Disuse \\ From Lamarch to Wcismann}

The second of the four great historical explanations appeals to a change not immediately connected with the outer world, but to one within the organism itself. 
Practice makes perfect is a familiar adage. Not only in human affairs do we find that a part through use becomes a better tool for performing its task, and through disuse degenerates; but in the field of animal behavior we find that many of the most essential types of behavior have been learned through repeated associations formed by contact with the outside.

It was not so long ago that we were taught that the instincts of animals are the inherited experience of their ancestors-lapsed intelligence was the current phrase.

Lamarck's name is always associated with the application of the theory of the inheritance of acquired characters. Darwin fully endorsed this view and made use of it as an explanation in all of his writings about animals. 'Today the theory has few followers amongst trained investigators, but it still has a popular rogue that is widespread and vociferous.

'To Weismann more than to any other single individual should be ascribed the disfavor into which this view has fallen. In a series of brilliant essays he laid bare the inadequacy of the supposed evidence on which the inheritance of 
acquired character's rested. Your neighbor's cat, for instance, has a short tail, and it is said that it had its tail pinched off by a closing door. In its litter of kittens one or more is found without a tail. Your neighbor believes that here is a case of cause and effect. He may even have known that the mother and grandmother of the cat had natural tails. But it has been found that short tail is a dominant character; therefore, until we know who was the father of the short-tailed kittens the accident to its mother and the normal condition of her maternal ancestry is not to the point.

Weismann appealed to common sense. He made few experiments to disprove Lamarck's hypothesis. 'True, he cut off the tails of some mice for a few generations but got no tailless offspring and while he gives no exact measurements with coefficients of error he did not observe that the tails of the descendants had shortened one whit. 'The combs of fighting cocks and the tails of certain breeds of sheep have been cropped for many generations and the practice continues today, because their tails are still long. While in Lamarck's time there 
was no evidence opposed to his ingenious theory, based as it was on an appeal to the acknowledged facts of improvement that take place in the organs of an individual through their own functioning (a fact that is as obvious and remarkable today as in the time of Lamarck), yet now there is evidence as to whether the effects of use and disuse are inherited, and this evidence is not in accord with Lamarck's doctrine.

THE UNFOLDING PRINCIPLE

\section{Nägeli and Bateson}

I have rentured to put down as one of the four great historical explanations, under the heading of the unfolding principle, a conception that has taken protean forms. At one extreme it is little more than a mystic sentiment to the effect that evolution is the result of an inner driving force or principle which goes under many names such as Bildungstrieb, nisus formativus, vital force, and orthogenesis. Evolutionary thought is replete with variants of this idea, often naïvely expressed, sometimes unconsciously implied. Evolution once meant, in 
fact, an unfolding of what pre-existed in the egg, and the term still carries with it something of its original significance.

Nägeli's speculation written several years after Darwin's "Origin of Species" may be taken as a typical case. Nägeli thought that there exists in living material an innate power to grow and expand. He vehemently protested that he meant only a mechanical principle but as he failed to refer such a principle to any properties of matter known to physicists and chemists his view seems still a mysterious affirmation, as difficult to understand as the facts themselves which it purports to explain.

Nägeli compared the process of evolution to the growth of a tree, whose ultimate twigs represent the living world of species. Natural selection plays only the rôle of the gardener who prumes the tree into this or that shape but who has himself produced nothing. As an imaginative figure of speech Nägeli's comparison of the tree might eren today seem to hold if we substituted "mutations" for "growth", but although we know so little about what causes mutations there is no reason for suppos- 
ing them to be due to an inner impulse, and hence they furnish no justification for such a hypothesis.

In his recent presidential address before the British Association Bateson has inverted this idea. I suspect that his effort was intended as little more than a tour de force. He claims for it no more than that it is a possible line of speculation. Perhaps he thought the time had come to give a shock to our too confident views concerning evolution. Be this as it may, he has invented a striking paradox. Evolution has taken place through the steady loss of inhibiting factors. Living matter was stopped down, so to speak, at the beginning of the world. As the stops are lost, new things emerge. Living matter has changed only in that it has become simpler.

\section{Natural Selection}

\section{Darwin}

Of the four great historical speculations about evolution, the doctrine of Natural Selection of Darwin and Wallace has met with the most widespread acceptance. In the last lec- 
ture I intend to examine this theory critically. Here we are concerned only with its broadest aspects.

Darwin appealed to chance iariations as supplying evolution with the material on which natural selection works. If we accept, for the moment, this statement as the cardinal doctrine of natural selection it may appear that evolution is due, (1) not to an orderly response of the organism to its enviromment, (2) not in the main to the activities of the animal through the use or disuse of its parts, (3) not to any innate principle of living material itself. and (4) above all not to purpose either from within or from without. Darwin made quite clear what he meant by chance. By chance he did not mean that the variations were not causal. On the contrary he taught that in Science we mean by chance only that the particular combination of causes that bring about a variation are not known. 'They are accidents, it is true, but they are causal accidents.

In his famous book on "Animals and Plants under Domestication", Darwin dwells at great length on the nature of the conditions that 
bring about variations. If his views seem to us today at times vague, at times problematical, and often without a secure basis, nevertheless we find in every instance, that Darwin was searching for the physical causes of variation. He brought, in consequence, conviction to many minds that there are abundant indications, even if certain proof is lacking, that the causes of variation are to be found in natural processes.

'Today the belief that evolution takes place by means of natural processes is generally accepted. It does not seem probable that we shall ever again have to renew the old contest between evolution and special creation.

But this is not enough. We can never remain satisfied with a negative conclusion of this kind. We must find out what natural causes bring about variations in animals and plants; and we must also find out what kinds of variations are inherited, and how they are inherited. If the circumstantial evidence for organic evolution, furnished by comparative anatomy, embryology and paleontology is cogent, we should be able to observe evolution going on at 


\section{THEORY OF ETOLU'TION}

the present time, i.e. we should be able to observe the occurrence of variations and their transmission. This has actually been done by the geneticist in the study of mutations and Mendelian heredity, as the succeeding lectures will show. 


\section{CHAP'TER II}

THE BEARING OF MENDEL'S DISCOVERY ON THE ORIGIN OF HEREDITARY CHARACTERS

Between the years 1857 and 1868 Gregor Mendel, Augustinian monk, studied the heredity of certain characters of the common edible pea, in the garden of the monastery at Brünn.

In his account of his work written in $\mathbf{1 8 6 8 ,}$ he said:

"It requires indeed some courage to undertake a labor of such a far-reaching extent; it appears, however, to be the only right way by which we can finally reach the solution of a question the importance of which cannot be over-estimated in connection with the history of the evolution of organic forms."

He tells us also why he selected peas for his work:

"The selection of the plant group which shall serve for experiments of this kind must be made with all possible care if it be desired to avoid from the outset every risk of questionable results."

"The experimental plants must necessarily 
1. Possess constant differentiating characters.

2. The hybrids of such plants must, during the flowering period, be protected from the influence of all foreign pollen, or be easily capable of such protection."

Why do biologists throughout the world today agree that Mendel's discovery is one of first rank?

A great deal might be said in this connection. What is essential may be said in a few words. Biology had been, and is still, largely a descriptive and speculative science. Mendel showed by experimental proof that heredity could be caplained by a simple mechanism. His discovery has been exceedingly fruitful.

Science begins with naïve, often mystic conceptions of its problems. It reaches its goal whenever it can replace its early guessing by verifiable hypotheses and predictable results. 'This is what Mendel's law did for heredity.

\section{Mendel's First Discorer - Segregation}

Let us tum to the demonstration of his first law-the law of segregation. The first case I choose is not the one given by Mendel but one worked out later by Correns. If the common 
garden plant called four o'clock (Mirabilis jalapa) with red flowers is crossed to one having white flowers, the offspring are pink (fig. 13). The hybrid, then, is intermediate in the color of
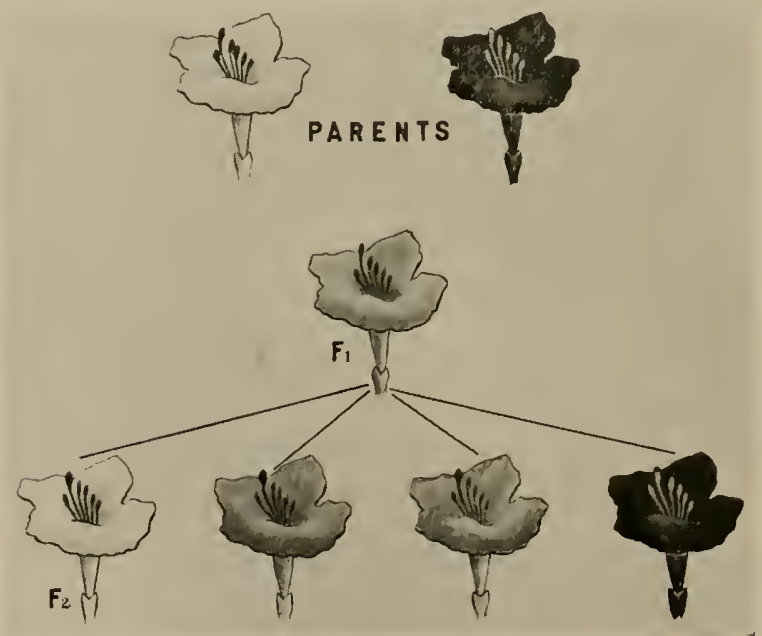

Fig. 13. Diagram illustrating a cross between a red (dark) and a white variety of four o'clock (Mirabilis jalapa).

its flowers between the two parents. If these hybrids are inbred the offspring are white, pink and red, in the proportion of 1:2:1. All of these had the same ancestry, yet they are of three different kinds. If we did not know their 
history it would be quite impossible to state what the ancestry of the white or of the red had been, for they might just as well have come from pure white and pure red ancestor's respectively as to have emerged from the pink hybrids. Moreover, when we test them we find that they are as pure as are white or led flowering plants that have had all white or all red flowering ancestors.

Mendel's Law explains the results of this cross as shown in figure 14 .

'The egg cell from the white parent carries the factor for white, the pollen cell from the red parent carries the factor for red. 'The hybrid formed by their union carries both factors. 'The result of their combined action is to produce flowers intermediate in color.

When the hybrids mature and their germ cells (eggs or pollen) ripen, each carries only one of these factors, either the red or the white, but not both. In other words, the two factors that have been brought together in the hybrid separate in its germ cells. Half of the egg cells are white bearing, half red bearing. Half of the pollen cells are white bearing, half red 
bearing. Chance combinations at fertilization give the three classes of individuals of the second generation.

'The white flowering plants should forever breed true, as in fact they do. The red flowering

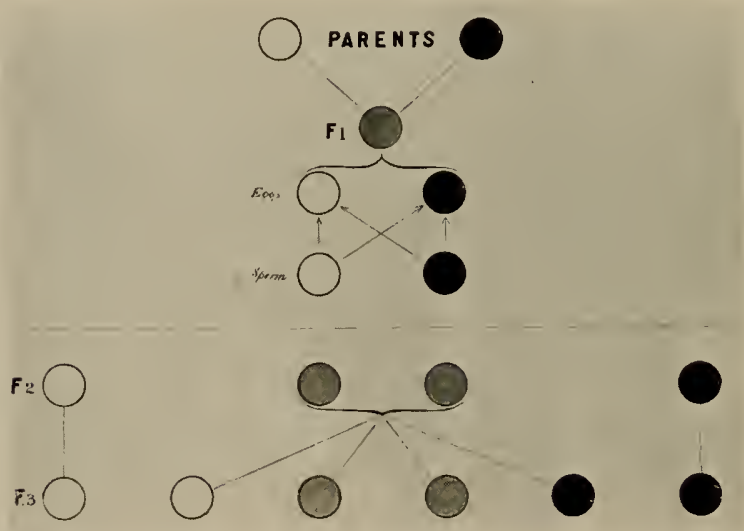

Fig. 14. Diagram illustrating the history of the factors in the germ cells of the cross shown in Fig. 13.

plants also breed true. The pink flowering plants, having the same composition as the hybrids of the first generation, should give the same kind of result. 'They do, indeed, give this result i.e. one white to two pink to one red flowered offspring. 
Another case of the same kind is known to breeders of poultry. One of the most beautiful of the domesticated breeds is known as the An-

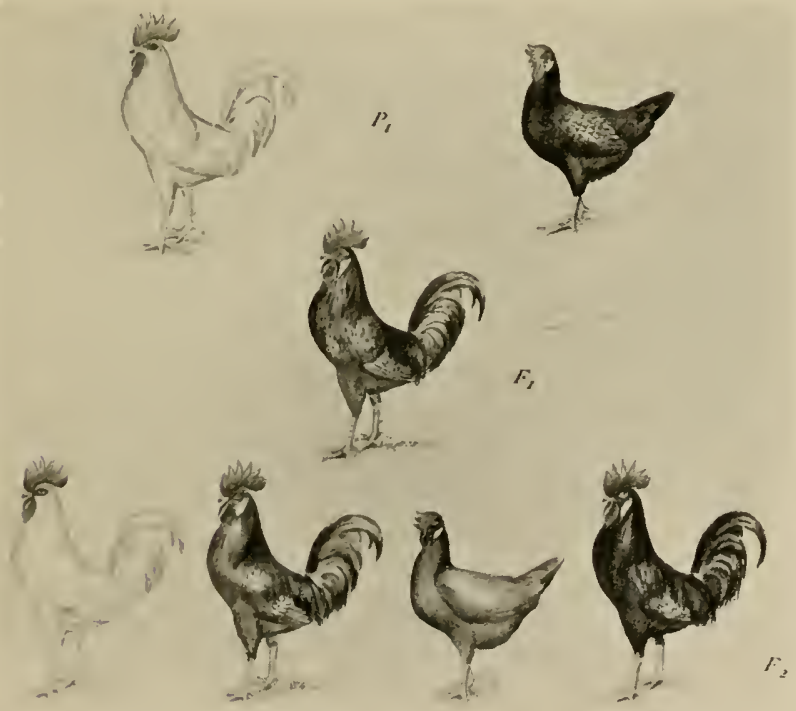

FIg. 15. Diagram illustrating a cross between special races of white and black fowls, producing the blue (here gray) Andalusian.

dalusian. It is a slate blue bird shading into blue-black on the neck and back. Breeders know that these blue birds do not breed true but produce white, black, and blue offspring. 
'The explanation of the failure to produce a pure race of Andalusians is that they are like the pink flower's of the four o'clock, i.e., they are a hybrid type formed by the meeting of the white and the black germ cells. If the whites produced by the Andalusians are bred to the

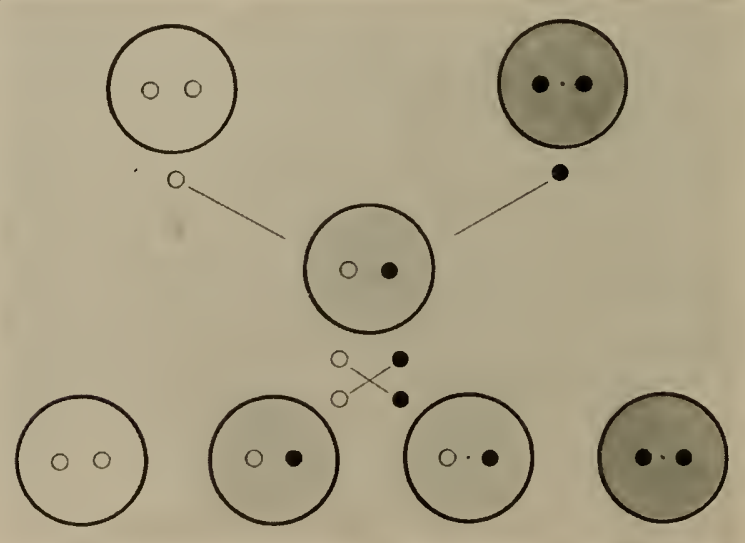

Fig. 16. Diagram showing history of germ cells of cross of Fig. 15. The larger circles inclicate the color of the birds; their enclosed small circles the nature of the factors in the germ cells of such birds.

blacks (both being pure strains), all the offspring will be blue (fig. 15); if these blues are inbred they will give 1 white, to 2 blues, to 1 
black. In other words, the factor for white and the factor for black separate in the germ cells of the hybrid Andalusian birds (fig. 16).

'The third case is Mendel's classical case of yellow and green peas (fig. 17). He crossed a plant belonging to a race having yellow peas with one having green peas. 'The hybrid plants had yellow seeds. 'These hybrids inbred gave three yellows to one green. The explanation

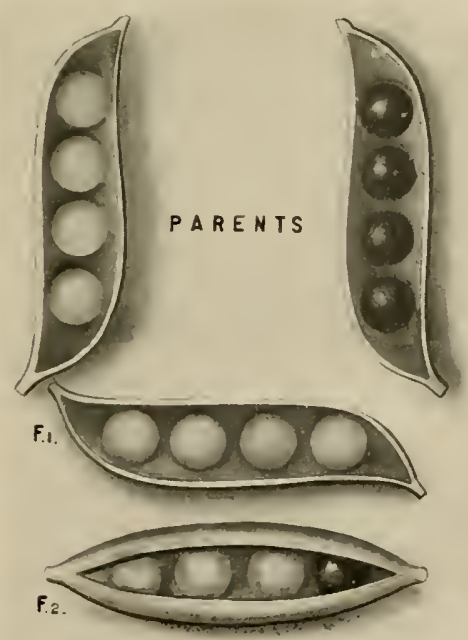

Fig. 17. Diagram of Mendel's cross between yellow (dominant) and green (recessive) peas. 
(fig. 18) is the same in principle as in the preceding cases. 'The only difference between them is that the hybrid which contains both the rellow and the green factors is in appearance

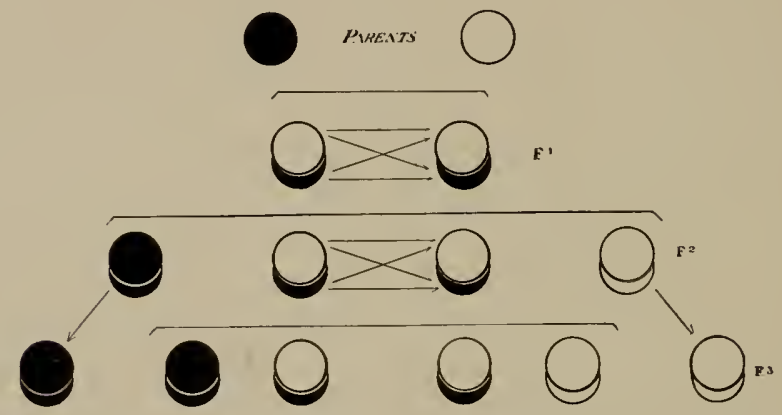

Fig. 18. Diagram illustrating the history of the factors in the cross shown in Fig. 17.

not intermediate, but like the yellow parent stock. Yellow is said therefore to be dominant and green to be recessive.

Another example where one of the contrasted characters is dominant is shown by the cross of Drosophila with vestigial wings to the wild type with long wings (fig. 19). The $F_{1}$ flies have long wings not differing from those of the wild fly, so far as can be observed. When two such flies are inbred there result three long to one vestigial. 

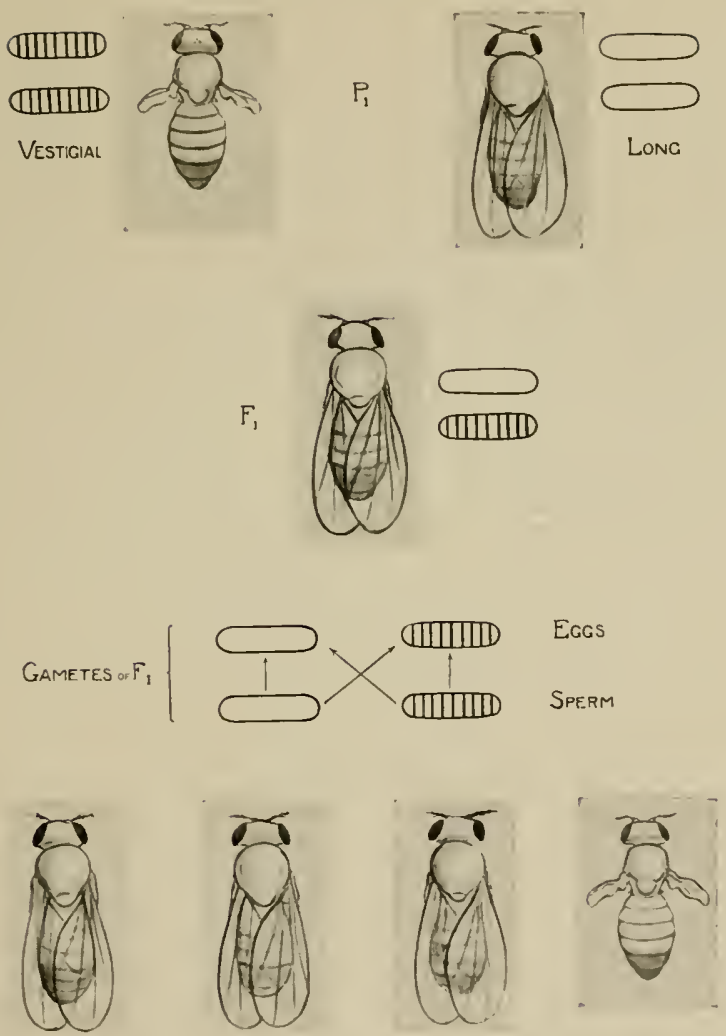

$\mathrm{F}_{2}$
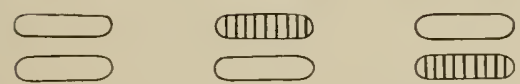

\section{(IIII)D}

बIIIIIDD

Fig. 19. Diagram illustrating a cross between a fly (Drosophila ampelophila) with long wings and a mutant fly with restigial wings. 
'The question as to whether a given character is dominant or recessive is a matter of no theoretical importance for the principle of segregation, although from the notoriety given to it one might easily be misled into the erroneous supposition that it was the discovery of this relation that is Mendel's crowning achievement.

Let me illustrate by an example in which the hybrid standing between two types orerlaps them both. 'There are two mutant races in our cultures of the fruit fly Drosophila that have dark body color, one called sooty, another which is even blacker, called ebony (fig. 20). Sooty crossed to ebony gives offspring that are intermediate in color. Some of them are so much like sooty that they cannot be distinguished from sooty. At the other extreme some of the hybrids are as dark as the lightest of the ebony flies. If these hybrids are inbred there is a continuous series of individuals, sooties, intermediates and ebonies. Which color here shall we call the dominant? If the ebony, then in the second generation we count three ebonies to one sooty, putting the hybrids with the ebonies. If the dominant is the sooty then we count three 
sooties to one ebony, putting the hybrids with the sooties. The important fact to find out is whether there actually exist three classes in the second generation. This can be ascertained
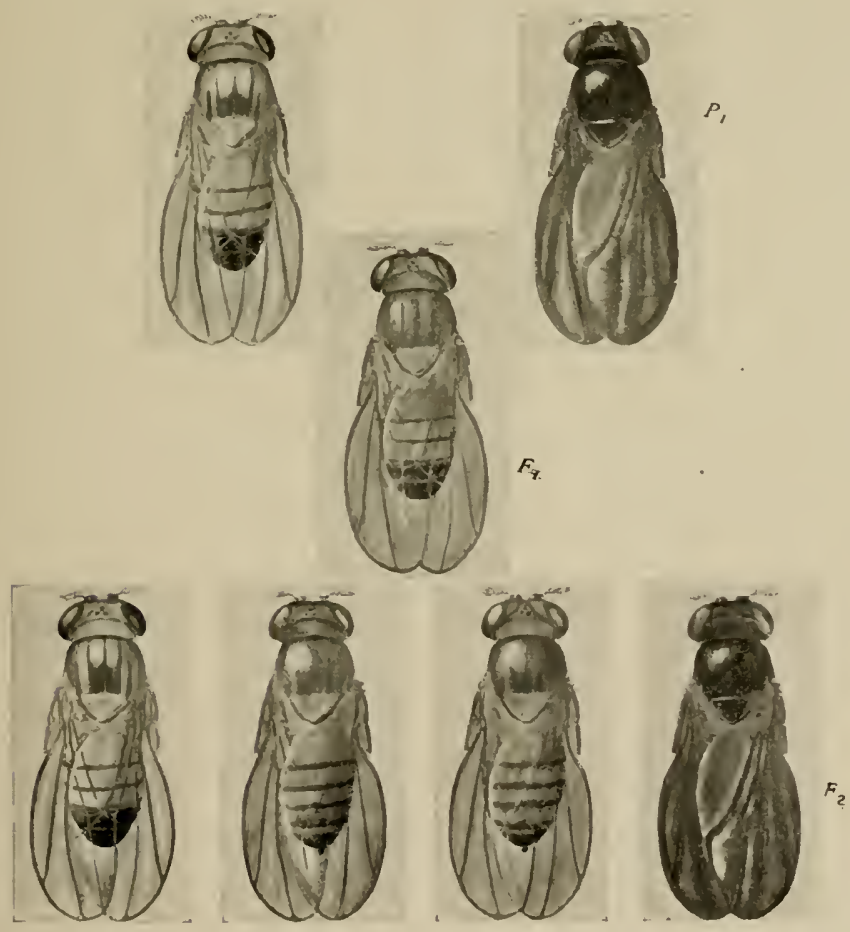

Fig. 20. Cross between two allelomorphic races of Drosophila, sooty and ebony, that give a completely graded series in $F_{2}$. 
even when, as in this case, there is a perfectly graded series from one end to the other, by testing out individually enough of the flies to show that one-fourth of them never produce any descendants but ebonies, one-fourth never any but sooties, and one-half of them give rise to both ebony and sooty.

\section{Mendel's Second Discovery-Independent Assortment}

Besides his discovery that there are pairs of characters that disjoin, as it were, in the germ cells of the hybrid (law of segregation) Mendel made a second discovery which also has far-reaching consequences. The following case illustrates Mendel's second law.

If a pea that is yellow and round is crossed to one that is green and wrinkled (fig. 21), all of the offspring are yellow and round. Inbred, these give 9 yellow round, 3 green round, 3 yellow wrinkled, 1 green wrinkled. All the yellows taken together are to the green as $3: 1$. All the round taken together are to the wrinkled as three to one; but some of the yellows are now wrinkled and some of the green are now 
round. 'There has been a recombination of characters, while at the same time the results, for each pair of character's taken separately, are in

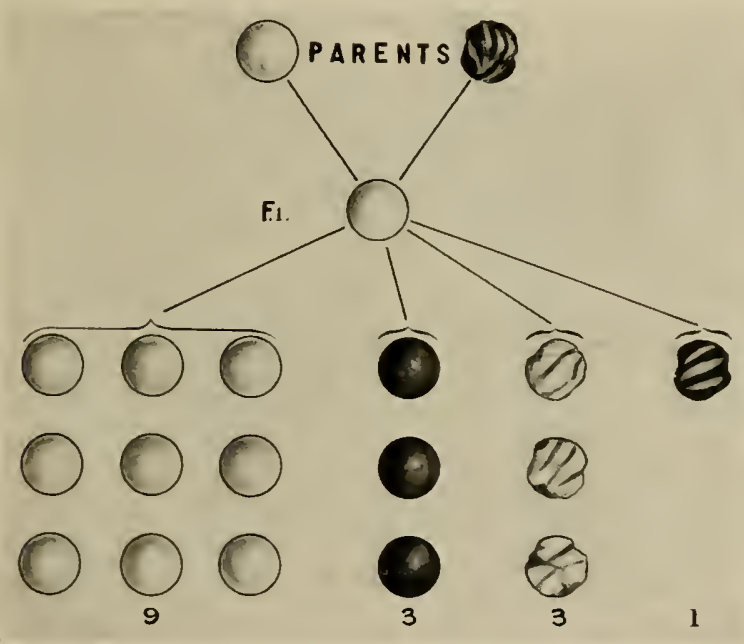

Fig. 21. Cross between yellow-round and green-wrinkled peas, giving the 9:3:3: 1 ratio in $\mathrm{F}_{2}$.

accord with Mendel's Law of Segregation, (fig. 22). 'The second law of Mendel may be called the law of independent assortment of different character pairs.

We can, as it were, take the characters of one organism and recombine them with those 
of a different organism. We can explain this result as due to the assortment of factors for these characters in the germ cells according to a definite law.

As a second illustration let me take the clas-

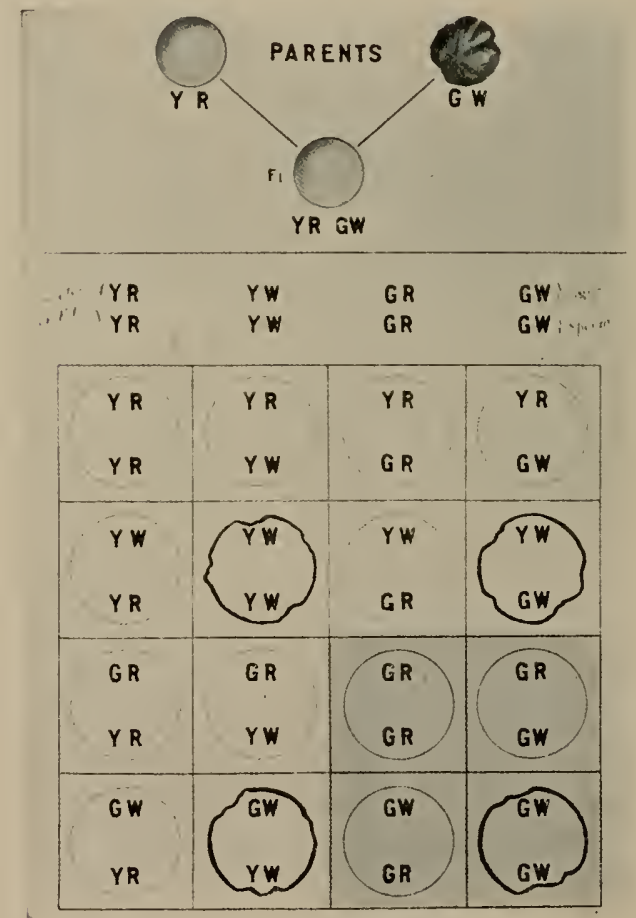

Fig. 22. Diagram to show the history of the factor pairs yellow-green and round-wrinkled of the cross in Fig. 21 . 
sic case of the combs of fowls. If a bird with a rose comb is bred to one with a pea comb (fig. 2:3), the offspring have a comb different from either. It is called a walnut comb. If two such individuals are bred they give 9 walnut,

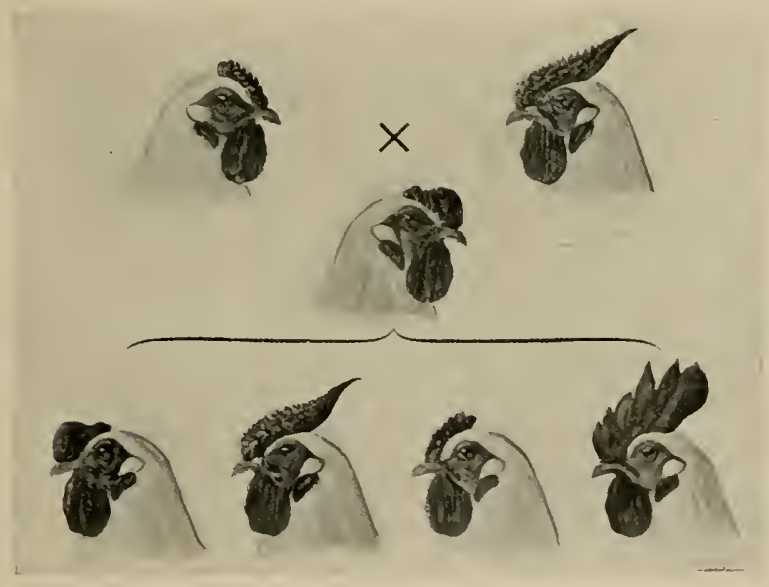

Fig. 23. Cross between pea anc rose combed fowls. (Charts of Baur and Goldschmidt.)

3 rose, 3 pea, 1 single. 'This proportion shows that the grandparental types differed in respect to two pairs of characters.

A fourth case is shown in the fruit fly, where an ebony fly with long wings is mated to a grey fly with restigial wings (fig. 24). The off- 

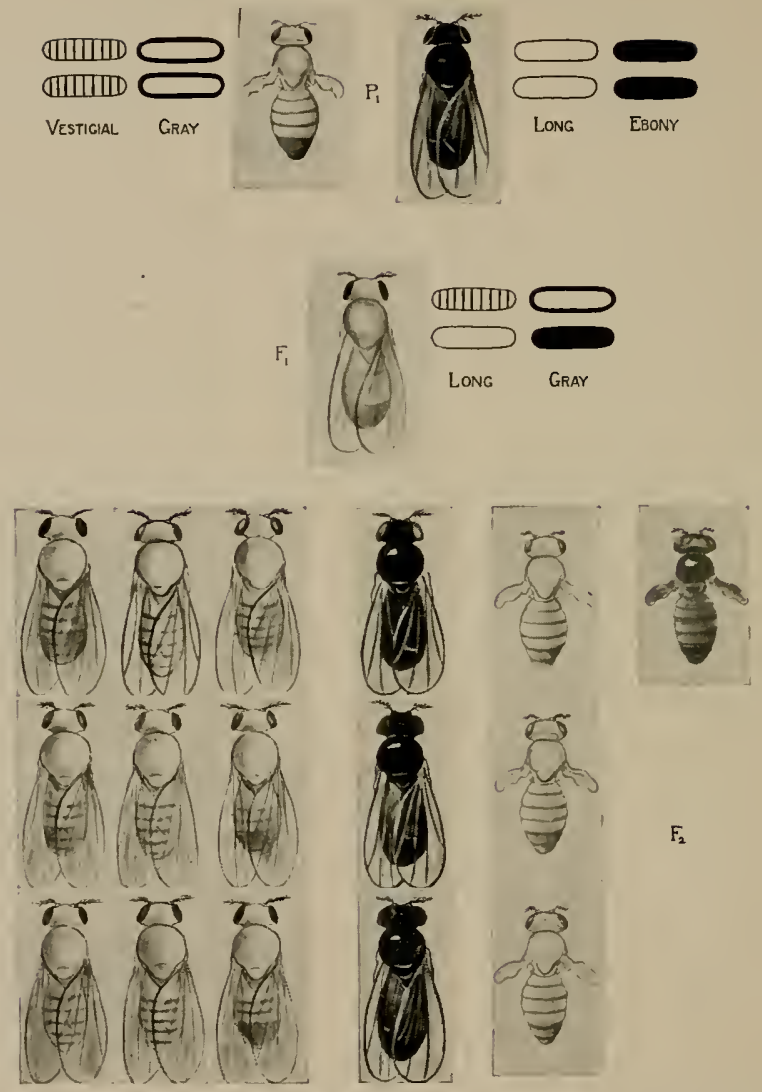

Frg. 24. Cross between long ebony and gray vestigial flies. spring are gray with long wings. If these are inbred they give 9 gray long, 3 gray vestigial, 3 ebony long, 1 ebony restigial (figs. 24 and $25)$. 
'The possibility of interchanging characters might be illustrated over and over again. It is true not only when two pairs of characters are involved, but when three, four, or more enter the cross.

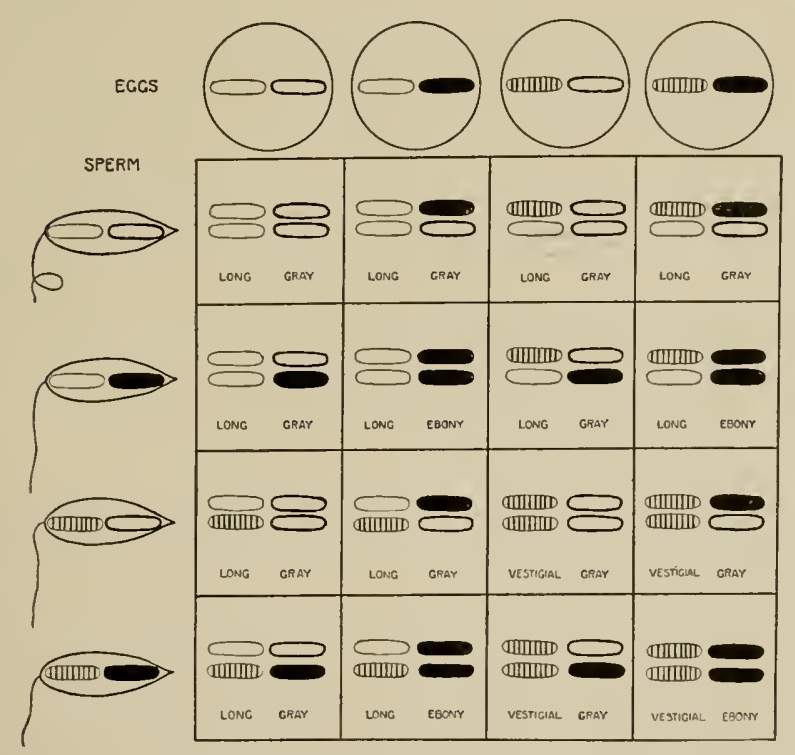

Fig. 25. Diagram to show the history of the factors in the cross shown in Fig. 24 .

It is as though we took indiriduals apart and put together parts of two, three or more individuals by substituting one part for another. 
Not only has this power to make whatever combinations we choose great practical importance, it has even greater theoretical significance; for, it follows that the individual is not in itself the unit in heredity, but that within the germ-cells there exist smaller units concerned with the transmission of characters.

'The older mystical statement of the individual as a unit in heredity has no longer any interest in the light of these discoreries, except as a past phase of biological history. We see, too, more clearly that the sorting out of factors in the germ plasm is a very different process from the influence of these factors on the development of the organism. 'There is today no excuse for confusing these two problems.

If mechanistic principles apply also to embryonic development then the course of development is capable of being stated as a series of chemico-physical reactions and the "individual" is merely a term to express the sum total of such reactions and should not be interpreted as something different from or more than these reactions. So long as so little is known of the actual processes involved in devel- 
opment the use of the term "individuality", while giving the appearance of profundity, in reality often serves merely to cover ignorance and to make a mystery out of a mechanism.

The Characters of Wild Axmals and Plants Follow the Same Laws of Inheritance as do the Characters of Domesticated Aximals axp Plants.

Darwin based many of his conclusions concerning variation and heredity on the evidence derived from the garden and from the stock farm. Here he was handicapped to some extent, for he had at times to rely on information much of which was uncritical, and some of which was worthless.

Today we are at least better.informed on two important points; one conceming the linds of rariations that furnish to the cultivator the materials for his selection; the other concerning the modes of inheritance of these variations. We know now that new characters are continually appearing in domesticated as well as in wild animals and plants, that these characters are often sharply marked 
off from the original characters, and whether the differences are great or whether they are small they are transmitted alike according to Mendel's law.

Many of the characteristics of our domesticated animals and cultivated plants originated long ago, and only here and there have thit records of their first appearance been preserved. In only a few instances are these records clear and definite, while the complete history of any large group of our domesticated products is unknown to us.

Within the last five or six years, however, from a common wild species of fly, the fruit fly, Drosophila ampelophila, which we have brought into the laboratory, have arisen over a hundred and twenty-five new types whose origin is completely known. Let me call attention to a few of the more interesting of these types and their modes of inheritance, comparing them with wild types in order to show that the kinds of inheritance found in dismesticated races occur also in wild types. The results will show beyond dispute that the characters of wild types are inherited in precisely 
the same way as are the characters of the mutant types - a fact that is not generally appreciated except by students of genetics, although it is of the most far-reaching significance for the theory of evolution.

A mutant appeared in which the eye color of the female was different from that of the male. 'The eyre color of the mutant female is a dark eosin color, that of the male yellowish eosin. From the beginning this difference was as marked as it is to-day. Breeding experiments show that eosin eye color differs from the red color of the eye of the wild fly by a single mutant factor. Here then at a single step a type appeared that was sexually dimorphic.

Zoölogists know that sexual dimorphism is not uncommon in wild species of animals, and Darwin proposed the theory of sexual selection to account for the difference between the sexes. He assumed that the male preferred certain kinds of females differing from himself in a particular character, and thus in time through sexual selection, the sexes came to differ from each other. 
In the case of eosin eye color no such process as that postulated by Darwin to account for the differences between the sexes was involved;
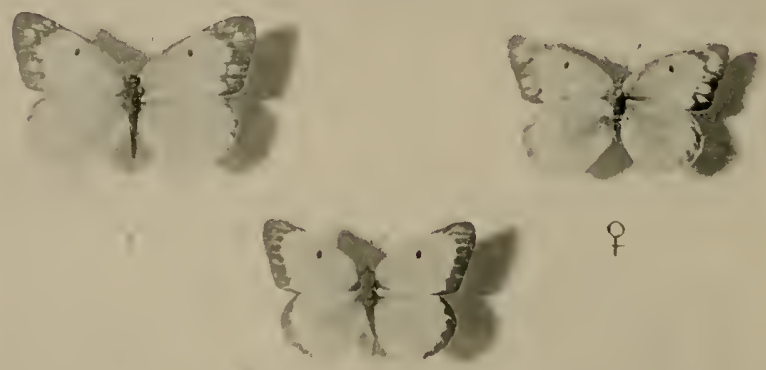

†

Fig. 26. Clover butterfly (Colias philodice) with two types of females, above; and one type of male, below.

for the single mutation that brought about the change also brought in the dimorphism with it.

In recent years zoölogists have carefully studied several cases in which two types of female are found in the same species. In the common clover butterfly, there is a yellow and a white type of female, while the male is yellow (fig. 26). It has been shown that a single factor difference determines whether the female 
is yellow or white. The inheritance is, according to Gerould, strictly Mendelian.

In Papilio turnus there exist, in the southern states, two kinds of females, one yellow like the male, one black (fig. 27). The evidence here is not so certain, but it seems probable that
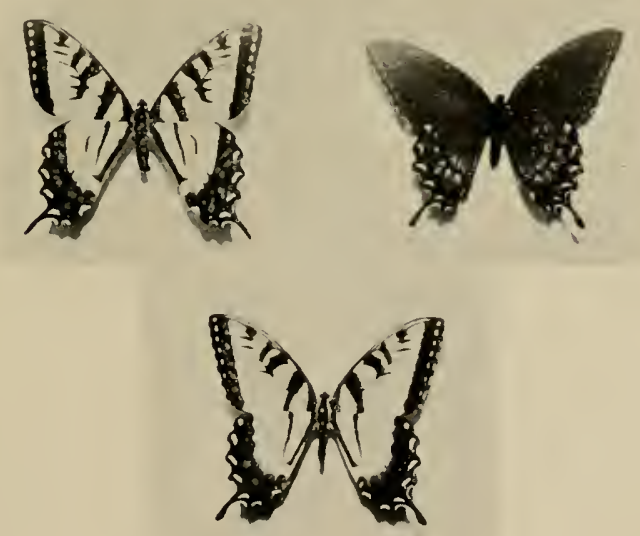

Fig. 2\%. Papilio turnus with two types of females above and one type of male below.

a single factor difference determines whether the female shall be yellow or black.

Finally in Papilio polytes of Ceylon and India three different types of females appear, 
(fig. 28 to right) only one of which is like the male. Here the analysis of the breeding data shows the possibility of explaining this case

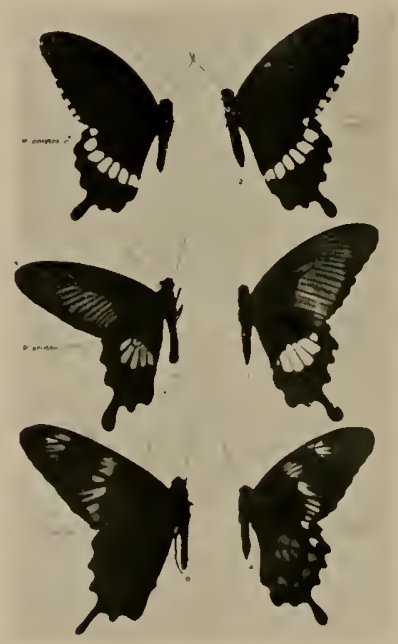

FIG. 28. Papilio polytes, with three types of female to right and one type of male alove to left.

as due to two pairs Mendelian factors which give in combination the three types of female.

Taking these cases together, they furnish a much simpler explanation than the one proposed by Darwin. 'They show also that characters like these shown by wild species may follow Mendel's law. 
'There has appeared in our cultures a fly in which the third division of the thorax with its appendages has changed into a segment like the second (fig. 29). It is smaller than the

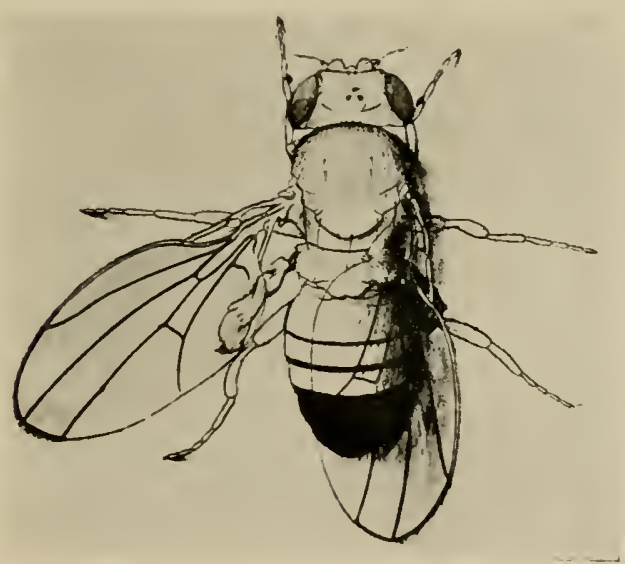

Fig. 29. Hlutant race of fruit fly with intercalated duplicate mesothorax on dorsal side.

normal mesothorax and its wings are imperfectly dereloped, but the bristles on the upper surface may have the typical arrangement of the normal mesothorax. 'The mutant shows how great a change nay result from a single factor difference.

A factor that causes duplication in the legs 
has also been found. Here the interesting fact was discovered (Hoge) that duplication takes place only in the cold. At ordinary temperatures the legs are normal.

In contrast to the last case, where a character is doubled, is the next one in which the eyes are lost (fig. 30). This change also took place at a single step. All the flies of this stock

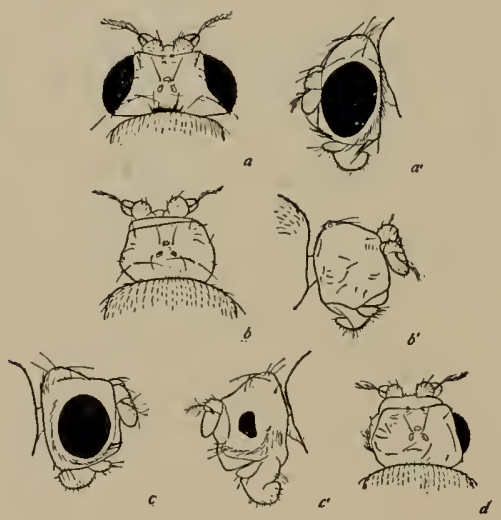

Fig. 30. Mutant race of fruit fyy, called eyeless; a, a' normal eỵe.

however, cannot be said to be eyeless, since many of them show pieces of the eye-indeed the variation is so wide that the eye may even appear like a normal eye unless carefully ex- 
amined. Formerly we were taught that eyeless animals arose in cares. This case shows that they may also arise suddenly in glass milk bottles, by a change in a single factor.

I may recall in this connection that wingless flies (fig. $5 \mathrm{f}$ ) also arose in our cultures by a single mutation. We used to be told that wingless insects occurred on desert islands because those insects that had the best dereloped wings had been blown out to sea. Whether this is true or not, I will not pretend to say, but at any rate wingless insects may also arise, not through a slow process of elimination, but at a single step.

'The preceding examples have all related

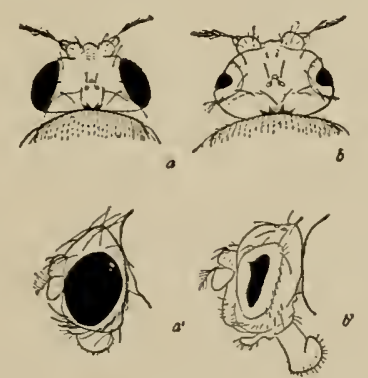

Frci. 31. Mutant race of fruit fly called bar to the right (normal to the left). The eye is a narrow vertical har, the outline of the original eye is indicated. 
to recessive characters. 'The next one is dominant.

A single male appeared with a narrow vertical red bar (fig. 31) instead of the broad red oval eye. Bred to wild females the new character was found to dominate, at least to the extent that the eyes of all its offspring were narrower than the normal eye, although not so narrow as the eye of the pure stock. Around

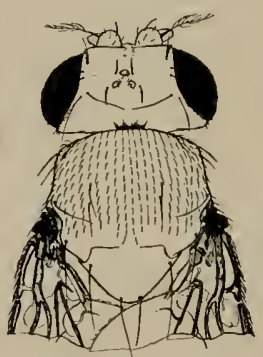

Fig. 32. Mutant race of fruit fly, called speck. There is a minute black speck at base of wing.

the bar there is a wide border that corresponds to the region occupied by the rest of the eye of the wild fly. It lacks however the elements of the eye. It is therefore to be looked upon as a rudimentary organ, which is, so to speak, a by-product of the dominant mutation. 
'The preceding cases have all involved rather' great changes in some one organ of the body. The following three cases involve slight changes, and yet follow the same laws of inheritance as do the larger changes.

At the base of the wings a minute black speck appeared (fig. 32). It was found to be a Mendelian character. In another case the spines on the thorax becane forked or kinky
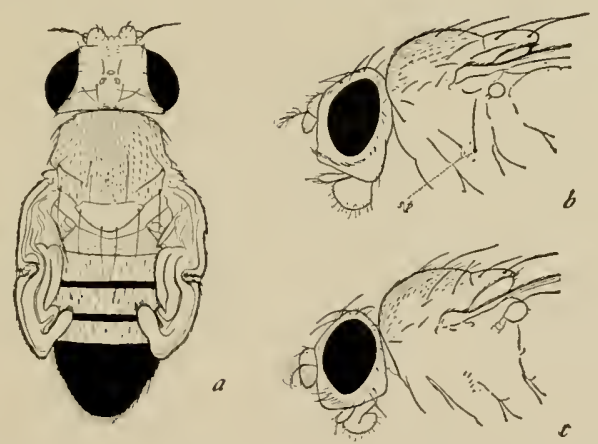

Fig. 33. IItant race of fruit fly called club. The wings often remain unexpanded and two bristles present in wild fly (b) are ahsent on side of thorax (c).

(fig. 5:b). 'This stock breeds true, and the character is inherited in strictly Mendelian fashion.

In a certain stock a number of flies appeared 
in which the wing pads did not expand (fig. 33). It was found that this peculiarity is shown in only about twenty per cent of the individuals supposed to inherit it. Later it was found that this stock lacked two bristles on the sides of the thorax. By means of this knowledge the heredity of the character was easily determined. It appears that while the expansion of the wing pads fails to occur once in five times-probably because it is an environmental effect peculiar to this stock, - yet the minute difference of the presence or absence of the two lateral bristles is a constant feature of the flies that carry this particular factor.

In the preceding cases I have spoken as though a factor influenced only one part of the body. It would have been more accurate to have stated that the chicf effect of the factor was observed in a particular part of the body. Most students of genetics realize that a factor difference usually affects more than a single character. For example, a mutant stock called l'udimentary wings has as its principle characteristic very short wings (fig. 34). But the factor for rudimentary wings also produces other ef- 
fects as well. 'The females are almost completely sterile, while the males are fertile. The viability of the stock is poor. When flies with rudimentary wings are put into competition

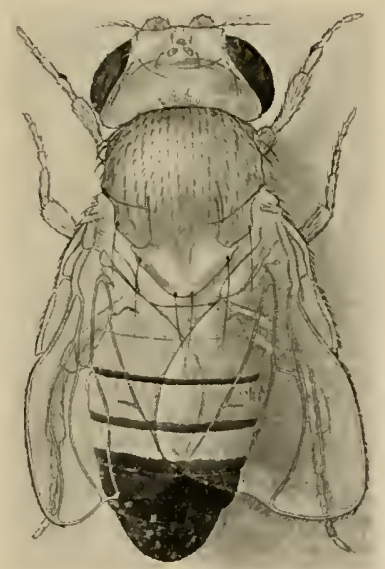

Fig. 34. Mutant race of fruit fly, called rudimentary.

with wild flies relatively few of the rudimentary flies come through, especially if the culture is crowded. The hind legs are also shortened. All of these effects are the results of a single factor-difference.

One may renture the guess that some of the specific and rarietal differences that are char- 
acteristic of wild types and which at the same time appear to have no survival value, are only by-products of factors whose most important effect is on another part of the organism where their influence is of vital importance.

It is well known that systematists make use of characters that are constant for groups of species, but which do not appear in themselves to have an adaptive significance. If we may suppose that the constancy of such characters may be only an index of the presence of a factor whose chief influence is in some other direction or directions, some physiological influence, for example, we can give at least a reasonable explanation of the constancy of such characters.

I am inclined to think that an overstatement to the effect that each factor may affect the entire body, is less likely to do harm than to state that each factor affects only a particular character. 'The reckless use of the phrase "unit character" has done much to mislead the uninitiated as to the effects that a single change in the germ plasm may produce on the organism. Fortunately, the expression "unit character" 
is being less used by those students of genetics who are more careful in regard to the implications of their terminology.

'There is a class of cases of inheritance, due to the XY chromosomes, that is called sex linked inheritance. It is shown both by mutant characters and characters of wild species.

For instance, white eye color in Drosophila shows sex linked inheritance. If a white eyed male is mated to a wild red eyed female (fig. 35) all the offspring have red eyes. If these are inbred, there are three red to one white eyed offspring, but white eyes occur only in the males. 'The grandfather has transmitted his peculiarity to half of his grandsons, but to none of his granddaughter's.

The reciprocal cross (fig. 36) is also interesting. If a white eyed female is bred to a red eyed male, all of the daughters have red eyes and all of the sons have white eyes. We call this criss-cross inheritance. If these offspring are inbred, they produce equal numbers of red eyed and white eyed females and equal numbers of red eyed and white eyed males. The ratio is $1: 1: 1: 1$, or ignoring sex, 2 reds to 
2 whites, and not the usual 3:1 Mendelian ratio. Yet, as will be shown later, the result is in entire accord with Mendel's principle of segregation.
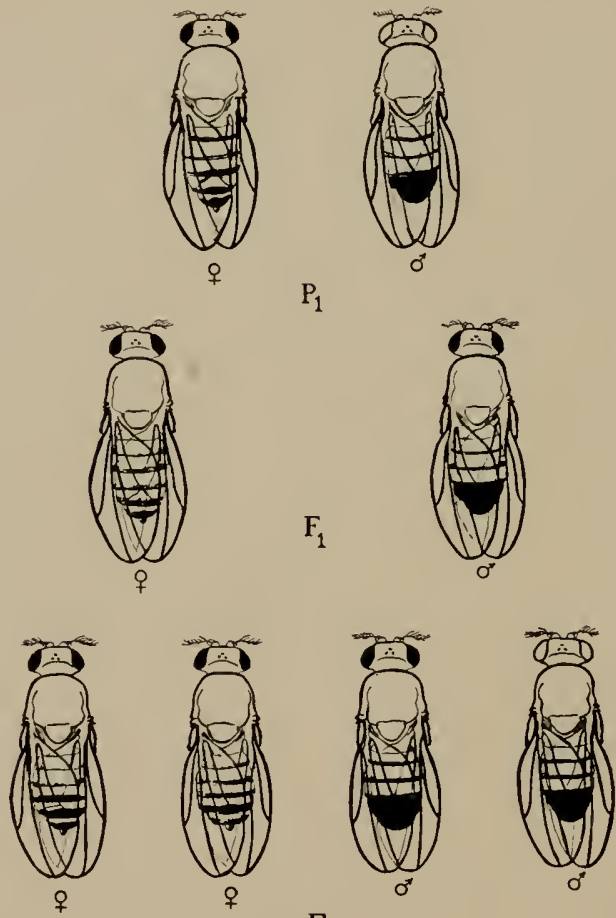

$\mathrm{F}_{2}$

F16. 35. Diagram showing a cross between a white eyed male and a red eyed female of the fruit fly. Sex linked inheritance. 


\section{THEORY OF EVOLU'TION}
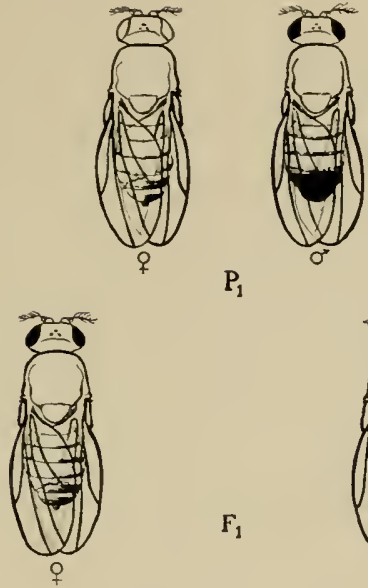

$P_{1}$
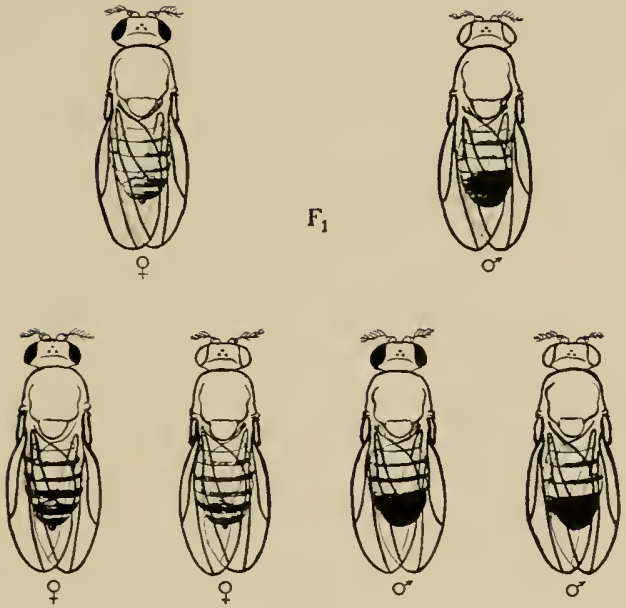

$F_{2}$

Fig. 36. Diagram illustrating a cross between a red eyed male and white ered female of the fruit fly (reciprocal cross (of that shown in Fig. 3.5).

It has been shown by Sturterant that in a wild species of Drosophila, viz., D. repleta, two rarieties of individuals exist, in one of which the thorax has large splotches and in the 
other type smaller splotches (fig. 37). The factors that differentiate these varieties are sex linked.

Certain types of color blindness (fig. 38) and certain other abnormal conditions in man such as haemophilia, are transmitted as sex linked characters.
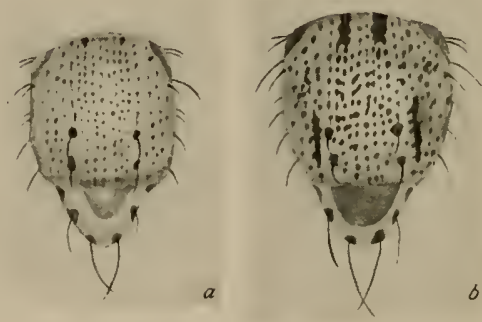

Fig. 37. Two types of markings on thorax of Drosophila repleta, both found "wild". They show sex linked inheritance.

In domestic fowls sex linked inheritance has been found as the characteristic method of transmission for at least as many as six characters, but here the relation of the sexes is in a sense reversed. For instance, if a black Langshan hen is crossed to a barred Plymouth Rock cock (fig. 39), the offspring are all 


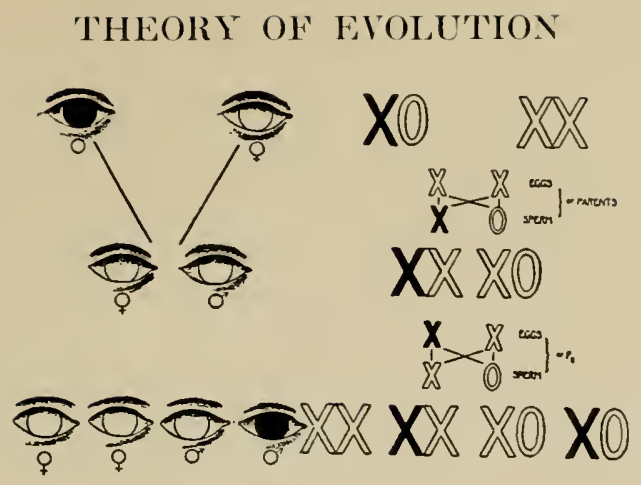

Fıg. 38, A. Diagram illustrating inheritance of color blindness in man; the iris of the color-blind eye is here black.

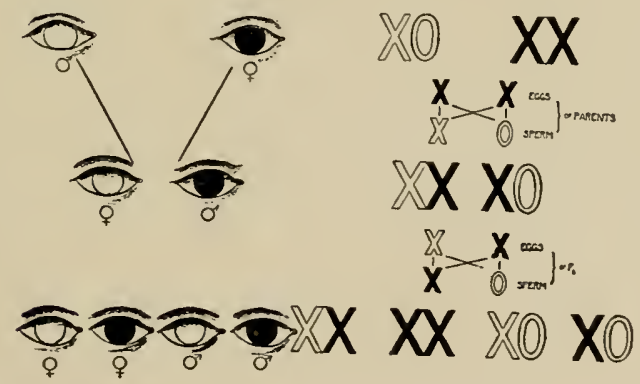

Fig, 38, B. Reciprocal of cross in Fig. 38 a.

barred. If these are inbred half of the daughters are black and half are barred all of the sons are barred. 'The grandmother has transmitted her color to half of her granddaughters but to none of her grandsons. 
In the reciprocal cross (fig. 40) black cock by barred hen, the daughters are black and the sons barred-criss-cross inheritance. These

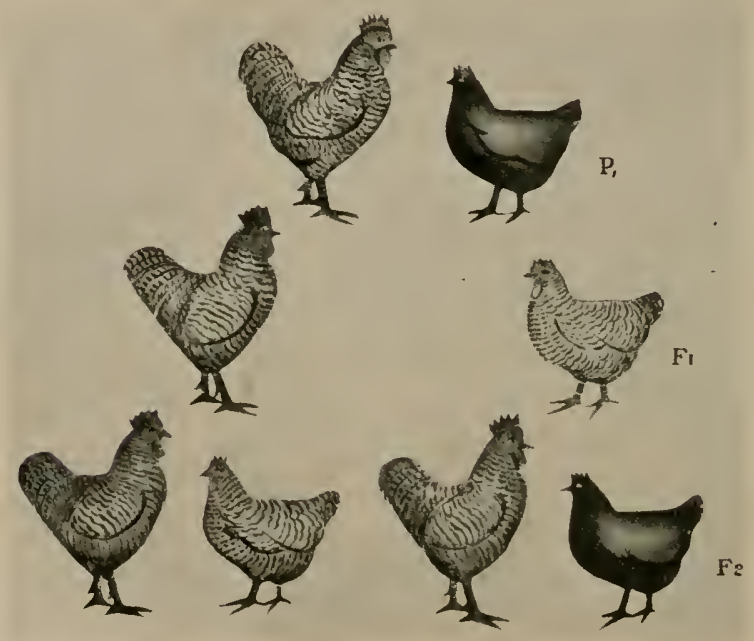

FIg. 39. Sex-linked inheritance in domesticated birds shown here in a cross between barred Plymouth Rock male and black Langshan female.

inbred give black hens and black cocks, barred hens and barred cocks.

There is a case comparable to this found in a wild species of moth, Abraxas grossulariata. A wild rariation of this type is lighter in color 
and is known as A. lacticolor. When these two types are crossed they exhibit exactly the same type of heredity as does the black-barred com-

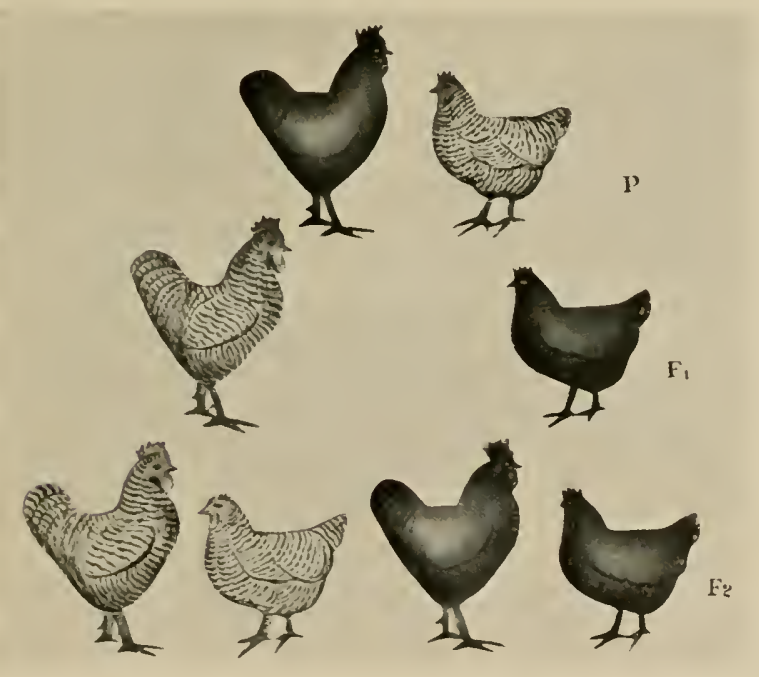

Fig. 40. Reciprocal of Fig. 39.

bination in the domestic fowl. As shown in figure 41 , lacticolor female bred to grossulariata male gives grossulariata sons and daughters. 'These inbred give grossulariata males and females and lacticolor females. Reciprocally lacticolor male by grossulariata female. 
(fig. 42) gives lacticolor daughters and grossulariata sons and these inbred give grossulariata males and females and lacticolor males and females.

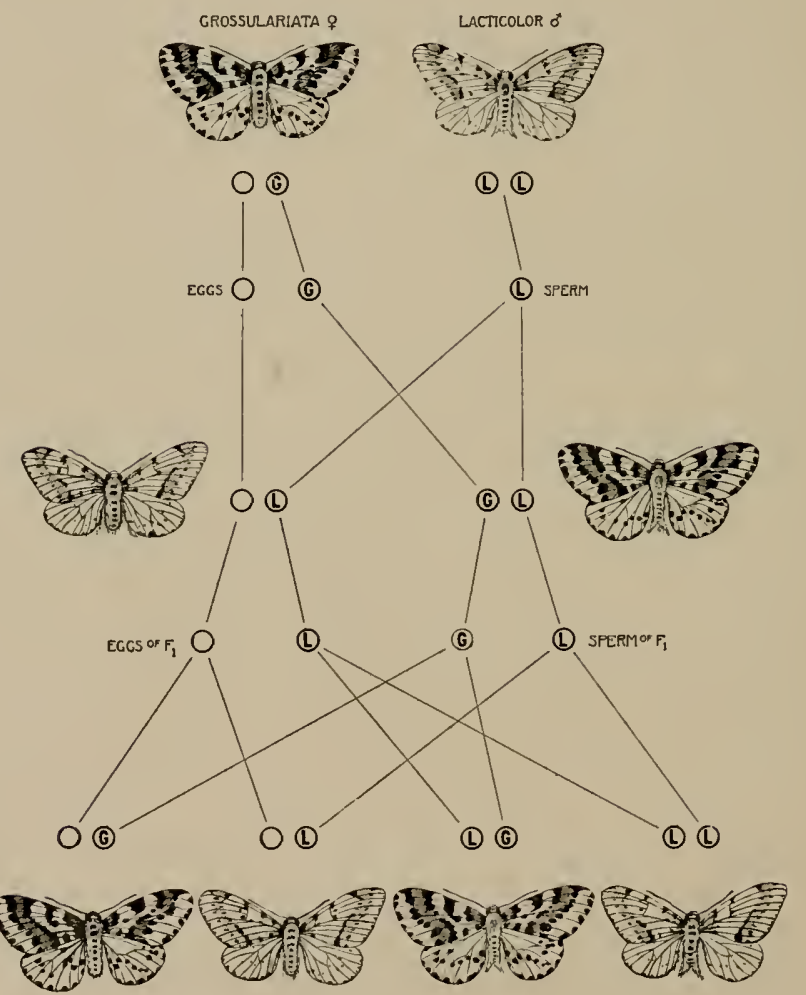

Fig, 41. Sex-linked inheritance in the wild moth, Abraxas grossulariata (darker) and $\mathrm{A}$. lacticolor. 
It has been found that there may be even more than two factors that show Mendelian segregation when brought together in pairs. For example, in the southern States there are sereral races of the grouse locust (Paratettix)

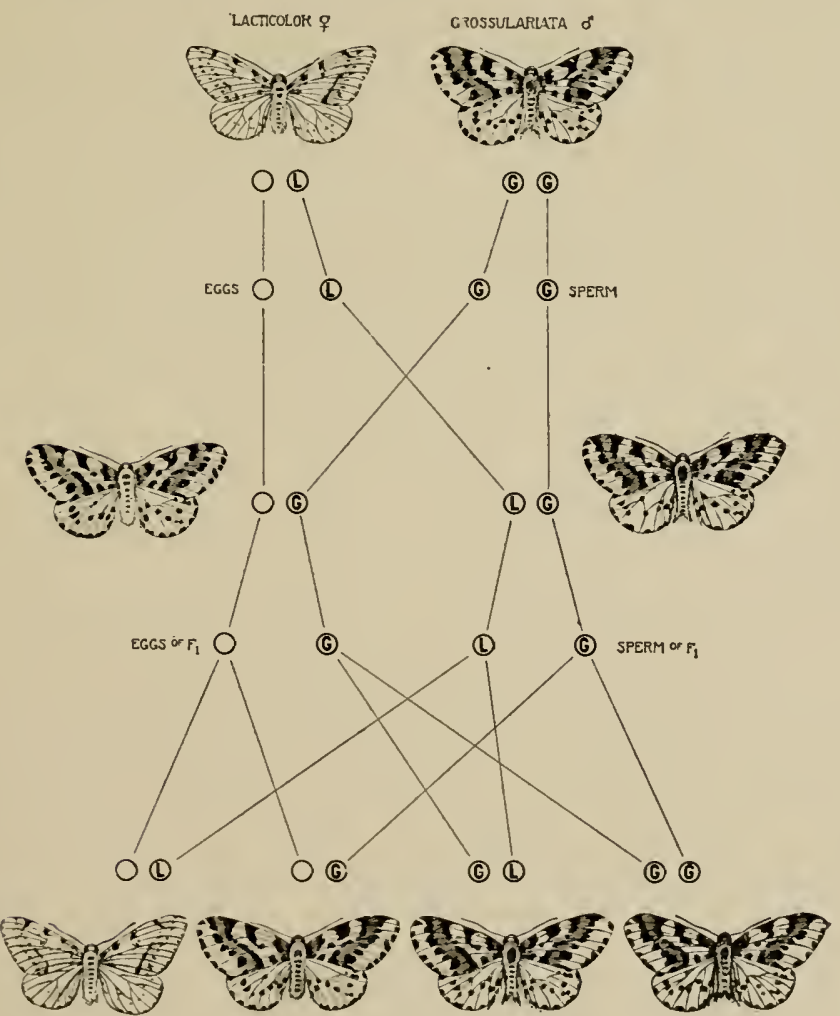

Fig. 42. Reciprocal of Fig. 41 . 
that differ from each other markedly in color patterns (fig. 43). When any two individuals of these races are crossed they give, as Nabours has shown, in $\mathrm{F}_{2}$ a Mendelian ratio of $1: 2: 1$. It is obvious, therefore, that there are here at least nine characters, any two of which behave as a Mendelian pair. These races have
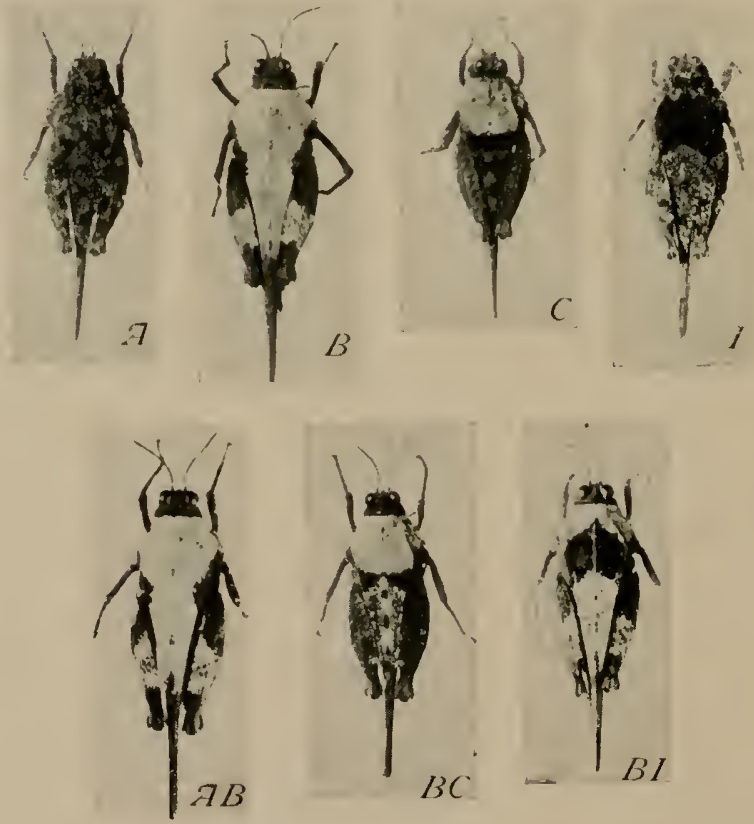

Fig. 13. Four wild types of Paratettix in upper line with three hybrids below. 
arisen in nature and differ definitely and strikingly from each other, yet any two differ by only one factor difference.

Similar relations have been found in a number of domesticated races. In mice there is a quadruple system represented by the gray house mouse, the white bellied, the yellow and the black mouse (fig. 44). In rabbits there is.
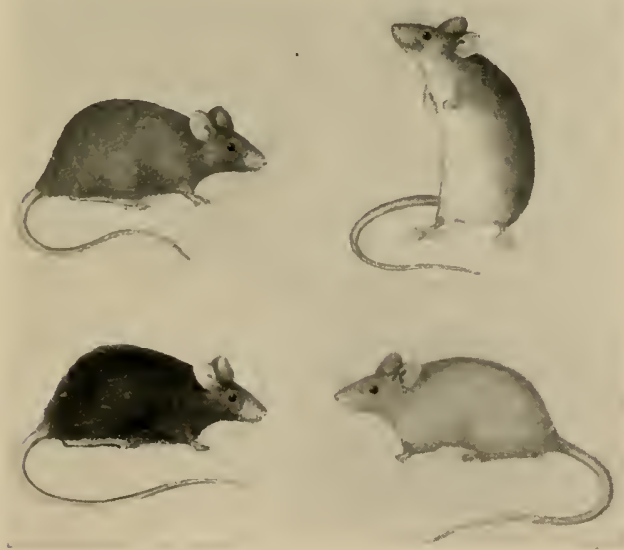

FIG. 4t. Diagram illustrating four allelomorphs in mice, viz. gray bellied gray (wild type) (above, to left); white bellied gray (ahove, to right); yellow (heiow, to right); and black (below, to left).

probably a triple system, that includes the albino, the Himalayan, and the black races. In 
the silkworm moth there have been described four types of larvae, distinguished by different color markings, that form a system of quadruple allelomorphs. In Drosophila there is a quintuple system of factors in the sex chromosome represented by eye colors, a triple system of body color's, and a triple system of factors for eye colors in the third chromosome.

\section{Mutation and Evolution}

What bearing has the appearance of these new types of Drosophila on the theory of erolution may be asked. The objection has been raised in fact that in the breeding work with Drosophila we are dealing with artificial and unnatural conditions. It has been more than implied that results obtained from the breeding pen, the seed pan, the flower pot and the milk bottle do not apply to evolution in the "open", nature "at large" or to "wild" types. To be consistent, this same objection should be extended to the use of the spectroscope in the study of the evolution of the stars, to the use of the test tube and the balance by the chemist, of the galvanometer by the physicist. All these 
are unnatural instruments used to torture $\mathrm{Na}$ ture's secrets from her. I venture to think that the real antithesis is not between umatural and natural treatment of Nature, but rather between controlled or verifiable data on the one hand, and unrestrained generalization on the other.

If a systematist were asked whether these new races of Drosophila are comparable to wild species, he would not hesitate for a moment. He would call them all one species. If he were asked why, he would say, I think, "These races differ only in one or two striking points, while in a hundred other respects they are identical eren to the minutest details." $\mathrm{He}$ would add, that as large a group of wild species of flies would show on the whole the reverse relations, $v i$, they would differ in nearly every detail and be identical in only a few points. In all this I entirely agree with the systematist, for I do not think such a group of types differing by one character each, is comparable to most wild groups of species because the difference between wild species is due to a large number of such single differences. 'The characters 
that have been accumulated in wild species are of significance in the maintenance of the species, or at least we are led to infer that even though the visible character that we attend to may not itself be important, one at least of the other effects of the factors that represent these characters is significant. It is, of course, hardly to be expected that any random change in as complex a mechanism as an insect would improve the mechanism, and as a matter of fact it is doubtful whether any of the mutant types so far discovered are better adapted to those conditions to which a fly of this structure and habits is already adjusted. But this is beside the mark, for modern genetics shows rery positively that adaptive characters are inherited in exactly the same way as are those that are not adaptive; and I have already pointed out that we cannot study a single mutant factor without at the same time studying one of the factors responsible for normal characters, for the two together constitute the Mendelian pair.

And, finally, I want to urge on your attention a question that we are to consider in more detail in the last lecture. Erolution of wild 
species appears to have taken place by modifying and improving bit by bit the structures and habits that the animal or plant already possessed. We have seen that there are thirty mutant factors at least that have an influence on eye color, and it is probable that there are at least as many normal factors that are involved in the production of the red eye of the wild fly.

Evolution from this point of view has consisted largely in introducing new factors that influence characters already present in the animal or plant.

Such a view gives us a somewhat different picture of the process of erolution from the old idea of a ferocious struggle between the individuals of a species with the survival of the fittest and the annihilation of the less fit. Erolution assumes a more peaceful aspect. New and advantageous characters survive by incorporating themselves into the race, improving it and opening to it new opportunities. In other words, the emphasis may be placed less on the competition between the individuals of a species (because the destruction of the less fit does 
88

not in itself lead to anything that is new) than on the appearance of new characters and modifications of old characters that become incorporated in the species, for on these depends the evolution of the race. 


\section{CHAP'TER III}

THE FAC'TORIAL THEORY OF HEREDITY AND THE COMPOSITION OF THE GERII PLASM

'The discovery that Mendel made with edible peas concerning heredity has been found to apply everywhere throughout the plant and animal kingdoms - to flowering plants, to insects, snails, crustacea, fishes, amphibians, birds, and mammals (including man).

There must be something that these widely separated groups of plants and animals have in common-some simple mechanism perhaps-to give such definite and orderly series of results. There is, in fact, a mechanism, possessed alike by animals and plants, that fulfills every requirement of Mendel's principles.

'The Cellular Basis of Organic Eyolution AND Heredity

In order to appreciate the full force of the eridence, let me first pass rapidly in reriew a 
few familiar, historical facts, that preceded the discovery of the mechanism in question.

Throughout the greater part of the last century, while students of evolution and of hered-

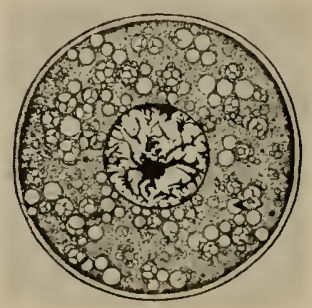

Fic. 45. Typical cell showing the cell wall, the protoplasm (with its contained materials); the nucleus with its contained chromatin and nuclear sap. (After Dahlgren.)

ity were engaged in what I may call the more general, or, shall I say, the grosser aspects of the subject, there existed another group of students who were engaged in working out the minute structure of the material basis of the living organism. They found that organs such as the brain, the heart, the liver, the lungs, the kidneys, etc., are not themselves the units of structure, but that all these organs can be reduced to a simpler unit that repeats itself a 
thousand-fold in every organ. We call this unit a cell (fig. 45) .

'The egg' is a cell, and the spermatozoon is a cell. The act of fertilization is the union of two cells (fig. 47, upper figure). Simple as the process of fertilization appears to us today, its discovery swept aside a vast amount of mystical speculation concerning the rôle of the male and of the female in the act of procreation.

Within the cell a new microcosm was revealed. Every cell was found to contain a spherical body called the nucleus (fig. 46a). Within the nucleus is a network of fibres, a sap fills the interstices of the network. 'The network resolves itself into a definite number of threads at each division of the cell (fig. 46 b-e). These threads we call chromosomes. Each species of animals and plants possesses a characteristic number of these threads which have a definite size and sometimes a specific shape and even characteristic granules at different levels. Beyond this point our strongest microscopes fail to penetrate. Observation has reached, for the time being, its limit.

'The story is taken up at this point by a new 

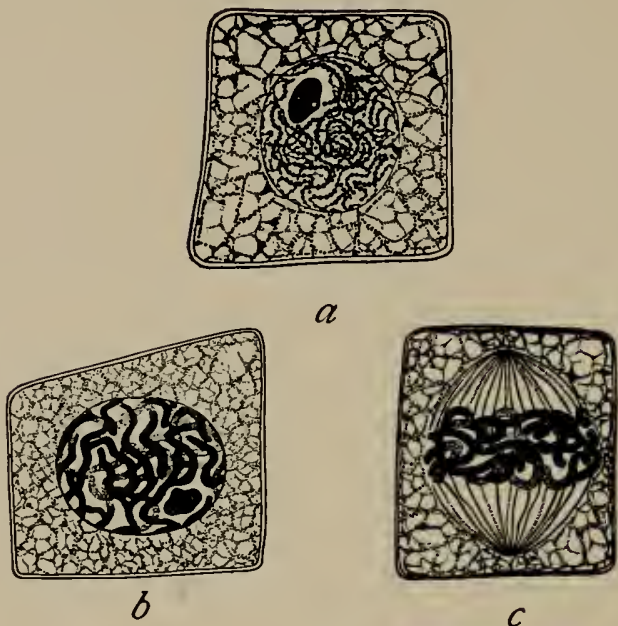

c
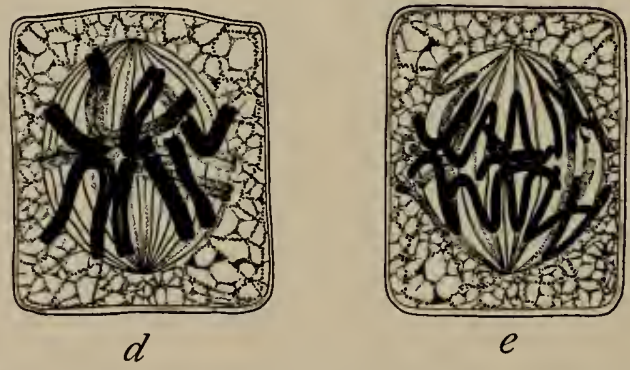

Fig. 46. A series of cells in process of cell division. The chromosomes are the black threads and rods. (After Dahlgren.)

set of students who have worked in an entirely different field. Certain observations and experiments that we have not time to consider 
now, led a number of biologists to conclude that the chromosomes are the bearers of the hereditary units. If so, there should be many such units carried by cach chromosome, for the number of chromosomes is limited while the number of independently inherited characters is large. In Drosophila it has been demonstrated not only that there are exactly as many groups of characters that are inherited together as there are pairs of chromosomes, but even that it is possible to locate one of these groups in a particular chromosome and to state the relative position there of the factors for the characters. If the validity of this evidence is accepted, the study of the cell leads us finally in a mechanical, but not in a chemical sense, to the ultimate units about which the whole process of the transmission of the hereditary factors centers.

But before plunging into this somewhat technical matter (that is difficult only because it is unfamiliar), certain facts which are familiar for the most part should be recalled, because on these turns the whole of the subsequent story.

The thousands of cells that make up the cell- 
state that we call an animal or plant come from the fertilized egg. An hour or two after fertilization the egg divides into two cells (fig. 47). Then each half divides again. Each
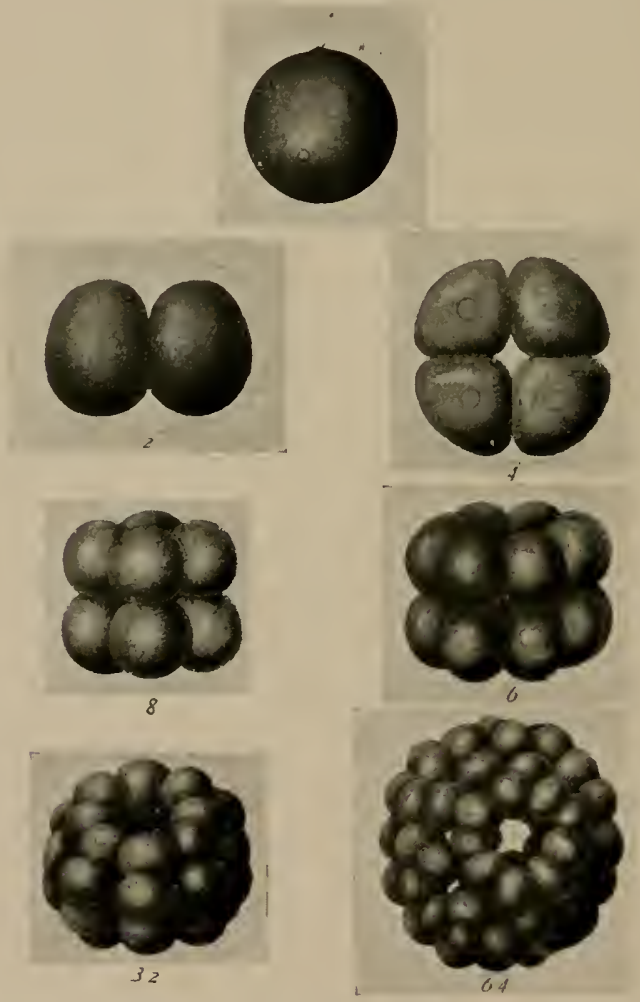

Fig. 47. An egg, and the division of the egg-the so-called process of cleavage. (After Selenka.) 
quarter next divides. The process continues until a large number of cells is formed and out of these organs mould themselves.

At every division of the cell the chromosomes also divide. Half of these have come from the mother, half from the father. Every cell con-
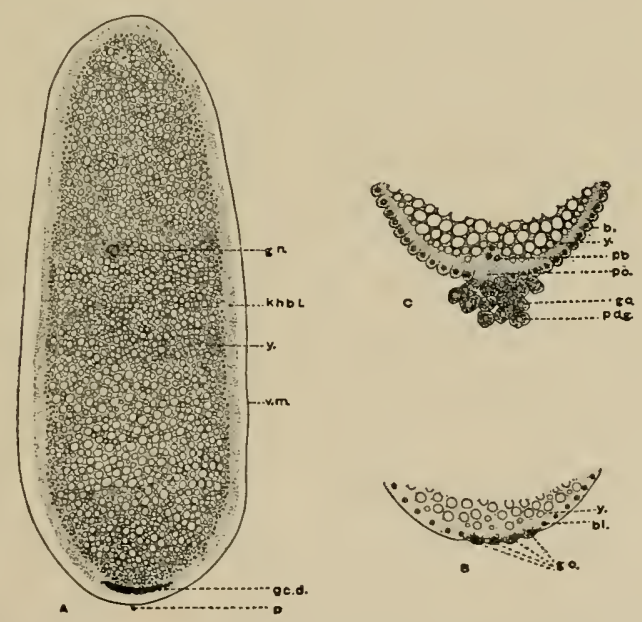

Fig. 48. Section of the egg of the beetle, Calligrapha, showing the pigment at one end where the germ cells will later develop as shown in the other two figures. (After Hegner.)

tains, therefore, the sum total of all the chromosomes, and if these are the bearers of the hereditary qualities, erery cell in the body, 
whatever its function, has a common inheritance.

At an early stage in the development of the animal certain cells are set apart to form the organs of reproduction. In some animals these cells can be identified early in the cleavage (fig. 48).

The reproductive cells are at first like all the other cells in the body in that they contain a full complement of chromosomes, half paternal and half matermal in origin (fig. 49). They divide as do the other cells of the body for a long time (fig. 49, upper row). At each division each chromosome splits lengthwise and its halves migrate to opposite poles of the spirdle (fig. $49 \mathrm{c}$ ).

But there comes a time when a new process appears in the germ cells (fig $49 \mathrm{e}-\mathrm{h}$ ). It is essentially the same in the egg and in the sperm cells. The discovery of this process we owe to the laborious researches of many workers in many countries. The list of their names is long, and I shall not even attempt to repeat it. 'The chromosomes come together in pairs (fig. 49 a). Each maternal chromosome mates with a paternal chromosome of the same kind. 

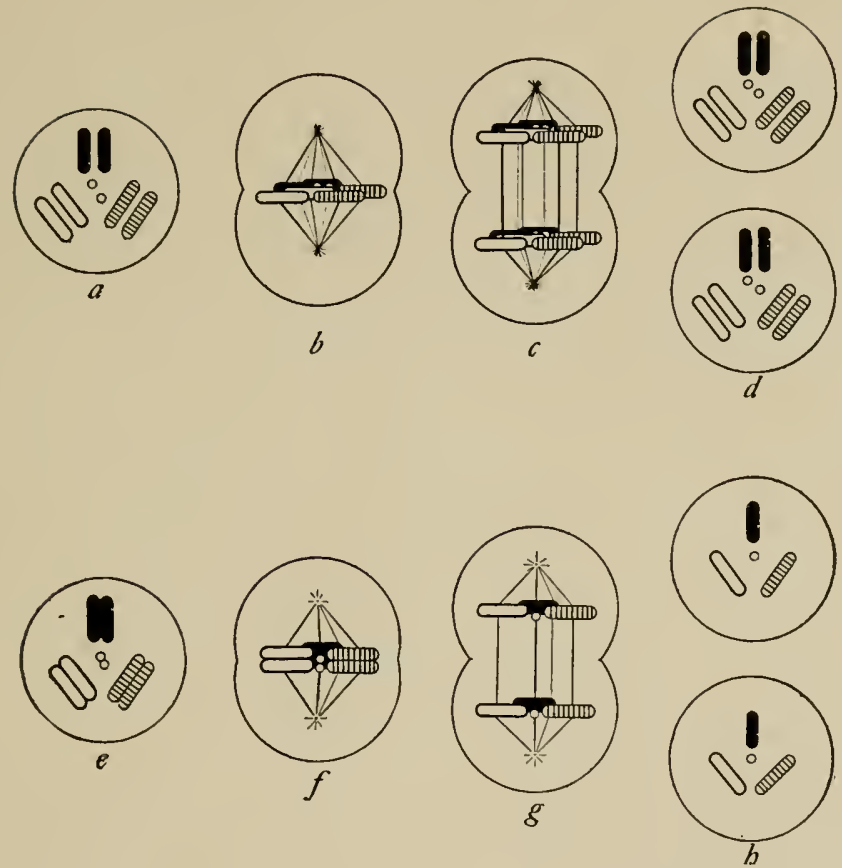

Fig. 49. In the upper row of the diagram a typical process of nuclear division, such as takes place in the early germ cells or in the body cells. In the lower row the separation of the chromosomes that have paired. This sort of separation takes place at one of the two reduction divisions.

Then follow two rapid divisions (fig. $49 \mathrm{f}$, $g$ and 50 and 51$)$. At one of the divisions the double chromosomes separate so that each resulting cell comes to contain some matemal and 

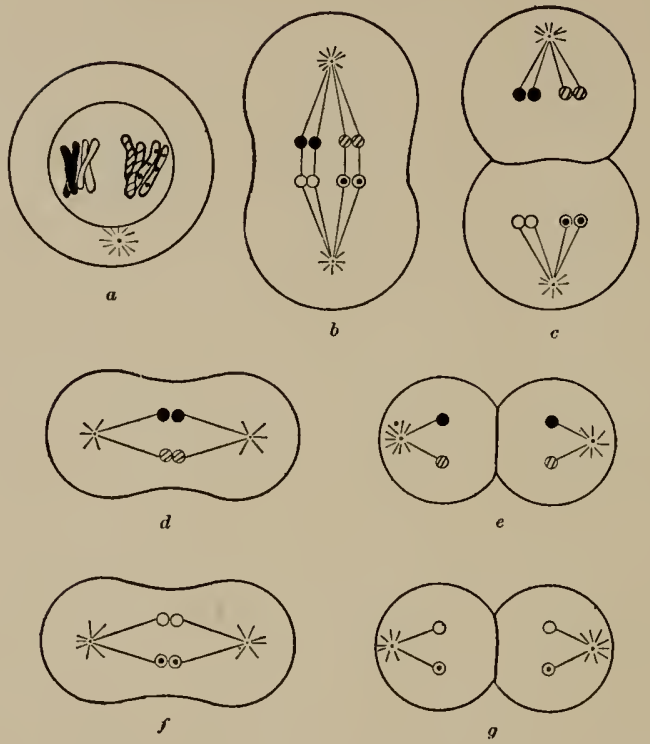

-Fig. 50. The two maturation divisions of the sperm cell. Four sperms result, each with half (haploid) the full number (diploid) of chromosomes.

some paternal chromosomes, i.e. one or the other member of each pair. At the other division each chromosome simply splits as in ordinary cell division.

The upshot of the process is that the ripe eggs (fig. 51) and the ripe spermatozoa (fig. 


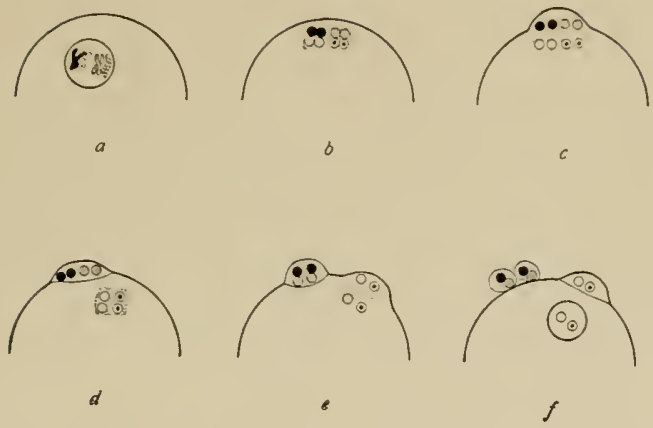

Fig. 51. The two maturation divisions of the egg. The divisions are unequal, so that two small polar bodies are formed one of these subsequently divides. The three polar bodies and the egg are comparable to the four sperms.

so) come to contain only half the total number of chromosomes.

When the eggs are fertilized the whole number of chromosomes is restored again.

\section{'The Mechanisid of Mendeliax Heredity Discovered in the Behavior of the Chromosomes}

If the factors in heredity are carried in the chromosomes and if the chromosomes are definite structures, we should anticipate that there should be as many groups of characters as there are kinds of chromosomes. In only one 
case has a sufficient number of characters been studied to show whether there is any correspondence between the number of hereditary groups of characters and the number of chromosomes. In the fruit fly, Drosophila ampelophila, we have found about 125 characters that are inherited in a perfectly definite way. On the opposite page is a list of some of them.

It will be observed in this list that the characters are arranged in four groups, Groups I, II, III and IV. 'Three of these groups are equally large or nearly so; Group IV contains only two characters. The characters are put into these groups because in heredity the members of each group tend to be inherited together, i.e., if two or more enter the cross together they tend to remain together through subsequent generations. On the other hand, any member of one group is inherited entirely independently of any member of the other groups; in the same way as Mendel's yellow-green pair of characters is inherited independently of the roundwrinkled pair.

If the factors for these characters are carried by the chromosomes, then we should ex- 


\begin{tabular}{|c|c|c|c|}
\hline Group $I$ & Group $I I$ & Group III & Group \\
\hline Abnormal & Antlered & Band & Bent \\
\hline Bar & Ipterous & Beaded & Eyeless \\
\hline Bifid & Arc & Cream III & \\
\hline Bow & Balloon & Deformed & \\
\hline Cherry & Black & Dwarf & \\
\hline Chrome & Blistered & Ebony & \\
\hline Cleft & Comma & Giant & \\
\hline Club & Confluent & Kidney & \\
\hline Depressed & Cream II & Low erossing o & ver \\
\hline Dot & Curved & Maroon & \\
\hline Eosin & Dachs & Peach & \\
\hline Facet & Extra vein & Pink & \\
\hline Forked & Fringed & Rough & \\
\hline Furrowed & Jaunty & Safranin & \\
\hline Fused & Limited & Sepia & \\
\hline Green & I.ittle crossover & Sooty & \\
\hline Jaunty & Morula & Spineless & \\
\hline Lemon & Olive & Spread & \\
\hline L.ethals, 13 & Plexus & Trident & \\
\hline Miniature & Purple & Truncate inten & sifier \\
\hline Sotch & Speck & Whitehead & \\
\hline Reduplicated & Strap & White ocelli & \\
\hline Ruby & Streak & & \\
\hline Rudimentary & Trefoil & & \\
\hline Sable & Truncate & & \\
\hline Shifted & Vestigial & & \\
\hline Short & & & \\
\hline Skee & & & \\
\hline Spoon & & & \\
\hline Spot & & & \\
\hline Tan & & & \\
\hline Truncate inter & sifier & & \\
\hline Vermilion & & & \\
\hline White & & & \\
\hline Yellow & & & \\
\hline
\end{tabular}


pect that those factors that are carried by the same chromosome would be inherited together, provided the chromosomes are definite structures in the cell.

In the chromosome group of Drosophila, (fig. 52) there are four pairs of chromosomes, three of nearly the same size and one much smaller. Not only is there agreement between
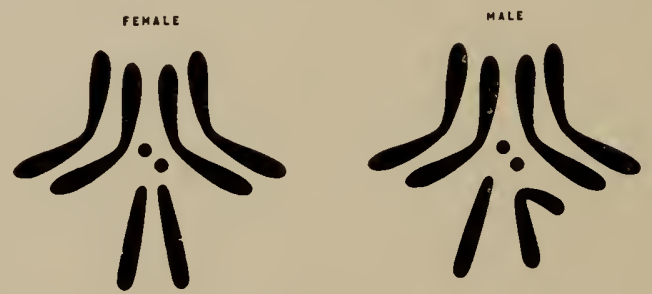

Fig. 5: Chromosomes (diploid) of D. ampelophila. The sex chromosomes are $\mathrm{XX}$ in the female and $\mathrm{XY}$ in the male. There are three other pairs of chromosomes.

the number of hereditary groups and the number of the chromosomes, but even the size relations are the same, for there are three great groups of characters and three pairs of large chromosomes, and one small group of characters and one pair of small chromosnmes. 
The Four Great Linkage Groups of

Drosophila a MPELOPHILA

'The following description of the characters of the wild fly may be useful in connection with the account of the modifications of these characters that appear in the mutants.

The head and thorax of the wild fly are grayish-yellow, the abdomen is banded with alternate stripes of yellow and black. In the male, (fig. 4 to right), there are three narrow bands and a black tip. In the female there are five black bands (fig. 4 to left). 'The wings are gray with a surface texture of such a kind that at certain angles they are iridescent. The eyes are a deep, solid, brick-red. The minute hairs that cover the body have a very definite arrangement that is most obvious on the head and thorax. There is a definite number of larger hairs called bristles or chaetae which have a characteristic position and are used for diagnostic purposes in classifying the species. On the foreleg of the male there is a comb-like organ formed by a row of bristles; it is absent in the female. The comb is a secondary sexual character, and it is, so far as known, functionless. 
Some of the characters of the mutant types are shown in figures $5 \mathbf{2}, 53,54,55$. The drawing of a single fly is often used here to illustrate more than one character. This is done to economize space, but of course there would be no difficulty in actually bringing together in the same individual any two or more characters belonging to the same group (or to different groups). Without colored figures it is not possible to show many of the most striking differences of these mutant races; at most dark and light coloring can be indicated by the shading of the body, wings, or eyes.

\section{Group I}

In the six flies drawn in figure 53 there are shown five different wing characters. The first of these types (a) is called cut, because the ends of the wings look as though they had been cut to a point. The antennae are displaced downward and appressed and their bristle-like aristae are crumpled.

The second figure (b) represents a fly with a notch in the ends of the wings. This character is dominant, but the same factor that pro- 


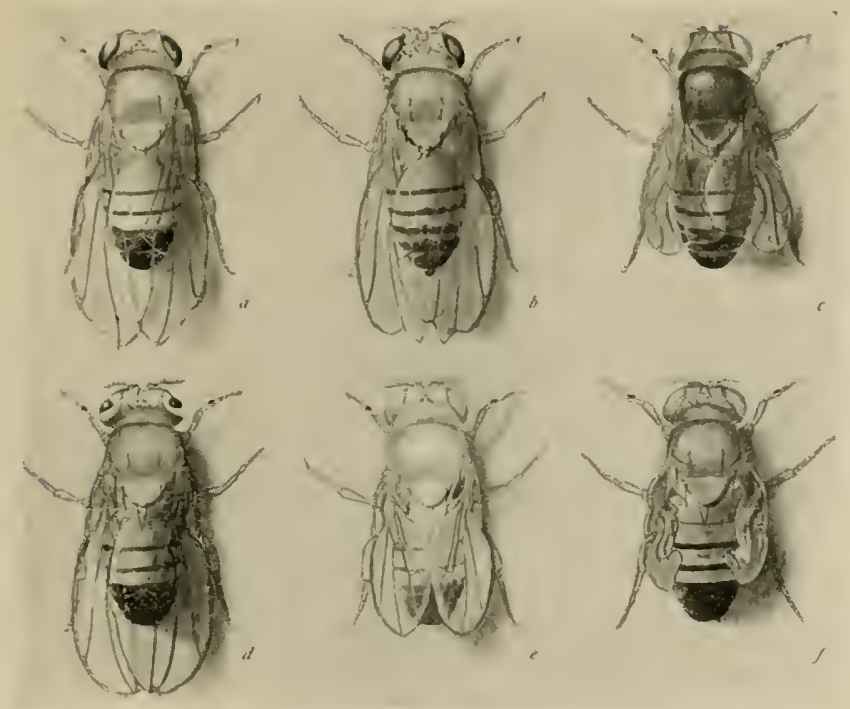

Fig, 53. Group I. (See text)

duces the notch in the wings is also a recessive lethal factor; because of this latter effect of the character no males of this race exist, and the females of the race are never pure but hybrid. Every female with notch wings bred to a wild male, will produce in equal numbers notch winged daughters and daughters with normal wings. There will be half as many sons as daughters. The explanation of 
this peculiar result is quite simple. Every notch winged female has one $\mathbf{X}$ chromosome that carries the factor for notch and one $\mathbf{X}$ chromosome that is "normal". Daughters receiving the former chromosomes are notched because the factor for notch is dominant, but they are not killed since the lethal effect of the notch factor is recessive to the normal allelomorph carried by the other chromosome that the daughters get from their father. This normal factor is recessive for notch but dominant for life. This same figure (b) is used here to show three other sex linked characters. 'The spines on the thorax are twisted or kinky, which is due to a factor called "forked". 'The effect is best seen on the thorax, but all spines on the body are similarly modified; even the minute hairs are also affected. Ruby eye color might be here represented-if the eyes in the figure were colored. The lighter color of the body and antennae is intended to indicate that the character tan is also present. The light color of the antennae is the most certain way of identifying tan. The tan flies are interesting because they have lost the positive heliotropism 
that is so marked a feature in the behavior of D. ampelophila. As this peculiarity of the tan flies is inherited like all the other sex linked characters, it follows that when a tan female is bred to a wild male all the sons inherit the recessive tan color and indifference to light, while the daughters show the dominant sex linked character of their father, i.e., they are "gray", and go to the light. Hence when such a brood is disturbed the females fly to the light, but the males remain behind.

One of the first mutants that appeared in D. ampelophila was called rudimentary on account of the condition of the wings (c). 'The same mutation has appeared independently several times. In the drawing (c) the dark body color is intended to indicate "sable" and the lighter color of the eyes is intended to indicate eosin. 'This eye color, which is an allelomorph of white, is also interesting because in the female the color is deeper than in the male. In other cases of sex linked factor's the character is the same in the two sexes.

In the fourth figure (d) the third and fourth longitudinal veins of the wing are fused into 
one vein from the base of the wing to the level of the first cross-vein and in addition converge and meet near their outer ends. The shape of the eye is represented in the figure as different from the normal, due to another factor called "bar". This is a dominant character, the hybrid condition being also narrow, but not so narrow as the pure type. Vermilion eye color might also be here represented-due to a factor that has appeared independently on several occasions.

In the fifth figure (e) the wings are shorter and more pointed than in the wild fly. This character is called miniature. 'The light color' of the drawing may be taken to represent yellow body color, and the light color of the eye white eye color.

In the last figure (f) the wings are represented as pads, essentially in the same condition that they are in when the fly emerges from the pupa case. Not all the flies of this stock have the wings in this condition; some have fully expanded wings that appear normal in all respects. Nevertheless, about the same percentage of offspring show the pads irrespective of 
whether the parents had pads or expanded wings.

'The flies of this stock show, however, another' character, which is a product of the same factor, and which is constant, i.e., repeated in all individuals. The two bristles on the sides of the thorax are constantly absent in this race. The lighter color of the eye in the figure may be taken to indicate buff-a faint yellowish color. 'The factor for this eye color is another' allelomorph of white.

'There are many other interesting characters that belong to the first group, such as abnormal abdomen, short legs, duplication of the legs, etc. In fact, any part of the body may be affected by a sex-linked factor.

\section{Group $I I$}

In the first figure (a) of figure 5t that contains members of Group II the wings are almost entirely absent or "vestigial". This condition arose at a single step and breeds true, although it appears to be influenced to some extent by temperature, also by modifiers that sometimes appear in the stock. Purple 


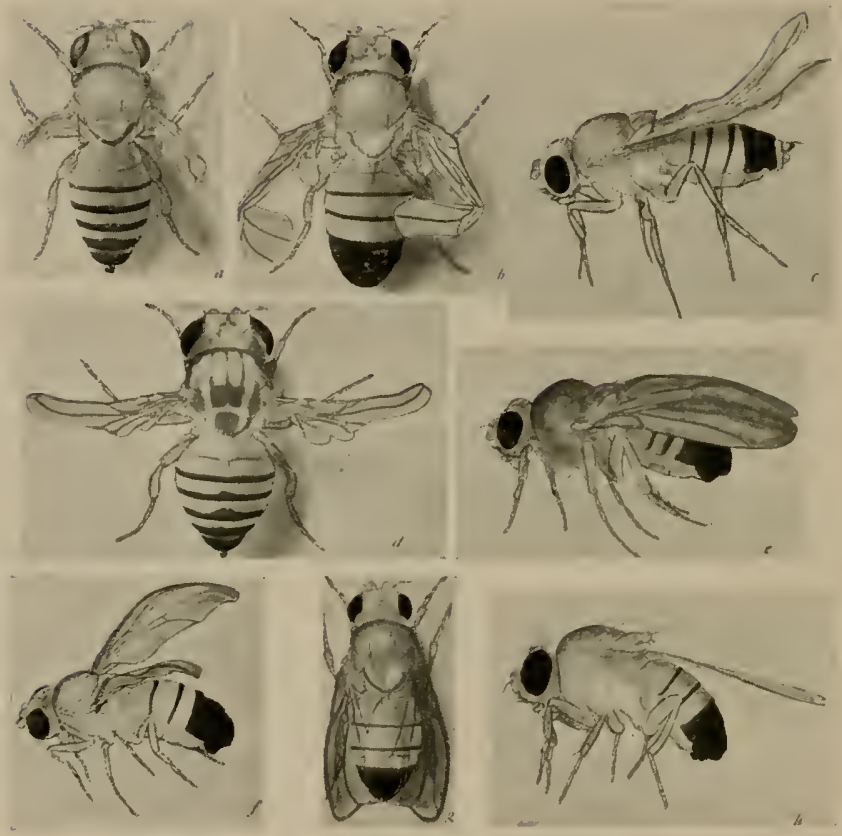

Fig. st. Group II. (See text.)

eye color belongs in Group II; it resembles the color of the eye of the wild fly but is darker and more translucent.

In the second figure (b) the wing is again long and narrow and sometimes bent back on itself, as shown here. In several respects the wing resembles strap (d) but seems to be due 
to another factor, called antler, insufficiently studied as yet.

In the third figure (c) the wings turn up at the end. This is brought about by the presence of the factor called jaunty.

In the fourth figure the wings are long and narrow and several of the veins are unrepresented. 'This character, "strap", is rery variable and has not yet been thoroughly studied. On the thorax there is a deep black mark called trefoil. Even in the wild fly there is a three pronged mark on the thorax present in many individuals. Trefoil is a further development and modification of this mark and is due to a special factor.

In the fifth figure (e) the wings are arched. 'The factor is called arc. 'The dark color of the body, and especially of the wings, indicates the factor for black.

'The sixth figure (f) shows the wings "curved" downwards. In addition there is present a minute black speck at the base of each wing, due to another factor called speck.

In the serenth figure $(\mathrm{g})$ the wing is trumcate. Its end is obliquely squared instead of 
rounded; it may be longer than the body, or shorter when other modifying factors are present. The mutation that produces this type of wing is of not infrequent occurrence. It has been shown by Muller and Altenburg that there are at least two factors that modify this character-the chief factor is present in the second chromosome; alone it produces the truncate wing in only a certain percentage of cases, but when the modifiers are also present about ninety percent of the individuals may show the trumcate condition of the wing. But the presence of these factors makes the stock very infertile, so that it is difficult to maintain.

In the eighth figure $(h)$ the legs are shortened owing to the absence of a segment of the tarsus. The stock is called dachs - a nickname given to it because the short legs suggested the dachshund.

\section{Group III}

In figure 55, (a), a mutant type called bithorax is shown. The old metathorax is replaced by another mesothorax thrust in between the normal mesothorax and the abdomen. It 
carries a pair of wings that do not completely unfold. On this new mesothorax the characteristic arrangement of the bristles is shown. Thus at a single step a typical region of the body has doubled. The character is recessive.

The size of the adult fly of D. ampelophila
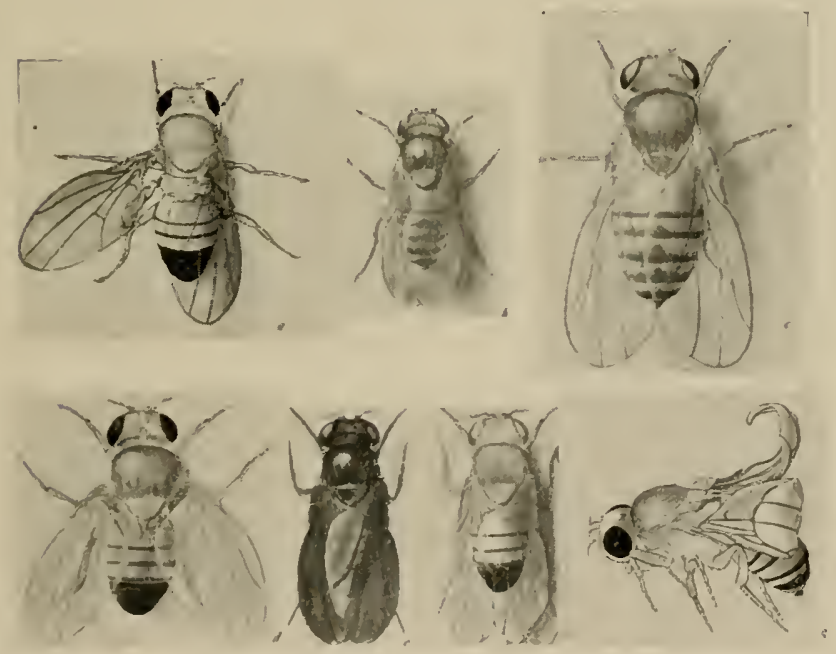

Fig. 5.5. Group III. (See text.)

varies greatly according to the amount of nourishment obtained by the larra. After the fly emerges its size remains nearly constant, as in many insects. 'Two races have. how- 
ever, been separated by Bridges that are different in size as a result of a genetic factor. The first of these, called dwarf, is represented by figure $55,(\mathrm{~b})$.

The race is minute, although of course its size is variable, depending on food and other conditions. The same figure shows the presence of another factor, "sooty", that makes the fly very dark. Maroon eye color might be here represented, due to still another factor.

In the third figure (c) the other mutation in size is shown. It is called "giant". 'The flies are twice the size of wild flies. An eye color, called peach, might here be represented. It is an allelomorph of pink.

In the fourth figure (d) the mutant called dichaete is shown. It is characterized by the absence of two of the bristles on the thorax. Other bristles may also be absent, but not so constantly as the two just mentioned. Another effect of the same factor is the spread-out condition of the wings. 'The very dark eye color in this figure may be taken to indicate the presence of another factor, "sepia", which causes the eyes to assume a brown color that 
becomes black with age. Most of the other mutations in eye color that have occurred tend to give a lighter color: this one, which is also recessive, makes the eyre darker.

In the fifth figure (e) the color of the darkest fly is due to a factor called ebony, which is an allelomorph of sooty.

In the sixth figure (f) the wings are beaded, i.e., the margin is defective at intervals, giving a beaded-like outline to the wings. This condition is very variable and much affected by other factors that influence the shape of the wings. 'The lighter eye color of the drawing may be taken to represent pink.

In the serenth figure $(g)$ the wings are curled up orer the back. This is a recessive character.

\section{Group IV}

Only two mutants have been obtained that do not belong to any of the preceding groups; these are put together in Group IV. It has been shown that they are linked to each other and the linkage is so close that it has thus far been impossible to obtain the dominant recessive. 
One of these mutants, called "eyeless" (fig. 56, $\left(\mathrm{a}, \mathrm{a}^{1}\right)$, is variable - the eyes are often entirely absent or represented by one or more groups of ommatidia. The outline of the original eye,
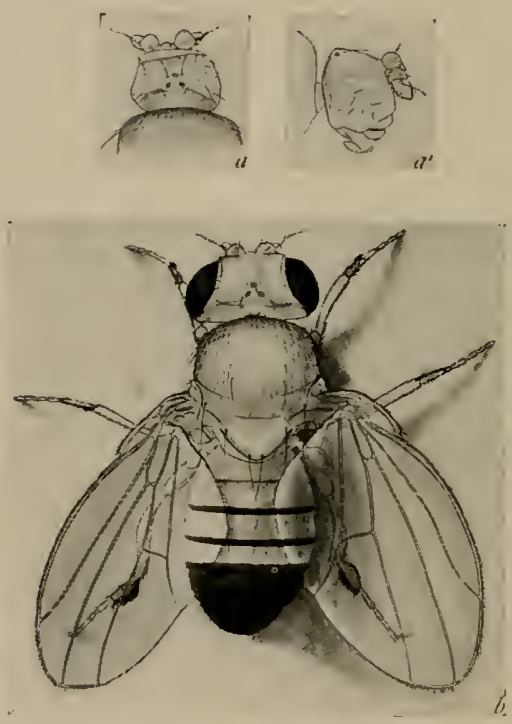

Fig. 56. Group IV. (See text.)

so to speak, is strongly marked out and its area might be called a rudimentary organ, if such a statement has any meaning here.

The other figure (b) represents "bent", so called from the shape of the wings. This mu- 
tant is likewise very variable, often indistinguishable from the wild type, yet when well developed strikingly different from any other. mutant.

This brief account of a few of the mutant. races that can be most easily represented by uncolored figures will serve to show how all parts of the body may change, some of the changes being so slight that they would be overlooked except by an expert, other's so great. that in the character affected the Hies depart far from the original species.

It is important to note that mutations in the first chromosome are not limited to any part of the body nor do they affect more frequently a particular part. The same statement holds equally for all of the other chromosomes. In fact, since each factor may affect visibly several parts of the body at the same time there. are no grounds for expecting any special relation between a given chromosome and special regions of the body. It can not too insistently be urged that when we say a character is the product of a particular factor we mean no more than that it is the most conspicuons effect of the factor. 
If, then, as these and other results to be described point to the chromosomes as the bearers of the Mendelian factors, and if, as will be shown presently, these factors have a definite location in the chromosomes it is clear that the location of the factors in the chromosomes bears no spatial relation to the location of the parts of the body to each other.

\section{Localization of Factors in the \\ Chromosomes}

The Eridence from Sew Linked Inheritance

When we follow the history of pairs of chromosomes we find that their distribution in successive generations is paralleled by the inheritance of Mendelian character's. This is best shown in the sex chromosomes (fig. 57). In the female there are two of these chromosomes that we call the $\mathbf{X}$ chromosomes; in the male there are also two but one differs from those of the female in its shape, and in the fact that it carries none of the normal allelomorphs of the mutant factor's. It is called the $\mathrm{Y}$ chromosome.

The course followed by the sex chromosomes and that by the characters in the case of sex 

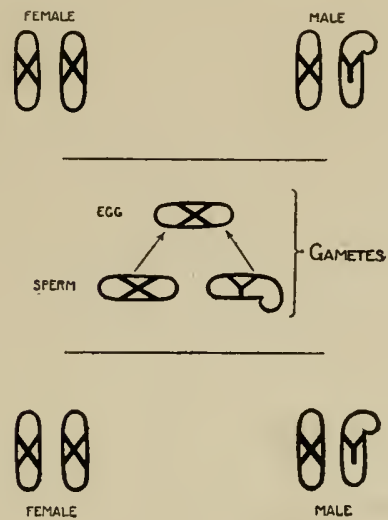

Fig. 5\%. Scheme of sex determination in Drosophila type. Each mature egg contains one $\mathrm{X}$, each mature sperm contains one $\mathrm{X}$, or a $\mathrm{Y}$ chromosome. Chance union of any egg with any sperm will give either XX (female) or XY (male).

linked inheritance are shown in the next diagram of Drosophila illustrating a cross between a white eyed male and a red eyed female.

The first of these represents a cross between a white eyed male and a red eyed female (fig. 58, top row). 'The $\mathbf{X}$ chromosome in the male is represented by an open bar, the $\mathrm{Y}$ chromosome is bent. In the female the two $\mathbf{X}$ chromosomes are black. Each egg of such a female will contain one "black" $X$ after the polar bodies have been thrown off. In the male 


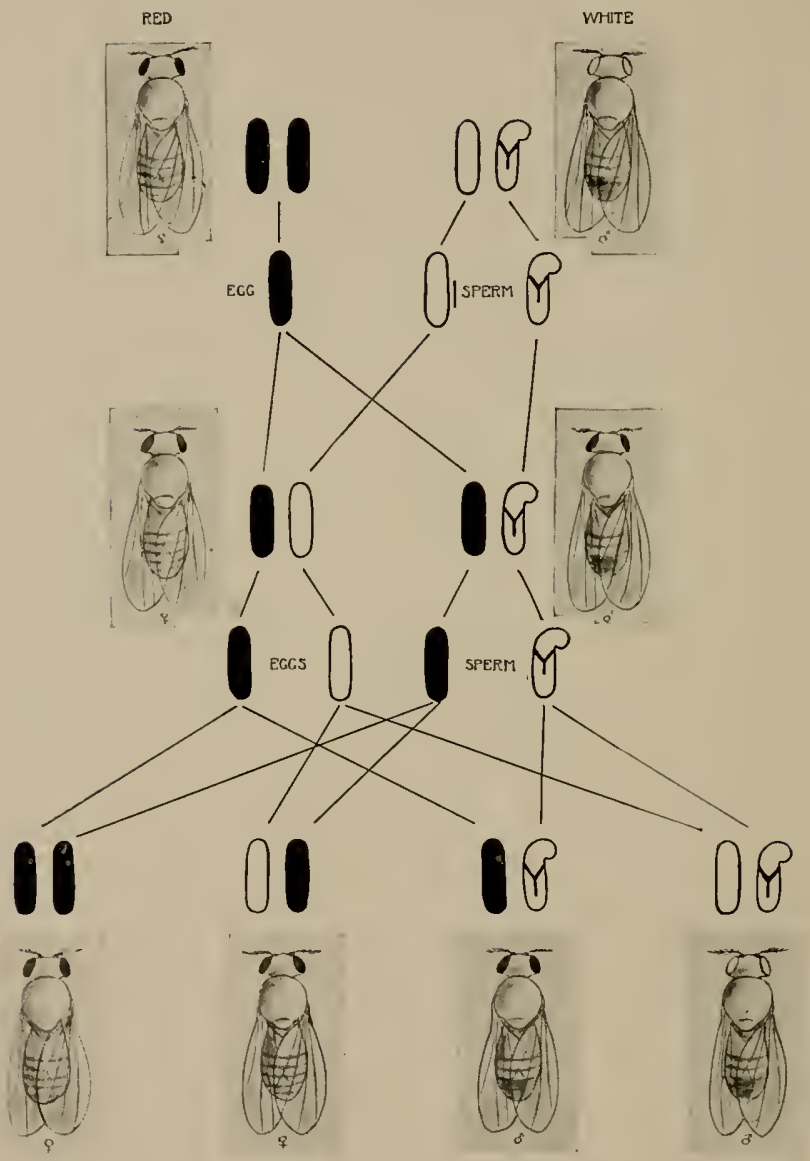

Fig. 58. Cross between white eyed male of D. ampelophila and red eyed female. The sex chromosomes are indicated by the rods. A black rod indicates that the chromosome carries the factor for red; the open chromosome the factor for white eye color. 
there will be two classes of sperm-the femaleproducing, carrying the (open) $\boldsymbol{X}$, and the male-producing, carrying the $\mathbf{Y}$ chromosome. Any egg fertilized by an $\mathbf{X}$ bearing sperm will produce a female that will have red eyes because the $\mathbf{X}$ (black) chromosome it gets from the mother carries the dominant factor for red. Any egg fertilized by a Y-bearing sperm will produce a male that will also have red eyes because he gets his (black) $\mathbf{X}$ chromosome from his mother.

When, then, these two $F_{1}$ flies (second row) are inbred the following combinations are expected. Each egg will contain a black $\mathbf{X}$ (red eye producing) or a white $\mathbf{X}$ (white eye producing) after the polar bodies have been extruded. The male will produce two kinds of sperms, of which the female producing will contain a black $\mathbf{X}$ (red eye producing). Since any egg may by chance be fertilized by any sperm there will result the four classes of individuals shown on the bottom row of the diagram. All the females will have red eyes. because irrespective of the two kinds of eggs involved all the female-producing sperm carry 


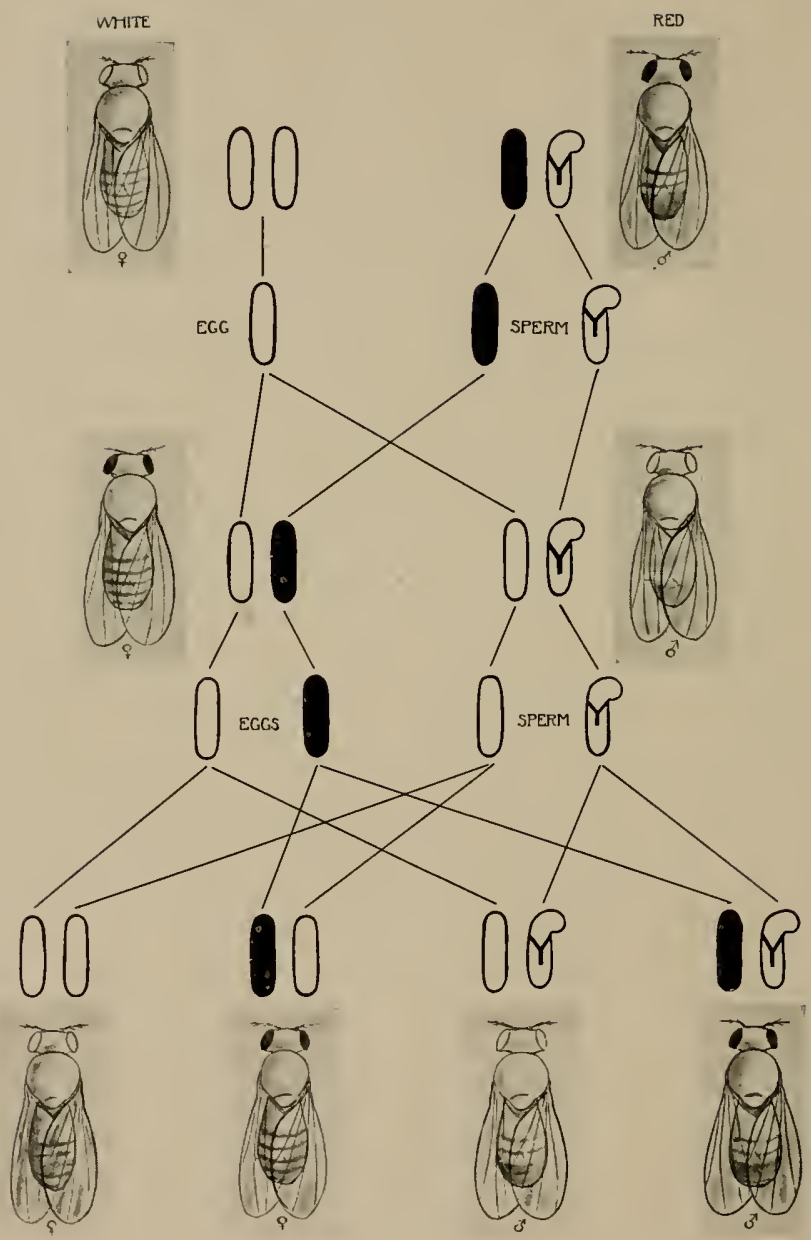

Fig. 59. Cross between red eyed male and white eyed female; reciprocal cross of Fig. 58. 
a black $\mathbf{X}$. Half of the males have red eyes because half of the egg's have had each a redproducing $\mathbf{X}$ chromosome. 'The other half of the males have white eyes, because the other half of the eggs had each a white-producing $\mathbf{X}$ chromosome. Other evidence has shown that the $\mathbf{Y}$ chromosome of the male is indifferent, so far as these Mendelian factors are concerned.

'The reciprocal experiment is illustrated in figure 59. A white eyed female is mated to a red eyed male (top row). All the mature eggs of such a female contain one white-producing I chromosome represented by the open bar in the diagram. The red eyed male contains female-producing $\mathbf{X}$-bearing sperm that carry the factor for red eye color, and male-producing $\mathbf{Y}$ chromosomes. Any egg fertilized by an $\mathbf{X}$-bearing sperm will become a red eyed female because the $\mathbf{X}$ chromosome that comes from the father carries the dominant factor for red eye color. Any egg fertilized by a Y-bearing sperm will become a male with white eyes because the only $\mathbf{X}$ chromosome that the male contains comes from his mother and is white producing. 
When these two $\mathrm{F}_{1}$ flies are inbred (middle row) the following combinations are expected. Half the eggs will contain each a white producing $\mathbf{X}$ chromosome and half red producing. 'The female-producing sperms will each contain a white $\mathbf{X}$ and the male-producing sperms will each contain an indifferent $Y$ chromosome. Chance meetings of egg and sperm will give the four $F_{2}$ classes (bottom row). These consist of white eyed and red eyed females and white eyed and red eyed males. 'The ratio here is $1: 1$ and not three to one $(3: 1)$ as in other Mendelian cases. But Mendel's law of segregation is not transgressed, as the preceding analysis has shown; for, the chromosomes have followed strictly the course laid down on Mendel's principle for the distribution of factor's. 'The peculiar result in this case is due to the fact that the $F_{1}$ male gets his single factor for eye color from his mother only and it is linked to or contained in a body (the $\mathbf{X}$ chromosome) that is involved in producing the females, while the mate of this body - the $\mathbf{Y}$ chromosome-is indifferent with regard to these factors, yet active as a mate to $\mathbf{X}$ in symapsis. 
In man there are several characters that show exactly this same kind of inheritance. Color blindness, or at least certain kinds of color blindness, appear to follow the same scheme. A color blind father transmits through his daughters his peculiarity to half of his grandsons, but to none of his grand-daughters (fig. 38 A).

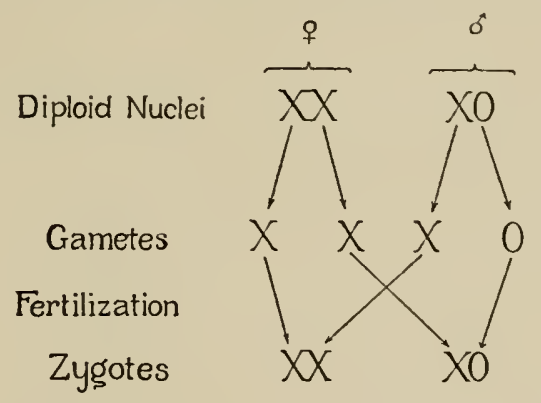

Fig. 60. Diagram of sex determination in trpe with $\mathrm{XX}$ female and xO male (after Wilson).

The result is the same as in the case of the white eyed male of Drosophila. Color blind women are rather unusual, which is expected from the method of inheritance of this character, but in the few known cases where such color blind women have married normal husbands the sons have inherited the peculiarity from the mother (fig. 38B). Here again the result is the same as for the similar combination in Drosophila. 
In man the sex formula appears to be $\mathbf{X X}$ for the female and $\mathrm{XO}$ for the male (fig. 60), and since the relation is essentially the same as that in Drosophila the chromosome explanation

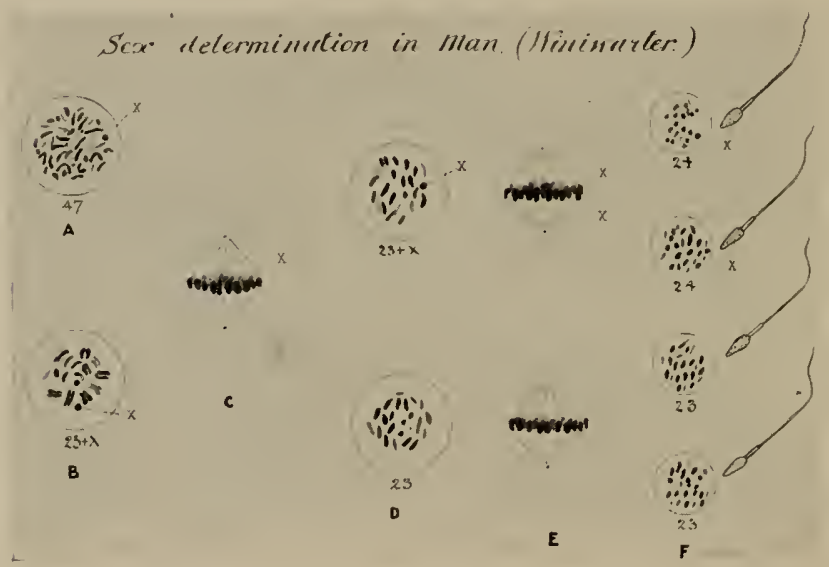

Fig. 61. Spermatogenesis in man. There are 47 chromosomes (diploid) in the male. After reduction half of the sperm carry 24 chromosomes (one of which is $\mathrm{X}$ ) and half carry 23 chromosomes (no X).

is the same. According to ron Winiwarter there are 48 chromosomes in the female and 47 in the male (fig. 61). After the extrusion of the polar bodies there are $\mathbf{2} 4$ chromosomes in the egg. In the male at one of the two maturation 
divisions the $\mathbf{X}$ chromosome passes to one pole undivided (fig. 61, C). In consequence there are two classes of sperms in man; female producing containing 24 chromosomes, and male producing containing $\mathbf{2 3}$ chromosomes. If the factor for color blindness is carried by the $\mathbf{X}$ chromosome its inheritance in man works out on the same chromosome scheme and in the same way as does white eye color (or any other sex linked character) in the fly, for the $O$ sperm in man is equivalent to the $Y$ sperm in the fly.

In these cases we have been dealing with a single pair of characters. Let us now take a case where two pairs of sex linked characters enter the cross at the same time, and preferably a case where the two recessives enter the cross from the same parent.

If a female with white eyes and yellow wings is crossed to a wild male with red eyes and gray wings (fig. 62 ), the sons are yellow and have white eyes and the daughters are gray and have red eyes. If two $F_{1}$ flies are mated they will produce the following classes. 


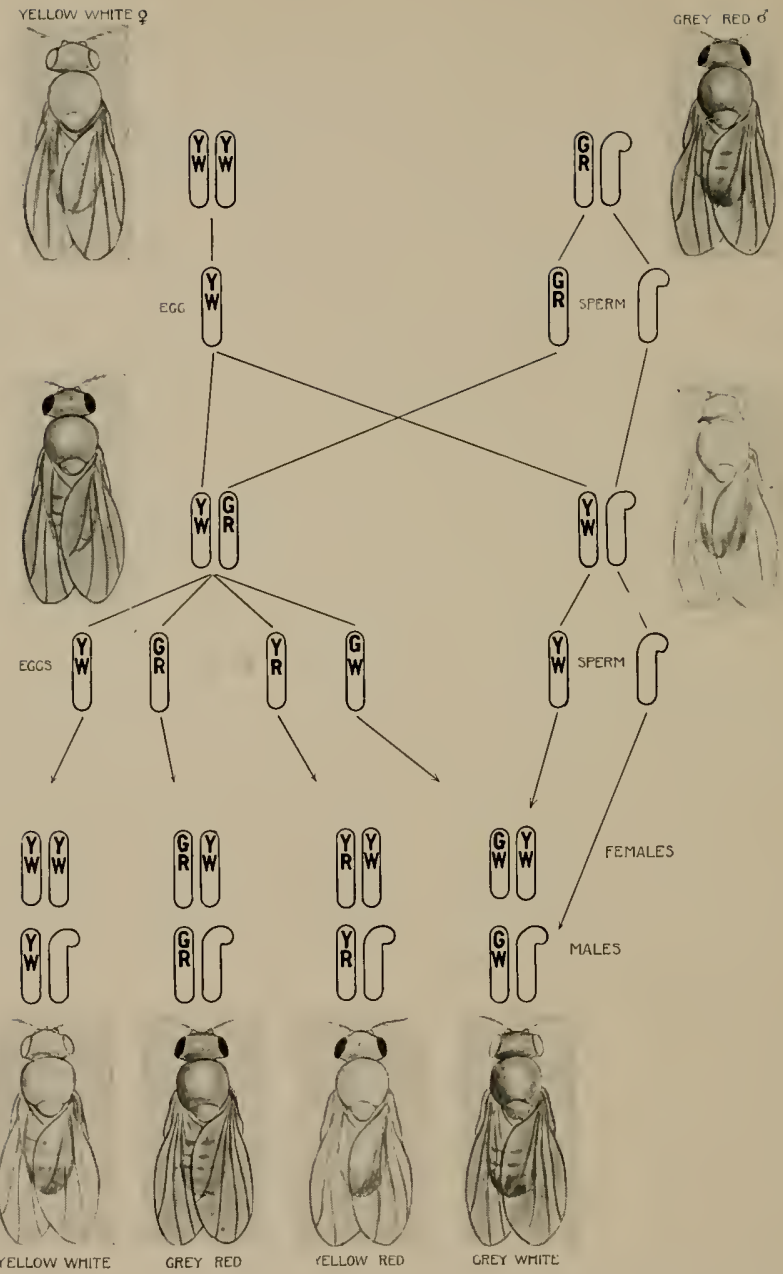

Fig. 62. Cross between a white eyed, yellow winged female of D. ampelophila and a red eyed, gray winged male. Two pairs of sex linked characters, viz., white-red and yellow-gray are involved. (See text.) 


\begin{tabular}{|c|c|c|c|}
\hline Yellow & Gray & Yellow & Gray \\
\hline W'hite & Red & Red & White \\
\hline & & & \\
\hline
\end{tabular}

Not only have the two grandparental combinations reappeared, but in addition two new combinations, viz., grey white and yellow red. 'The two original combinations far exceed in numbers the new or exchange combinations. If we follow the history of the $\mathbf{X}$ chromosomes we discover that the larger classes of grandchildren appear in accord with the way in which the $\mathbf{X}$ chromosomes are transmitted from one generation to the next.

'The smaller classes of grandchildren, the exchange combinations or cross-overs, as we call them, can be explained by the assumption that at some stage in their history an interchange of parts has taken place between the chromosomes. 'This is indicated in the diagrams.

The most important fact brought out by the experiment is that the factors that went in together tend to stick together. It makes no difference in what combination the members of 
the two pairs of characters enter, they tend to remain in that combination.

If one admits that the sex chromosomes carry these factors for the sex-linked charactersand the evidence is certainly very strong in favor of this view-it follows necessarily from these facts that at some time in their history there has been an interchange between the two sex chromosomes in the female.

'There are several stages in the conjugation of the chromosomes at which such an interchange between the members of a pair night occur. 'There is further a small amount of direct evidence, unfortunately very meagre at present, showing that an interchange does actually occur.

At the ripening period of the germ cell the members of each pair of chromosomes come together (fig. 49, e). In several forms they have been described as meeting at one end and then progressively coming to lie side by side as shown in fig. 63, e, f, g, h, i. At the end of the process they appear to have completely united along their length (fig. $63, \mathrm{j}, \mathrm{k}, \mathrm{l}$ ). It is always a maternal and a paternal chromo- 

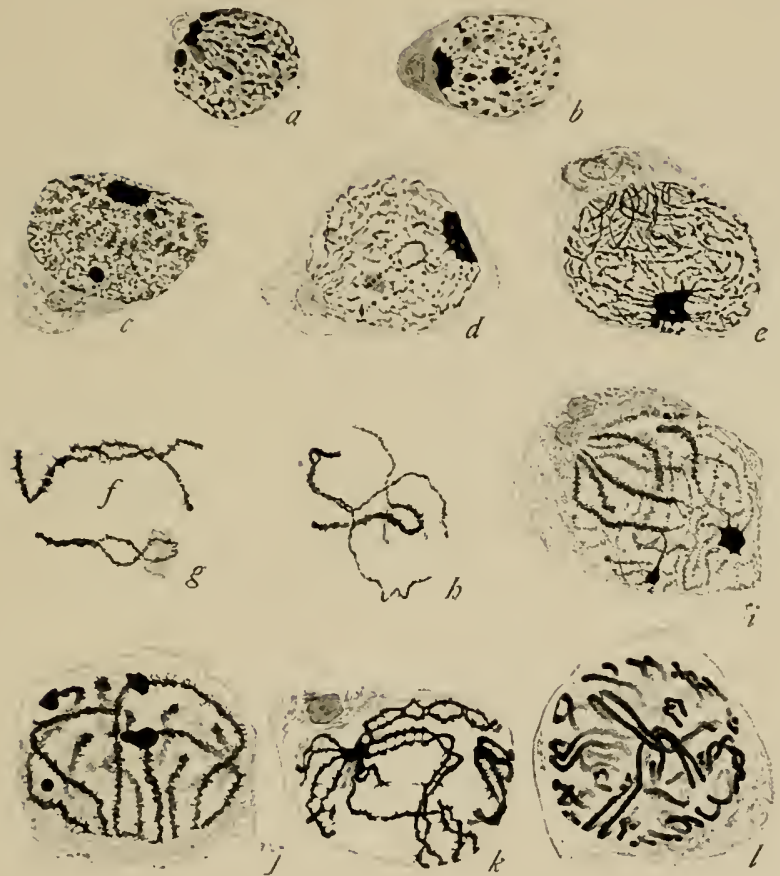

Fig. 63. Conjugation of chromosomes (side to side union) in the spermatogenesis of Batracoseps. (After Jansseis.)

some that meet in this way and always two of the same kind. It has been observed that as the nembers of a pair come together they occasionally twist aromd each other (fig. 63. g, 1 , and 64 , and 6.5$)$. In consequence a part of one 
chromosome comes to be now on one side and now on the other side of its mate.

When the chromosomes separate at the next division of the germ cell the part on one side passes to one pole, the part on the other to the
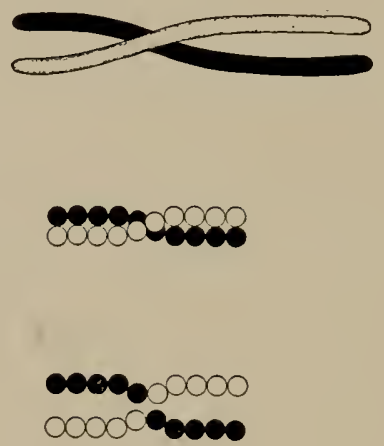

Fig. 64. Scheme to illustrate a method of crossing over of the chromosomes.

opposite pole, (figs. 64 and 65). Whenever the chromosomes do not untwist at this time there must result an interchange of pieces where they were crossed over each other.

Janssens has found at the time of separation 
evidence in faror of the riew that some such interchange probably takes place.

We find this same process of interchange of characters taking place in each of the other
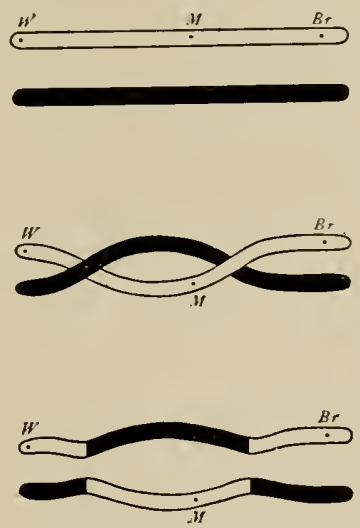

İI. 65. Scheme to illustrate double crosing over.

three groups of Drosophila. An example will show this for the Group II.

If a black restigial male is crossed to a gray long-winged female (fig. 66) the offspring are gray long. If an $\mathbf{F}_{1}$ female is back-crossed to a black restigial male the following kinds of flies are produced: 


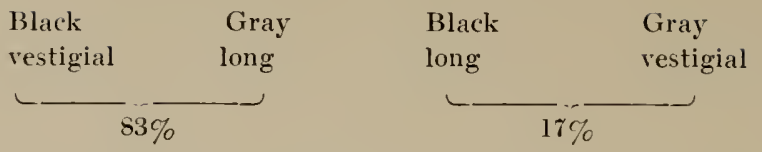

'The combinations that entered are more common in the $\mathbf{F}_{2}$ generations than the cross-over classes, showing that there is linkage of the factors that entered together.

Another curious fact is brought out if instead of back-crossing the $\mathbf{F}_{1}$ female we backcross the $\mathbf{F}_{1}$ male to a black vestigial female. Their offspring are now of only two kinds, black restigial and gray long. This means that in the male there is no crossing-over or interchange of pieces. This relation holds not only for the Group II but for all the other groups as well.

Why interchange takes place in the female of Drosophila and not in the male we do not know at present. We might surmise that when in the male the members of a pair come together they do not twist around each other, hence no crossing-over results.

Crossing-over took place between white and yellow only once in a hundred times. Other characters show different values, but the same 


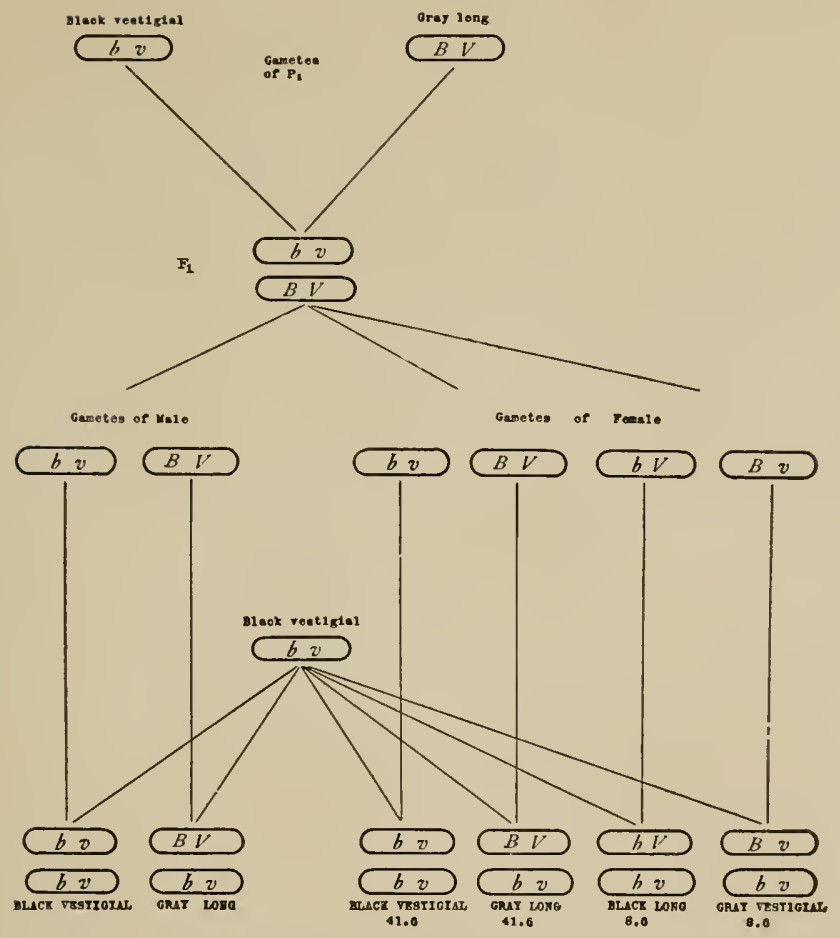

Fis. 66. Cross between hlack restigial and gray long flies. Two pairs of factors involred in the second group. The $\mathrm{l}_{1} \mathrm{fe}-$ male is back crossed (to right) to black vestigial male; and the $F_{1}$ male is back crossed to black vestigial lemale (to left). Crossing over takes place in the $F_{1}$ female but not in the $F_{\text {, male. }}$

value under the same conditions is obtained from the same pair of characters. 


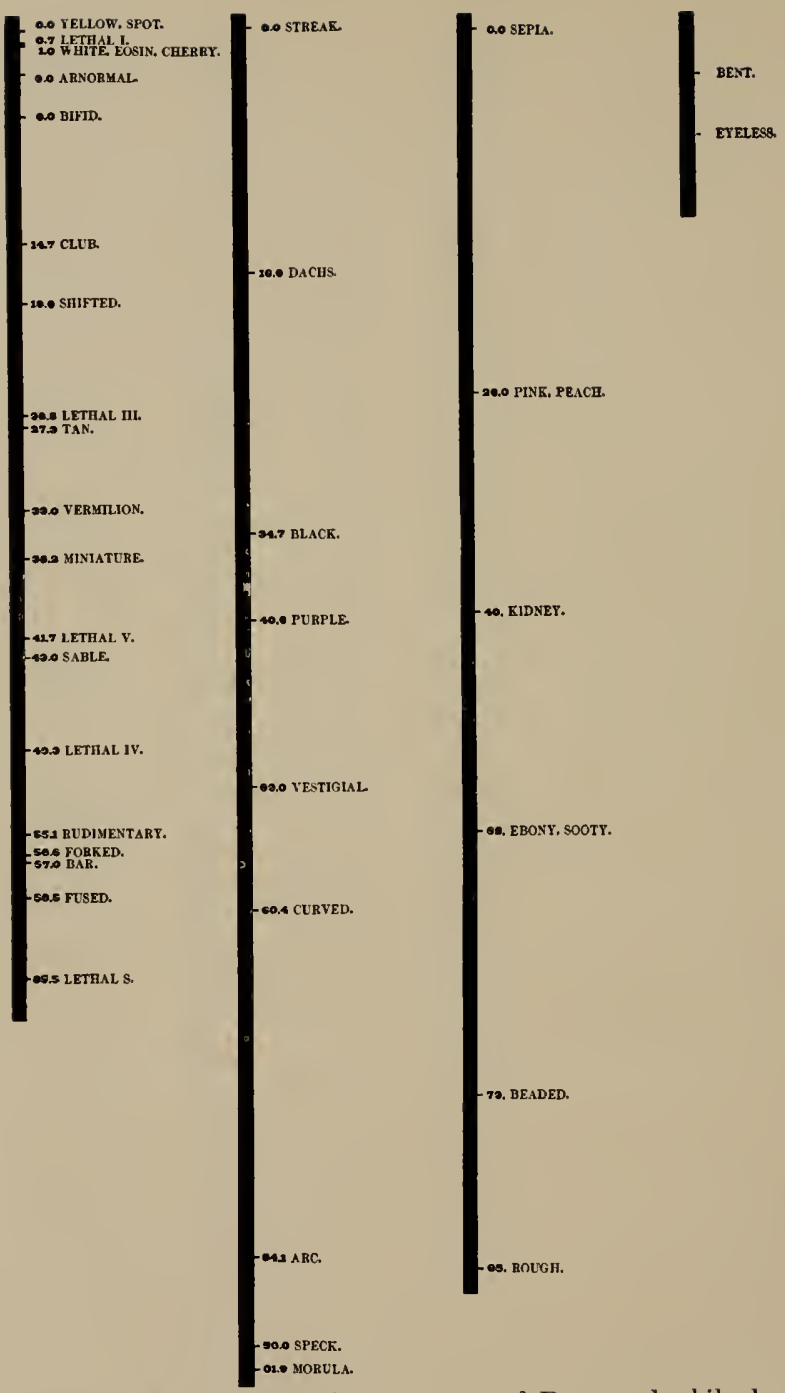

Fig. 67. Map of four chromosomes of D. ampelophila locating those factors in each group that have been most fully studied. 
If we assume that the nearer together the factors lie in the chromosome the less likely is a twist to occur between them, and conversely the farther apart they lie the more likely is a twist to occur between them, we can understand how the linkage is different for different pairs of factors.

On this basis we have made out chromosomal maps for each chromosome (fig. 6r). The diagram indicates those loci that have been most accurately placed.

\section{The Evidence from Interference}

There is a considerable body of information that we have obtained that corroborates the location of the factors in the chromosome. 'This evidence is too technical to take up in any detail, but there is one result that is so important that I must attempt to explain it. If, as I assume, crossing over is brought about by twisting of the chromosomes, and if owing to the material of the chromosomes there is a most frequent distance of internode, then, when crossing over between nodes takes place at same level at $a-b$ in figure 68 , the region on 
each side of that point, a to $\mathrm{A}$ and $\mathrm{b}$ to $\mathrm{B}$, should be protected, so to speak, from further crossing over. 'This in fact we have found to be the case. No other explanation so far proposed will account for this extraordinary relation.

What advantage, may be asked, is there in obtaining numerical data of this kind?

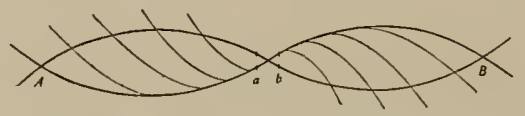

Fig. 68. Scheme to indicate that when the members of a pair of chromosomes cross (at a-b) the region on each side is protected inversely to the distance from a-b.

It is this:-whenerer a new character appears we need only determine in which of the four groups it lies and its distance from two members within that group. With this information we can predict with a high degree of probability what results it will give with any other member of any group. Thus we can do on paper what would require many months of labor by making the actual experiment. In a word we can predict what will happen in a situation where prediction is impossible without this numerical information. 


\section{The Eridence from Non-Disjunction}

In the course of the work on Drosophila exceptions appeared in one strain where certain individuals did not conform to the scheme of sex linked inheritance. For a moment the hypothesis seemed to fail, but a careful examination led to the suspicion that in this strain something had happened to the sex chromosomes. It was seen that if in some way the $\mathbf{X}$ chromosomes failed to disjoin in certain eggs, the exceptions could be explained. 'The analysis led to the suggestion that if the $\mathrm{Y}$ chromosome had got into the female line the results would be accounted for, since its presence there would be expected to cause this peculiar nondisjunction of the $\mathbf{X}$ chromosomes.

That this was the explanation was shown when the material was examined. The females that gave these results were found by Bridges to have two $\mathrm{X}$ 's and a $\mathrm{Y}$ chromosome.

The normal chromosome group of the female is shown in figure 52 and the chromosome group of one of the exceptional females is shown in figure 69. In a female of this kind 
there are three sex chromosomes $\mathrm{X} X \mathrm{Y}$ which are homologous in the sense that in normal individuals the two present are mates and separate at the reduction division. If in the $\mathrm{X}$ X $\mathrm{Y}$ individual $\mathrm{X}$ and $\mathrm{X}$ conjugate and separate at reduction and the unmated $\mathrm{Y}$ is free to move to either pole of the spindle, two kinds of mature eggs will result, viz., $\mathrm{X}$ and $\mathrm{XY}$. If, on the other hand, $\mathrm{X}$ and $\mathrm{Y}$ conjugate and

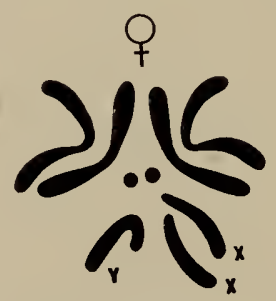

Fic. 69. Figure of the chromosome group of an XXY female, that gives non-disjunction.

separate at reduction and the remaining $\mathbf{X}$ is free to go to either pole, four kinds of eggs will result-XY-X-XX-Y. As a total result four kinds of eggs are expected: viz. many XY and X eggs and a few XX and Y eggs.

'These four kinds of eggs may be fertilized either by female-producing sperms or male- 
producing sperms, as indicated in the diagram (fig. 70).

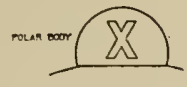

tax 597
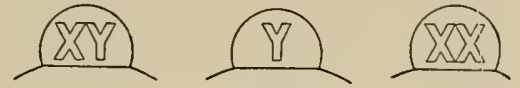

Y
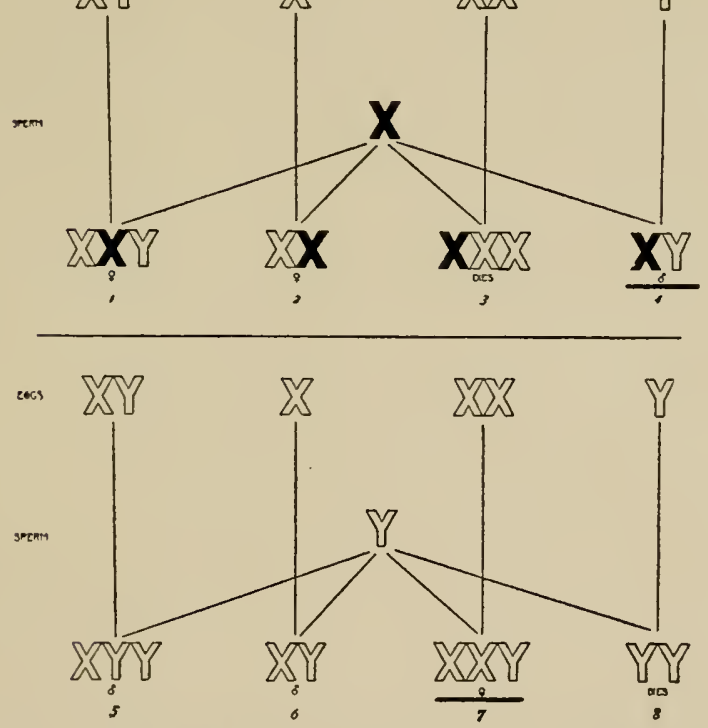

FIg. 70 . Scheme showing the results of fertilizing white lhearing eggs ( $t$ kinds) resulting from non-disjunction. The upper half of the diagram gives the results when these eggs are fertilized by normal red bearing, female producing sperm, the lower half by normal, male producing sperm.

If such an XXY female carried white bearing $\mathrm{X}$ s (open $\mathrm{X}$ in the figures), and the male 
carried a red bearing $\mathbf{X}$ (black $\mathbf{X}$ in the figures) it will be seen that there should result an exceptional class of sons that are red, and an exceptional class of daughters that are white. Tests of these exceptions show that they behave subsequently in heredity as their composition requires. Other tests may also be made of the other classes of offspring. Bridges has shown that they fulfill all the requirements predicted. Thus a result that seemed in contradiction with the chromosome hypothesis has turned out to give a brilliant confirmation of that theory both genetically and cytologically.

How Many Genetic Factors are there in the Germ-plasm of a Single Individual

In passing I invite your attention to a speculation based on our maps of the chromosomes-a speculation which I must insist does not pretend to be more than a guess but has at least the interest of being the first guess that we have ever been in position to make as to how many factors go towards the makeup of the germ plasm. 
We have found practically no factors less than .04 of a unit apart. If our map includes the entire length of the chromosomes and if we assume factors are uniformly distributed along the chromosome at distances equal to the shortest distance yet observed, viz. .04, then we can calculate roughly how many hereditary factors there are in Drosophila. 'The calculation gives about 7500 factors. 'The reader should be cautioned against accepting the above assumptions as strictly true, for crossingover values are known to differ according to different envirommental conditions (as shown by Bridges for age), and to differ eren in different parts of the chromosome as a result of the presence of specific genetic factors (as shown by Sturterant). Since all the chromosomes except the $\mathbf{X}$ chromosomes are double we must double our estimate to give the total number of factors, but the half number is the number of the different kinds of factors of Drosophila. 


\section{Conclusions}

I have passed in review a long series of researches as to the nature of the hereditary material. We have in consequence of this work arrived within sight of a result that seemed a few years ago far beyond our reach. 'The mechanism of heredity has, I think, been discovered-discovered not by a flash of intuition but as the result of patient and careful study of the evidence itself.

With the discovery of this mechanism I venture the opinion that the problem of heredity has been solved. We know how the factors carried by the parents are sorted out to the germ cells. The explanation does not pretend to state how factors arise or how they influence the development of the embryo. But these have never been an integral part of the doctrine of heredity. The problems which they present must be worked out in their own field. So, I repeat, the mechanism of the chromosomes offers a satisfactory solution of the traditional problem of heredity. 


\section{CHAP'TER IV}

\section{SELECTION AND EVOLUTION}

Darwin's 'Theory of Natural Selection still holds todar first place in every discussion of erolution, and for this very reason the theory calls for careful scrutiny; for it is not difficult. to show that the expression "natural selection" is to many men a metaphor that carries many meanings, and sometimes different meanings to different men. While I heartily agree with my fellow biologists in ascribing to Darwin himself, and to his work, the first place in biological philosophy, yet recognition of this claim should not deter us from a careful analysis of the situation in the light of work that has been done since Darwin's time.

\section{'The Theory of Natural Selection}

In his great book on the Origin of Species, Darwin tried to do two things: first. to show that the evidence bearing on evolution makes 
that explanation probable. No such great body of evidence had ever been brought together before, and it wrought, as we all know, a revolution in our modes of thinking.

Darwin also set himself the task of showing how evolution might have taken place. He pointed to the influence of the environment, to the effects of use and disuse, and to natural selection. It is to the last theory that his name is especially attached. He appealed to a fact familiar to everyone, that no two individuals are identical and that some of the differences that they show are inherited. He argued that those individuals that are best suited to their environment are the most probable ones to survive and to leave most offspring. In consequence their descendants should in time replace through competition the less well-adapted individuals of the species. 'This is the process Darwin called natural selection, and Spencer the survival of the fittest.

Stated in these general terms there is nothing in the theory to which anyone is likely to take exception. But let us examine the argument more critically. 
If we measure, or weigh, or classify any character shown by the individuals of a population, we find differences. We recognize that some of the differences are due to the varied experiences that the individuals have encoun-

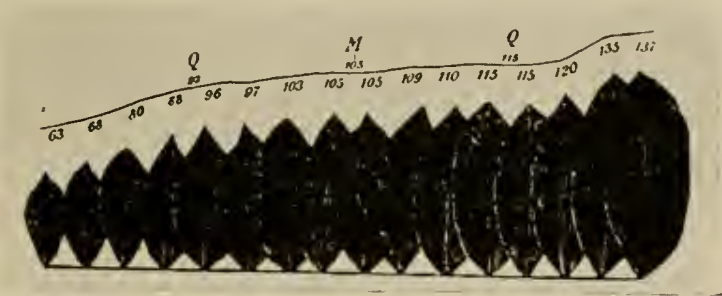

FIG, $i 1$. Series of leaves of a tree arranged according to size. (After de Vries.)

tered in the course of their lives, i.e. to their environment, but we also recognize that some of the differences may be due to individuals having different inheritances-different germ plasms. Some familiar examples will help to bring home this relation.

If the leares of a tree are arranged according to size (fig. 71), we find a continuous series, but there are more leares of medium size than extremes. If a lot of beans be sorted out 
according to their weights, and those between certain weights put into cylinders, the cylinders, when arranged according to the size of the beans, will appear as shown in figure 72. An imaginary line running over the tops of the

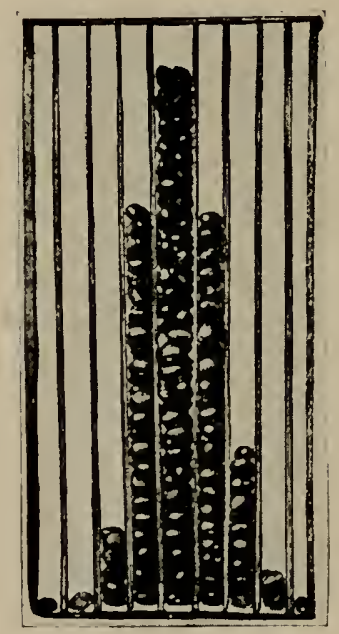

Fig. 79. Beans put into cylindrical jars according to the sizes of the beans. The jars arranged according to size of contained beans. (After de Vries.)

piles will give a curve (fig. 73) that corresponds to the curve of probability (fig. 74).

If we stand men in lines according to their height (fig. 75) we get a similar arrangement. 


\section{THEORY OF ETOLUTIGN}

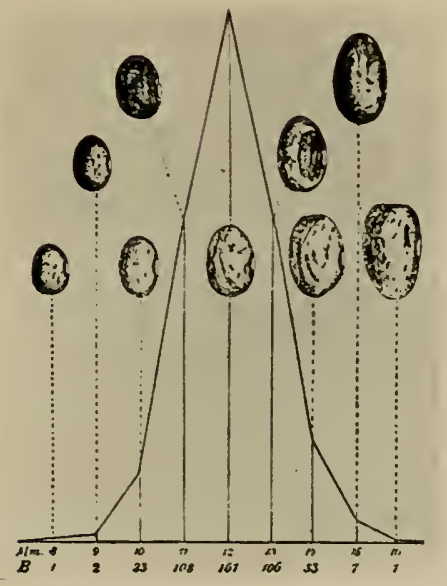

Fig. 73. A curre resulting from arrangement of beans according to size. (After de Vries.)

'The differences in size shown by the individual beans or by the individual men are due in part to heredity, in part to the environment

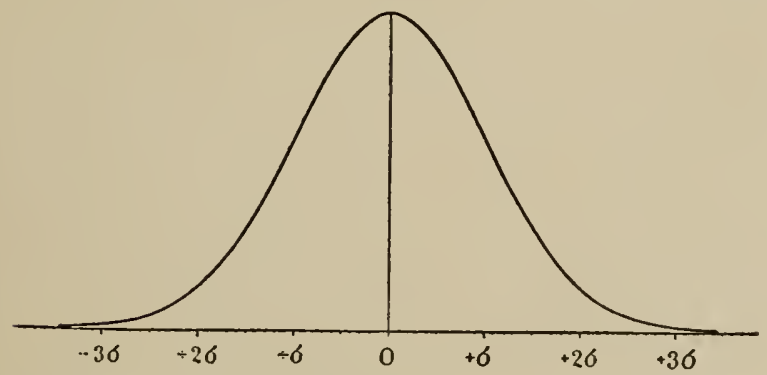

Fig. 74 . Curre of probability. 
in which they have dereloped. 'This is a familiar fact of almost every-day observation. It is well shown in the following example. In figure 76 the two boys and the two varieties of

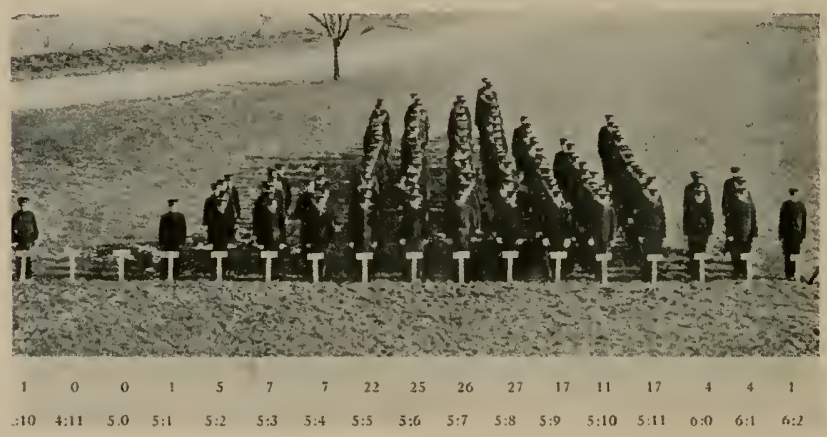

Fig. 75. Students arranged according to size. (After Blakeslee.)

corn, which they are holding, differ in height. 'The pedigrees of the boys (fig. 77) make it probable that their height is largely inherited and the two races of corn are known to belong to a tall and a short race respectively. Here, then, the chief effect or difference is due to heredity. On the other hand, if individuals of the same race develop in a favorable environment the result is different from the derelop- 
ment in an unfavorable enviromment, as shown in figure 78 . Here to the right the com is

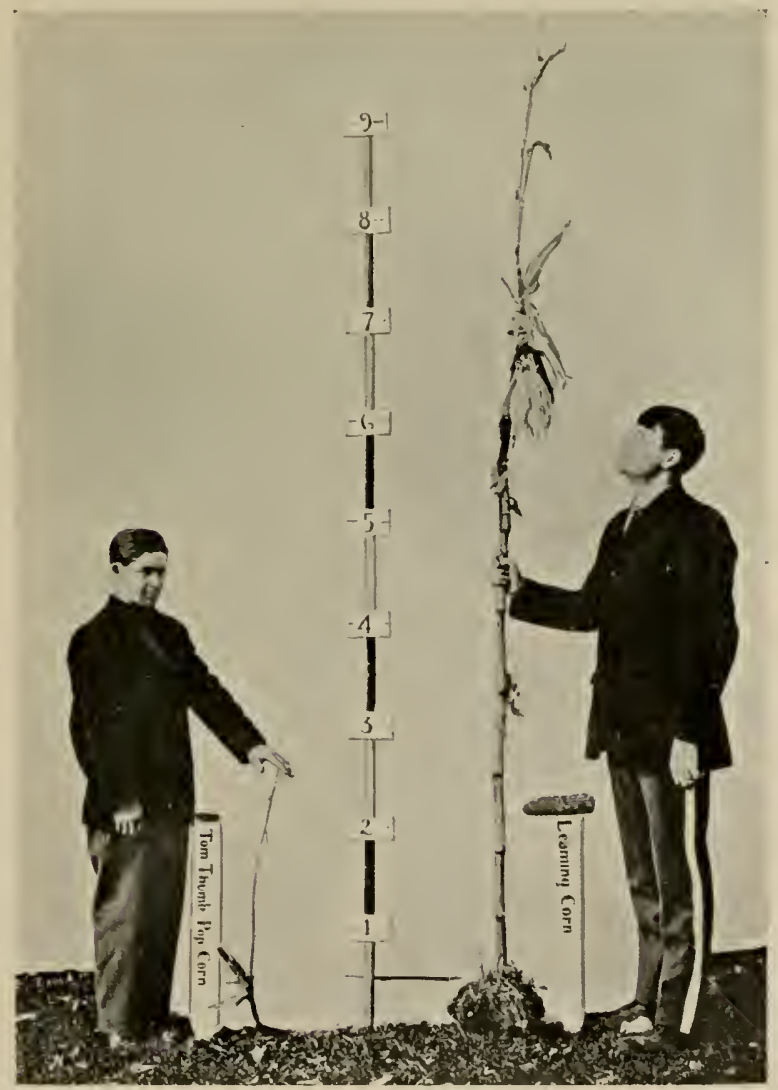

Fig. 76. $\Lambda$ short and a tall boy each holding a stalk of cornone stalk of a race or short corn, the other of tall corn. ( $\triangle \mathrm{fter}$ Blakeslee.) 
crowded and in consequence dwarfed, while to the left the same kind of corn has had more room to develop and is taller.

Darwin knew that if selection of particular kinds of individuals of a population takes place the next generation is affected. If the taller men of a community are selected the average of their offspring will be taller than the average of
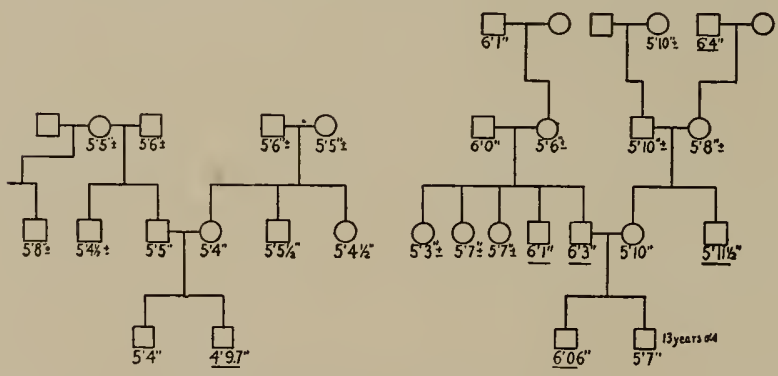

Fig. 77. Pedigree of boys shown in Fig. 76. (After Blakeslee.)

the former population. If selection for tallness again takes place, still taller men will on the average arise. If, amongst these, selection again makes a choice the process would, he thought, continue (fig. 79).

We now recognize that this statement contains an important truth, but we have found that 


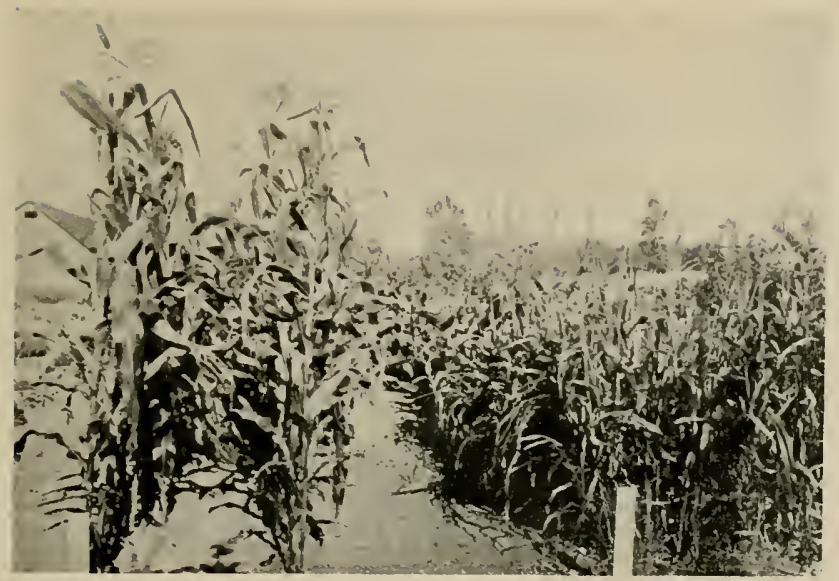

Fig. 7S. A race of corn reared under different conditions.

it contains only a part of the truth. Any one who repeats for himself this kind of selection experiment will find that while his average class will often change in the direction of his selection, the process slows down as a rule rather suddenly (fig. 80). He finds, moreorer, that the limits of variability are not necesarily transcended as the process continues even although the average may for a while be increased. More tall men may be produced by selection of this kind, but the tallest men are not necessarily any taller than the tallest in the original population. 
Selection, then, has not produced anything new, but only more of certain kinds of indi-

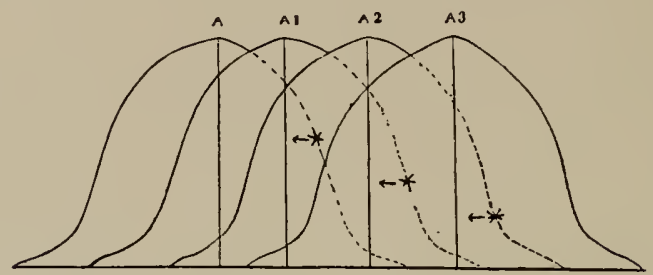

Fig. 79. Curves showing how (hypothetically) selection might be supposed to bring about progress in direction of selection. (After Goldschmidt.)

viduals. Evolution, however, means producing more new things, not more of what already exists.

Darwin seems to have thought that the range of variation shown by the offspring of a given individual about that type of individual would be as wide as the range shown by the original population (fig. 79), but Gralton's work has made it clear that this is not the case in a general or mixed population. If the offspring of individuals continued to show, as Darwin seems to have thought, as wide a range on each side of their parents' size, so to speak, as did the original population, then it would follow that se- 
lection could slide successive generations along in the direction of selection.

Darwin himself was extraordinarily careful, however, in the statements he made in this connection and it is rather by implication than by actual reference that one can ascribe this mean-

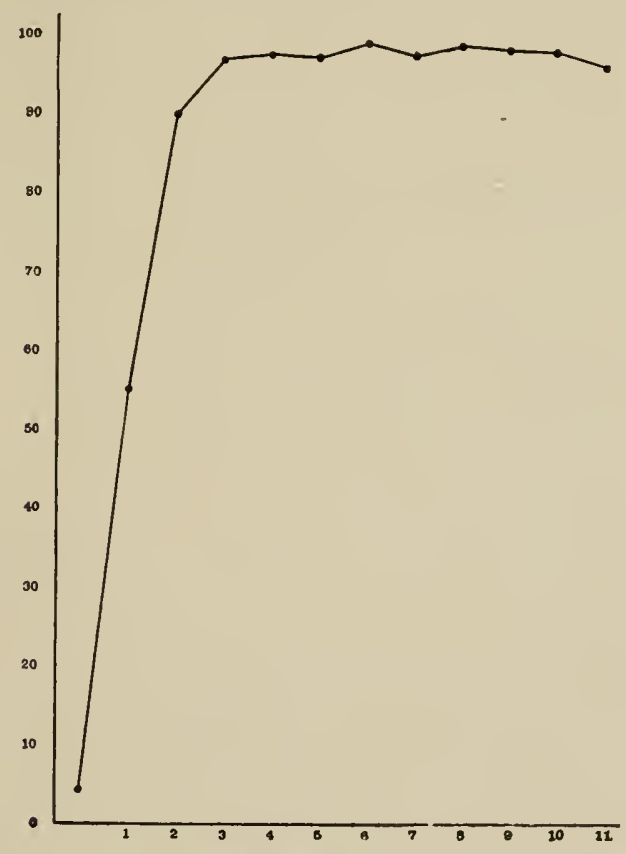

Fig. S0. Diagram illustrating the results of selection for extra bristles in D. ampelophila. Selection at first produces decided effects which soon slow down and then cease. (MacDowell.) 
ing to his views. His contemporaries and many of his followers, however, appear to have accepted this sliding scale interpretation as the cardinal doctrine of evolution. If this is doubted or my statement is challenged then one must explain why de Vries' mutation theory met with so little enthusiasm amongst the older group of zoölogists and botanists; and one must explain why Johannsen's splendid work met with such bitter opposition from the English school-the biometricians-who amongst the post-Darwinian school are assumed to be the lineal descendants of Darwin.

And in this connection we should not forget that just this sort of process was supposed to take place in the inheritance of use and disuse. What is gained in one generation forms the basis for further gains in the next generation. Now, Darwin not only believed that acquired characters are inherited but turned more and more to this explanation in his later writings. Let us, however, not make too much of the matter; for it is much less important to find out whether Darwin's ideas were rague, than it is to make sure that our own ideas are clear. 
If I have made sereral statements here that appear dogmatic let me now attempt to justify them, or at least give the evidence which seems to me to make them probable.

'The work of the Danish botanist, Johammsen, has given us the most carefully analyzed case of selection that has ever been obtained. There are, moreover, special reasons why the material that he used is better suited to give definite information than any other so far studied. Johannsen worked with the common bean, weighing the seeds or else measuring them. These beans if taken from many plants at random give the typical curve of probability (fig. 74). The plant multiplies by self-fertilization. Taking advantage of this fact Johannsen kept the seeds of each plant separate from the others, and raised from them a new generation. When curves were made from these new groups it was found that some of them had different modes from that of the original general population (fig. 81 A-E, bottom group). 'They are shown in the upper groups $(\mathrm{A}, \mathrm{B}, \mathrm{C}, \mathrm{D}$, E). But do not understand me to say that the offspring of each bean gave a different mode. 

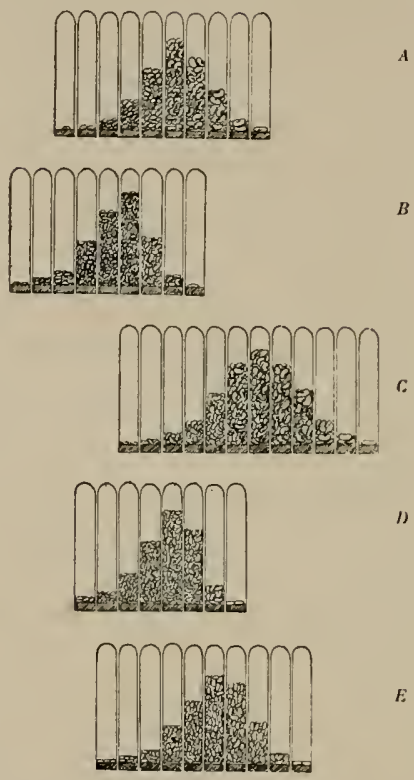

E

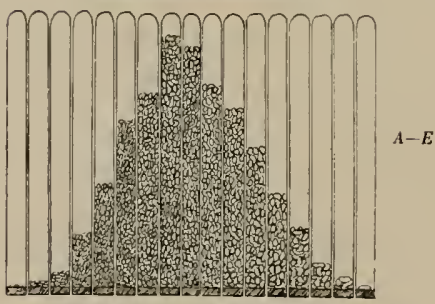

I

Fig. 81. Pure lines of beans. The lower figure gives the general population, the other figures gire the pure lines within the population. (After Johannsen.) 
On the contrary, sone of the lines would be the same.

'The result means that the general population is made up of definite kinds of individuals that may have been sorted out.

'That his conclusion is correct is shown by rearing a new generation from any plant or indeed from several plants of any one of these lines. Each line repeats the same modal class. There is no further breaking up into groups. Within the line it does not matter at all whether one chooses a big bean or a little one-they will give the same result. In a word, the germ plasm in each of these lines is pure, or homozygous, as we say. 'The differences that we find between the weights (or sizes) of the individual beans are due to external conditions to which they have been subjected.

In a word, Johannsen's work shows that the frequency distribution of a pure line is due to factors that are extrinsic to the germ plasm. It does not matter then which individuals in a pure line are used to breed from, for they all carry the same germ plasm.

We can now understand more clearly how 
selection acting on a general population brings about results in the direction of selection.

An individual is picked out from the population in order to get a particular kind of germ plasm. Although the different classes of individuals may overlap, so that one can not always judge an individual from its appearance, nevertheless on the whole chance favors the picking out of the kind of germ plasm sought.

In species with separate sexes there is the further difficulty that two individuals must be chosen for each mating, and superficial examination of them does not insure that they belong to the same group-their germ plasm cannot be inspected. Hence selection of biparental forms is a precarious process, now going forward, now backwards, now standing still. In time, however, the process forward is almost certain to take place if the selection is from a heterogeneous population. Johannsen's work was simplified because he started with pure lines. In fact, had he not done so his work would not have been essentially different from that of any selection experiment of a pure race of animals or plants. Whether Johannsen 
realized the importance of the condition or not is uncertain-curiously he laid no emphasis on it in the first edition of his "Elemente der exakten Erblichkeitslehre".

It has since been pointed out by Jennings and by Pearl that a race that reproduces by self-fertilization as does this bean, automatically becomes pure in all of the factors that make up its germ plasm. Since self-fertilization is the normal process in this bean the purity of the germ plasm already existed when Johamnsen began to experiment.

\section{How Has Shlection in Domesticated} Animals and Plants Brought About I'ts Results!

If then selection does not bring about transgressive variation in a general population, how can selection produce anything new? If it can not produce anything new, is there any other way in which selection becomes an agent in evolution?

We can get some light on this question if we turn to what man has done with his domesticated animals and plants. 'Through selection, 
i.e., artificial selection, man has undoubtedly brought about changes as remarkable as any shown by wild animals and plants. We know, moreover, a good deal about how these changes have been wrought.

(1) By crossing different wild species or by crossing wild with races already domesticated new combinations have been made. Parts of one individual have been combined with parts of others, creating new combinations. It is possible even that characters that are entirely new may be produced by the interaction of factors brought into recombination.

(2) New characters appear from time to time in domesticated and in wild species. 'These, like the mutants in Drosophila, are fully equipped at the start. Since they breed true and follow Mendel's laws it is possible to combine them with characters of the wild type or with those of other mutant races.

Amongst the new mutant factors there may be some whose chief effect is on the character that the breeder is already selecting. Such a modification will be likely to attract attention. Superficially it may appear that the 
factor for the original character has varied, while the truth may be that another factor has appeared that has modified a character already present. In fact, many or all Mendelian factor's that affect the same organ may be said to be modifiers of each other's effects. 'Thus the factor for vermilion causes the eye to be one color, and the factor for eosin another color, while eosin rermilion is different from both. Eosin may be said to be a modifier of rermilion or vermilion of eosin. In general, however, it is convenient to use the term "modifier" for cases in which the factor causes a detectable change in a character already present or conspicuous.

One of the most interesting, and at the same time most treacherous, kinds of modifying factors is that which produces an effect only when some other factor is present. 'Thus Bridges has shown that there is a factor called "cream" that does not affect the red color of the eyre of the wild fly, yet makes "eosin" much paler (fig. 8:2). Another factor" "whiting" which produces no effect on red makes eosin entirely white. Since cream or whiting may be 
carried by red eyred flies without their presence being seen until eosin is used, the experimenter must be continualy on the lookout for such factors which may lead to erroneous conclusions

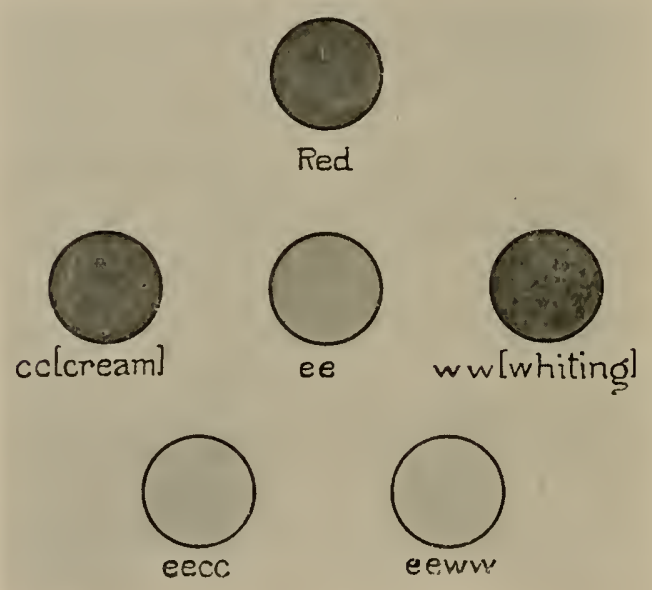

FIG. 82. Scheme to indicate influence of the modifying factors, cream and whiting. Neither produces any effect alone but they modify other eye colors such as eosin.

unless detected. As yet breeders have not realized the important rôle that modifiers have played in their results, but there are indications at least that the heaping up of modifying factors has been one of the ways in which 
highly specialized domesticated animals have been produced. Selection has accomplished this result not by changing factors, but by picking up modifying factors. 'The demonstration of the presence of these factors has already been made in some cases. 'Their study promises to be one of the most instructive fields for further work bearing on the selection hypothesis.

In addition to these well recognized methods by which artificial selection has produced new things we come now to a question that is the very crux of the selection theory today. Our whole conception of selection turns on the answer that we give to this matter and if I appear insistent and go into some detail it is because I think that the matter is worth very careful consideration.

\section{Are Factors Changed 'Through Selection?}

As we have seen, the rariation that we find from individual to individual is due in part to the environment; this can generally be demonstrated. Other differences in an or- 
dinary population are recognized as due to different genetic (hereditary) combinations. No one will dispute this statement. But is all the variability accounted for in these two ways? May not a factor itself fluctuate? Is it not a priori probable that factors do fluctuate? Why, in a word, should we regard factors as inviolate when we see that everything else in organisms is more or less in amount? I do not know of any a priori reason why a factor may not fluctuate, unless it is, as I like to think, a chemical molecule. We are, however, dealing here not with generalities but with evidence, and there are three known methods by means of which it has been shown that variability, other than environmental or recombinational, is not due to variability in a factor, nor to various "potencies" possessed by the same factors.

(1) By making the stock uniform for all of its factors-chief factors and modifiers alike. Any change in such a stock produced by selection would then be due to a change in one or more of the factors themselves. Johannsen's experiment is an example of this sort.

(2) The second method is one that is capa- 
ble of demonstrating that the effects of selection are actually due to modifiers. It has been

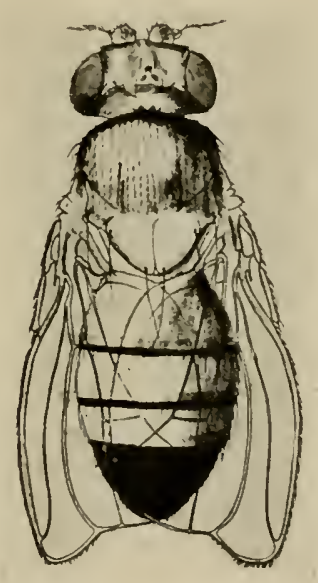

Fic. 83 a. Droosphila ampelsphila with truncate wings.

worked out in our laboratory, chiefly by Muller, and used in a particular case to demonstrate that selection produced its effect by isolating modifying factors. For example, a mutant type called truncate appeared, characterized by shorter wings, usually square at the end. (fig. 8:3a). 'The wings varied from those of normal length to wings much shorter (fig. $83 \mathrm{~b})$. For three rear's the mutant stock was 

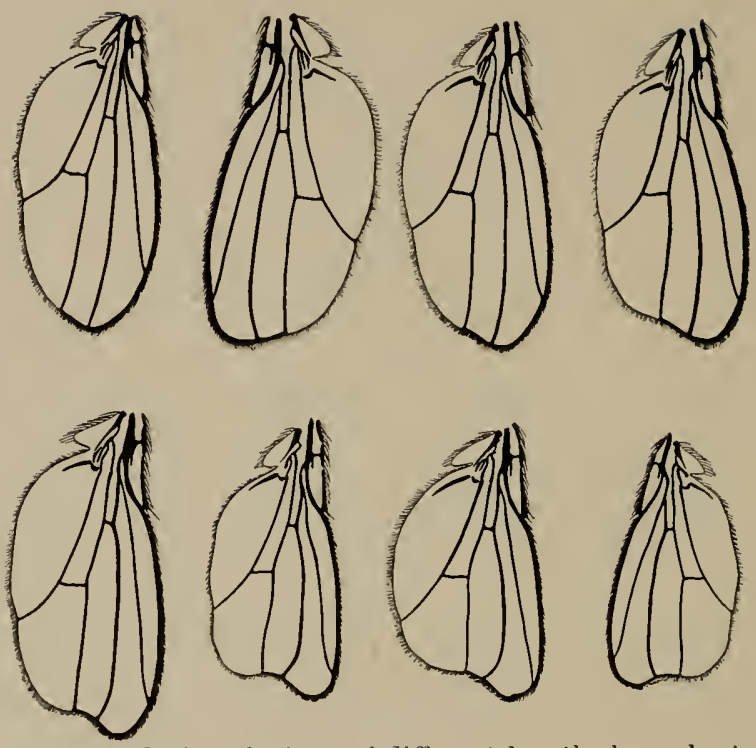

Fig. $83 \mathrm{~b}$. Series of wings of different length shown by truncate stock of D. ampelophila.

bred from individuals having the shorter wings until at last a stock was obtained in which some of the individuals had wings much shorter than the body. By means of linkage experiments it was shown that at least three factors were present that modified the wings. 'These were isolated by means of their linkage relations, and their mutual influence on the production of truncate wings was shown. 
An experiment of this kind can only be carried out in a case where the groups of linked gens are known. At present Drosophila is the only animal (or plant) sufficiently well known to make this test possible, but this does not prove that the method is of no value. On the contrary it shows that any claim that factors can themselves be changed can have no finality until the claim can be tested out by means of the linkage test. For instance, bar eye (fig. 31) arose as a mutation. All our stock has descended from a single original mutant. But Zeleny has shown that selection within our stock will make the bar eye narrower or broader according to the direction of selection. It remains to be shown in this case how selection has produced its effects, and this can be done by utilizing the same process that was used in the case of truncate.

Another mutant stock called beaded (fig. $84)$, has been bred for five rears and selected for wings showing more beading. In extreme cases the wings have been reduced to mere stumps (see stumpy, fig. .j), but the stock shows great variability. It is probable here 
as Dexter has shown, that a number of mutant factors that act as modifiers have been picked
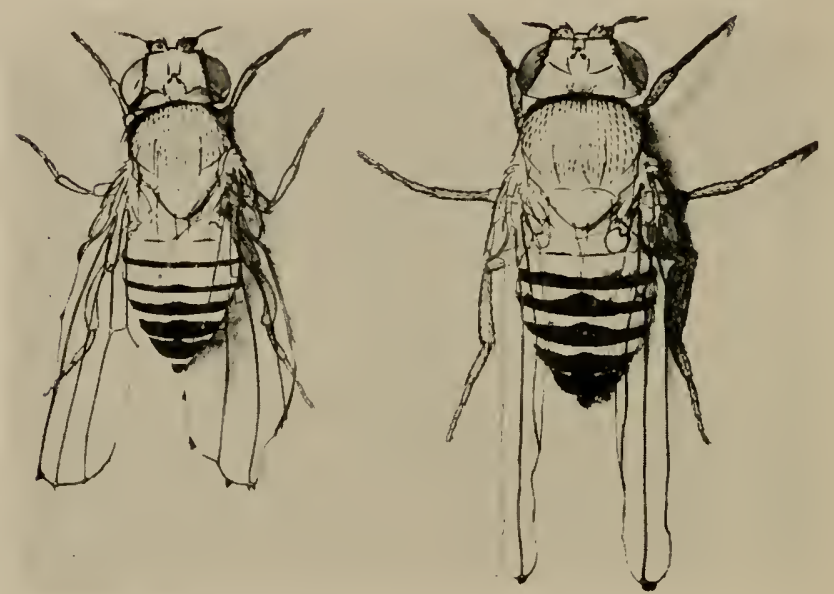

FIg. 8t. 'I'wo flies showing beaded wings.

up in the course of the selection, and when it is recalled that during those five years over 125 new characters have appeared elsewhere it does not seem improbable that factors also have appeared that modify the wings of this stock.

(3) The third method is one that has been developed principally by East for plants; also by MacDowell for rabbits and flies. The 
method does not claim to prove that modifiers are present, but it shows why certain results are in harmony with that expectation and can not be accounted for on the basis that a factor has changed. Let me give an example. When a Belgian hare with large body was crossed to a common rabbit with a small body the hybrid was intermediate in size. When the hybrid was crossed back to the smaller type it produced rabbits of rarious sizes in apparently a continuous series. MacDowell made measurements of the range of variability in the first and in the second generations.

He found that the variability was smaller in the first generation than in the second genera-

Classification in relation to parents based on skull lengths and utn t lengths, to show the relutive variability of two measurements $a n \approx$ of the first gineration $\left(F_{1}\right)$ and the tack cross (B.C.)

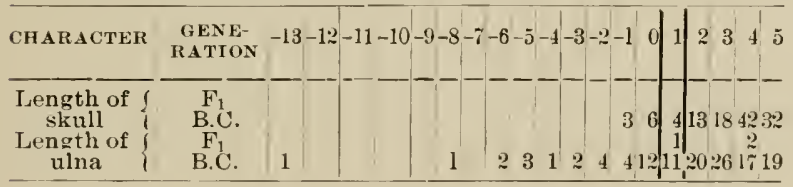

same table continued

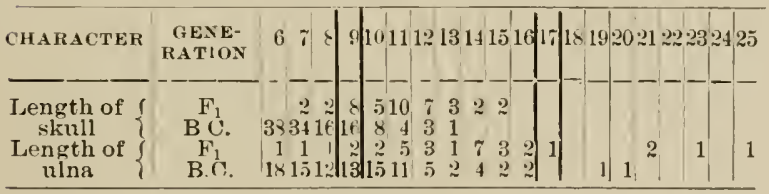


tion (back cross). This is what is expected if several factor-differences were involved, because the hybrids of the first generation are expected to be more uniform in factorial composition than are those in the second generation which are produced by recombination of the factors introduced through their grandparents. Excellent illustrations of the same kinds of results have been found in Indian corn. As shown in figure 8.5 the length of the cob in $\mathbf{F}_{1}$ is intermediate between the parent types while in $\mathbf{F}_{2}$ the range is wider and both of the original types are recovered. East states that similar relations have been found for 18 characters in corn. Emerson has recently furnished further illustrations of the same relations in the length of stalks in beans.

A similar case is shown by a cross between fantail and common pigeons (fig. 86). 'The latter have twelve feather's in the tail, while the selected race from which the fantails came had between 28 and 38 feathers in the tail. The $\mathbf{F}_{1}$ offspring (forty-one individuals) showed (fig. 87) between 12 and 20 tail feathers, while in $\mathrm{F}_{2}$ the numbers varied between $\mathbf{1 2}$ and 

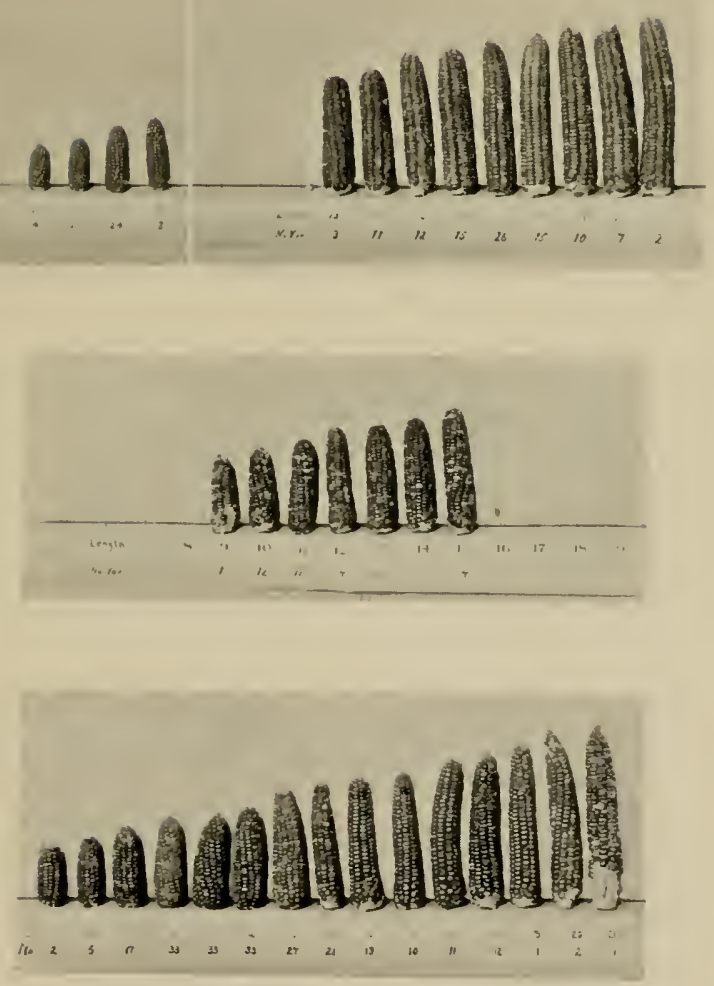

Fig. 85. Cross between two races of Indian com, one with short cols and one with long cobs. The range of varialility in $F_{1}$ is less than that in $F_{2}$. (After Fast.) 

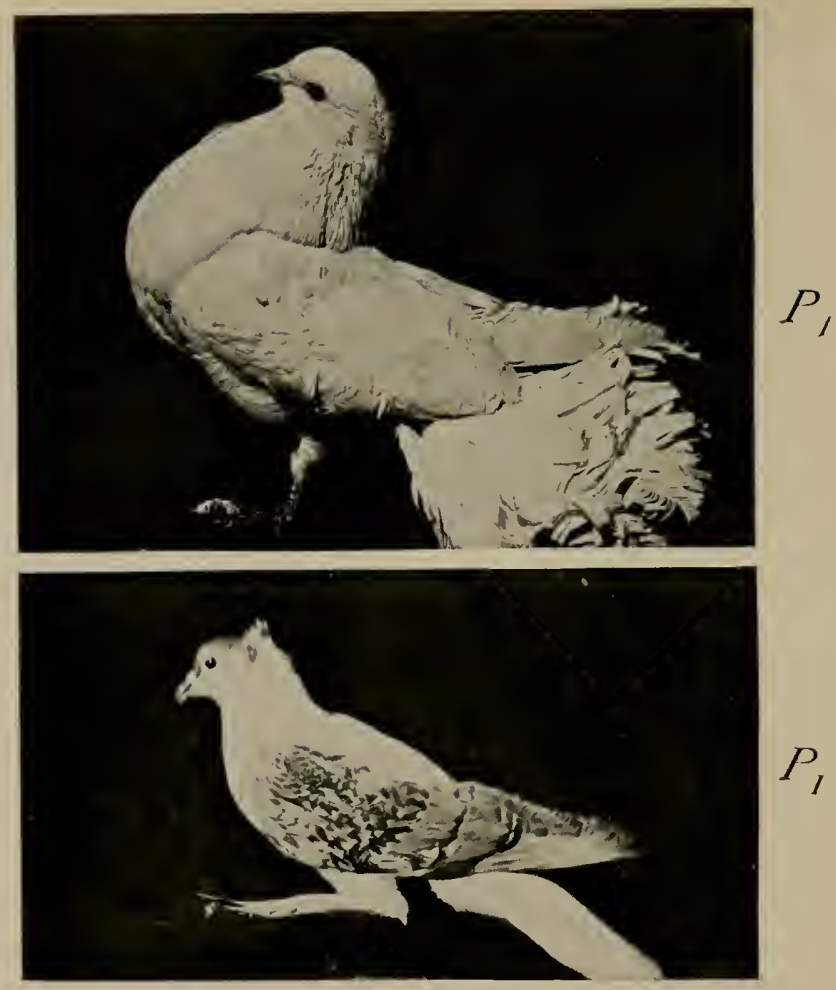

$P_{I}$

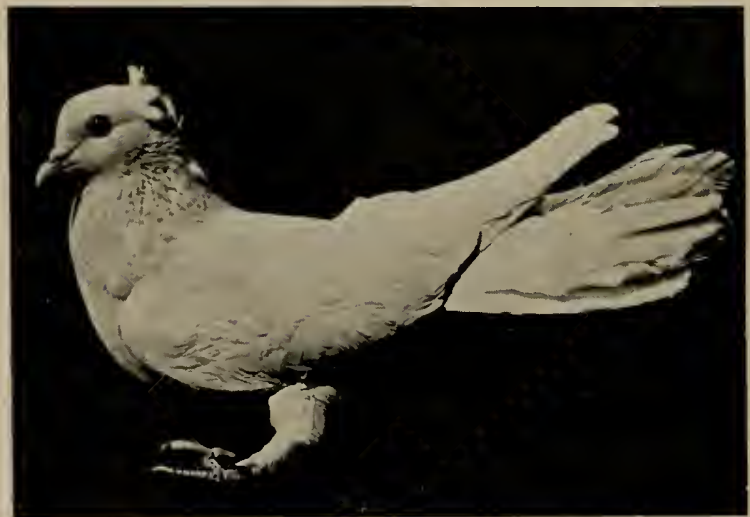

$F_{I}$

Fig. 86. Cross of pigeon with normal tail $P_{1}$ and fantail $P_{1}$; F, bird helow. 
25. Here one of the grand-parental types reappears in large numbers, while the extreme of the other grand-parental type did not reappear (in the counts obtained), although the $\mathrm{F}_{2}$ number would probably overlap the lower

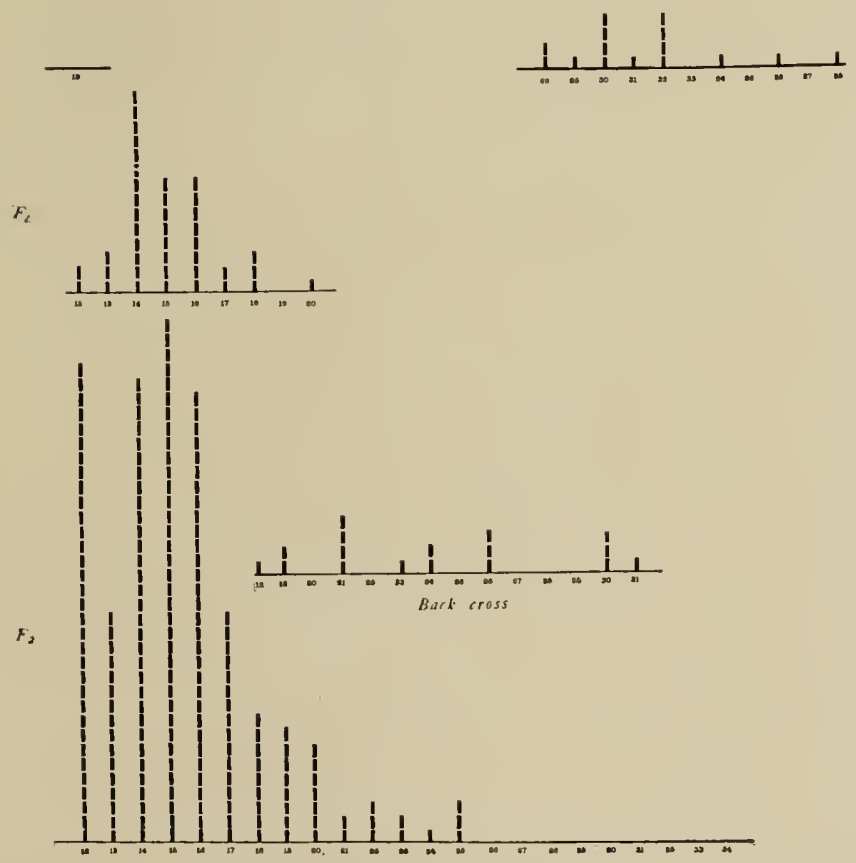

Fig. s\%. Cross of normal and fantail pigeons. (See lig. 86.) The $F_{2}$ range is wider than that of $F_{1}$. The normal grandparental type of 12 feathers was recovered in $F_{2}$ but the higher numbers characteristic of fantails were not recovered. 
limits of the race of fantail grandparents had not a selected (surviving) lot been taken for the figures given in the table.

'The preceding account attempts to point out how I should prefer to interpret the problem of selection in the light of the most recent work on breeding. But I would give a very incomplete account of the whole situation if I neglected to include some important work which has led some of my fellow-workers to a very different conclusion.

Castle in particular is the champion of a view based on his results with hooded rats.

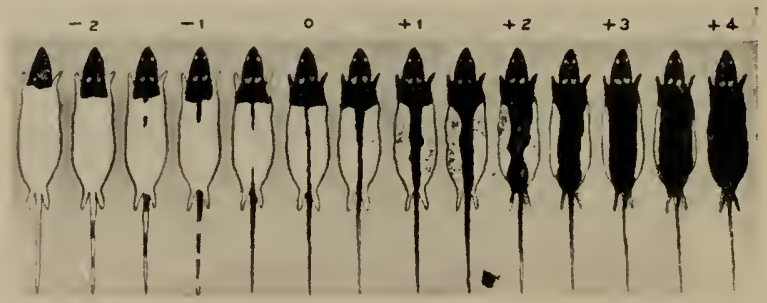

Fig. 88. Scheme to show classes of hooded rats used by Castle. (A fter Castle.)

Starting with individuals which have a narrow black stripe down the back he selected for a narrower stripe in one direction and for a 
broader stripe in the other. As the diagram shows (fig. 88) Castle has succeeded in producing in one direction a race in which the dorsal stripe has disappeared and in the other direction a race in which the black has extended over the back and sides, leaving only a white mark on the belly. Neither of these extremes occurs, he believes, in the ordinary hooded race of domesticated rats. In other words no matter how many of them came under observation the extreme types of his experiment would not be found.

Castle claims that the factor for hoodedness must be a single Mendelian unit, because if hooded rats are crossed to wild gray rats with uniform coat and their offspring are inbred there are produced in $\mathrm{F}_{2}$ three uniform rats to one hooded rat. Castle adrances the hypothesis that factors-by which he means Mendelian factors-may themselves vary in much the same way as do the characters that they stand for. He argues, in so many words, that since we judge a factor by the kind of character it produces, when the character varies the factor that stands for it may have changed. 
As early as 1903 Cuénot had carried out experiments with spotted mice similar to those of Castle with rats. Cuénot found that spotted crossed to uniform coat color gave in $\mathbf{F}_{2}$ a ratio of three uniform to one spotted, yet selection of those spotted mice with more white in their coat produced mice in successive generations that had more and more white. Conversely Cuénot showed that selection of those spotted mice that had more color in their coat produced mice with more and more color and less white. Cuénot does not however bring up in this connection the question as to how selection in these spotted mice brings about its results.

Without attempting to discuss these results at the length that they deserve let me briefly state why I think Castle's evidence fails to establish his conclusion.

In the first place one of the premises may be wrong. 'The three to one ratio in $\mathrm{F}_{2}$ by no means prores that all conditions of hoodedness are due to one factor. The result shows at most that one factor that gives the hooded types is a simple Mendelian factor. The changes in this type may be caused by modifying factors 
that can show an effect only when hoodedness is itself present. 'That this is not an imaginary objection but a real one is shown by an experiment that Castle himself made which fumishes the ground for the second objection.

Second. If the factor has really changed its potency, then if a very dark individual from one end of the series is crossed to a wild rat and the second generation raised we should expect that the hooded $\mathbf{F}_{2}$ rats would all be dark like their dark grandparent. When Castle made this test he found that there were many grades of hooded rats in the $\mathrm{F}_{2}$ progeny. 'They were darker, it is true, as a group than were the original hooded group at the beginning of the selection experiment, but they gave many intermediate grades. Castle attempts to explain this by the assumption that the factor made pure by selection became contaminated by its normal allelomorph in the $\mathbf{F}_{1}$ parent, but not only does this assmmption appear to beg the whole question, but it is in flat contradiction with what we have observed in hundreds of Mendelian cases where no evidence for such a contamination exists. 
Later Castle crossed some of the extracted rats of arerage grade (3.01) from the plus series to the same wild race and got $F_{2}$ hooded rats from this cross. 'These $\mathbf{F}_{2}$ hooded rats did not further approach the ordinary range but were nearer the extreme selected plus hooded rats (3.33) than were the $F_{2}$ 's extracted from the first cross (2.59). Castle concludes from this that multiple factors can not account for the result. As a matter of fact, Castle's evidence as published does not establish his conclusion because the wild rats used in the second experiment may have carried plus modifiers. 'This could only be determined by suitable tests which Castle does not furnish. This is the crucial point, without which the evidence carries no conviction.

Furthermore, from Castle's point of view, these latest results would seem to increase the difficulty of interpretation of his first $\mathbf{F}_{2}$ extracted cross, and it is now the first result that calls for explanation if one accepts his later conclusion.

'These and other objections that might be taken up show, I think, that Castle's experi- 
ment with hooded rats fails entirely to establish his contention of change in potency of the germ or of contamination of factors, while on the contrary they are in entire accord with the view that he is dealing with a case of modifying factors.

Equally important are the results that Jennings has obtained with certain protozoa. Paramecium multiplies by dividing across in the

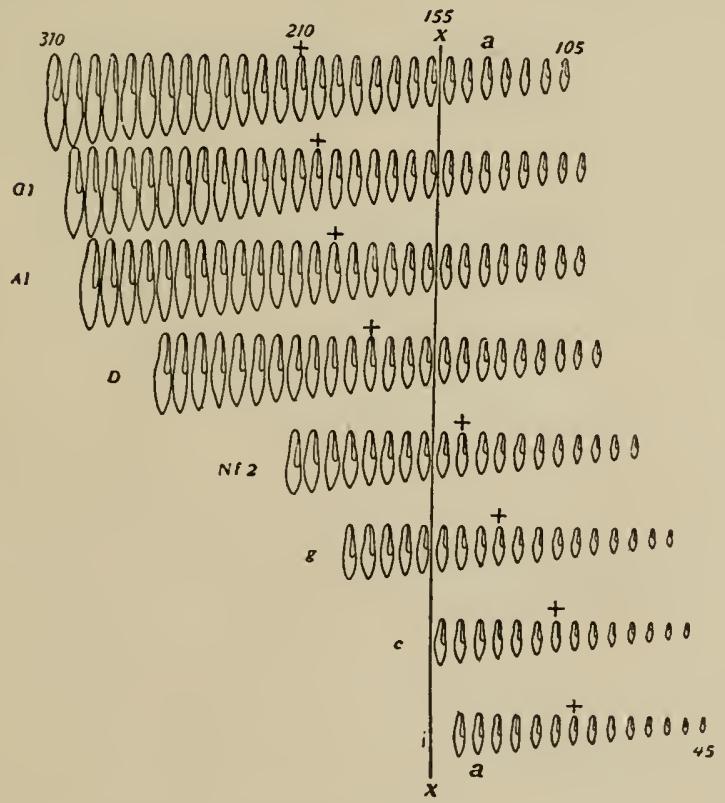

Fig. S9. Races of Paramecium. ( $\mathrm{ffter}$ Jennings.) 
middle, each half replacing its lacking part. Both the small nucleus (micronucleus) and the large nucleus (macronucleus) divide at each division of the body. Jennings found that while individuals descended from a single faramecium vary in size (fig. 89), yet the population from a large individual is the same as the population derived from a small individual. In other words, selection produces no result and the probable explanation is, of course, that the different sizes of individuals are due to the environment, while the constancy of the type is genetic. Jemnings found a number of races of paramecium of different sizes living under natural conditions. 'The largest individual of a small race might overlap the smallest individual of other larger races (fig. 89) ; nevertheless each kind reproduced its particular race. The results are like those of Johannsen in a general way, but differ in that reproduction takes place in paramecium by direct division instead of through self-fertilization as in beans, and also in that the paramecia were probably not homozygous. Since, however, so far as known no "reduction" takes place in 
paramecium at each division, the genetic composition of parent and off'spring should be the same. Whether pseudo-parthenogenesis that Woodruff and Erdmann have found occurring in paramecium at intervals involves a redistribution of the hereditary factors is not clear. Jemnings's eridence seems incompatible with such a view.

More recently one of Jenning's's students, Middleton, has made a careful series of selection experiments with Stylonychia (fig. 90) in which he selected for lines showing more rapid
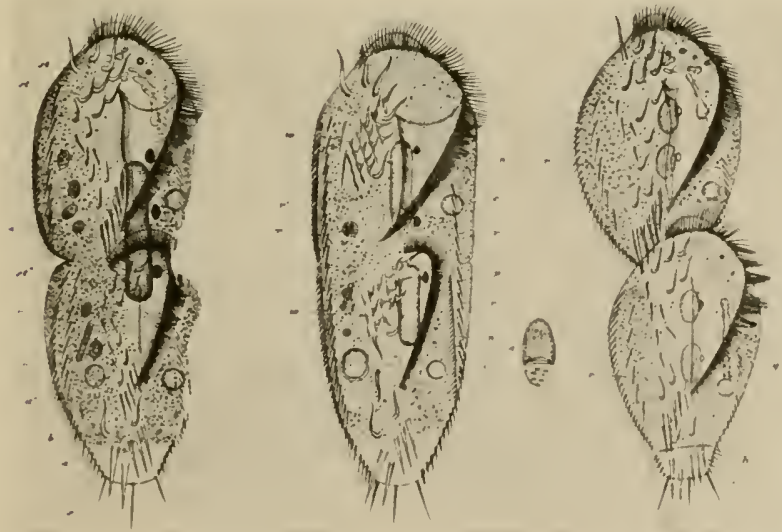

F's. 90. Stỵlongchia showing division into two. (Ifter Stein.) 
or slower rates of division. His observations seem to show that his selection separated two such lines that came from the same original stock. 'The rapidity of the effects of selection seems to preclude the explanation that pseudoparthenogenesis has complicated the results. Nevertheless, the results are of such a kind as to suggest that they were due to selection of vegetative (somatic) differences and that no genetic change of factors was involved, for his conclusion that the rapidity with which the effects gained by long selection might be suddenly reversed when selection was reversed is hardly consistent with an interpretation of the results based on changes in the "potencies" of the factors present.

Equally striking are the interesting experiments that Jennings has recently carried out with Difflugia (fig. 91). This protozoon secretes a shell about itself which has a characteristic shape, and often carries spines. The opening at one end of the shell through which the protoplasm protrudes to make the pseudopodia is surrounded by a rim haring a characteristic pattern. The protoplasm contains 
several nuclei and in addition there is scattered material or particles called chromidia that are

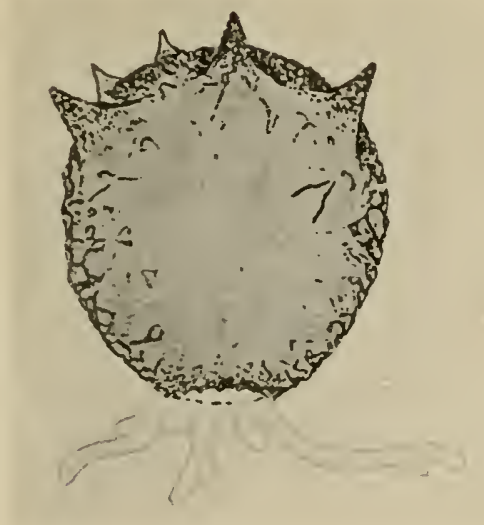

Fig. 91. Difflugia Corona. (After Cash.)

supposed to be chromatic in nature and related to the material of the nuclei, possibly by direct interchange.

When Difflugia divides, part of the protoplasm protrudes from the opening and a new shell is secreted about this mass which becomes a daughter individual. 'The behavior of the nucleus and of the chromidia at this time is obscure. but there is some evidence that their materials may be irregularly distributed be- 
tween parent and offspring. If this is correct, and if in the protozoa the chromatin has the same influence that it seems to have in higher animals, the mode of reproduction in Difflugia would be expected to give little more than random sampling of the germ plasm.

Jennings was able by means of selection to get from the descendants of one original indi-

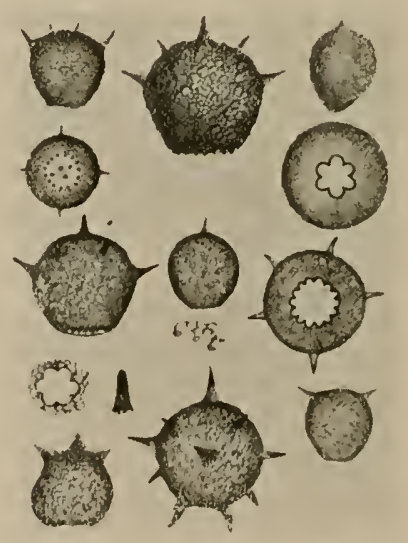

Fig. 92. Races of Diffugia. ( $\triangle$ fter Leidy.)

vidual a number of different types that themselves bred true, except in so far as selection could affect another change in them. In this connection it is interesting to note that Leidy 
has published figures of Difflugia (fig. 92) that show that a great many "types" exist. If through sexual union (a process that occurs in Difflugia) the germ plasm (chromatin) of these wild types has in times past been recombined, then selection would be expected to separate certain types again, if, at division, irregular sampling of the germ plasm takes place. Until these points are settled the bearing of these important experiments of Jemnings on the general problem of selection is uncertain.

\section{How Does Nateral Selaction Ixfluexce the Course of Erolution?}

The question still remains: Does selection play any rôle in evolution, and, if so, in what sense? Does the elimination of the unfit influence the course of evolution, except in the negative sense of leaving more room for the fit? There is something further to be said in this commection, although opinions may differ as to whether the following interpretation of the term "natural selection" is the only possible one.

If through a mutation a character appears 
that is neither advantageous nor disadvantageous, but indifferent, the chance that it may become established in the race is extremely small, although by good luck such a thing may occur rarely. It makes no difference whether the character in question is a dominant or a

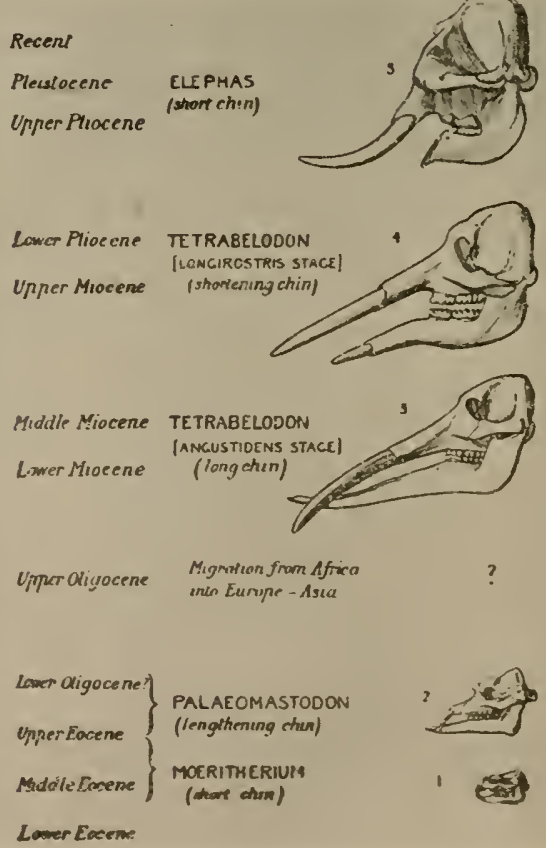

Fig. 93. Evolution of elephant's skulls. (After Dendr.) 
recessive one, the chance of its becoming established is exactly the same. If through a mutation a character appears that has an injurious effect, howerer slight this may be, it has practically no chance of becoming established.

If through a mutation a character appears

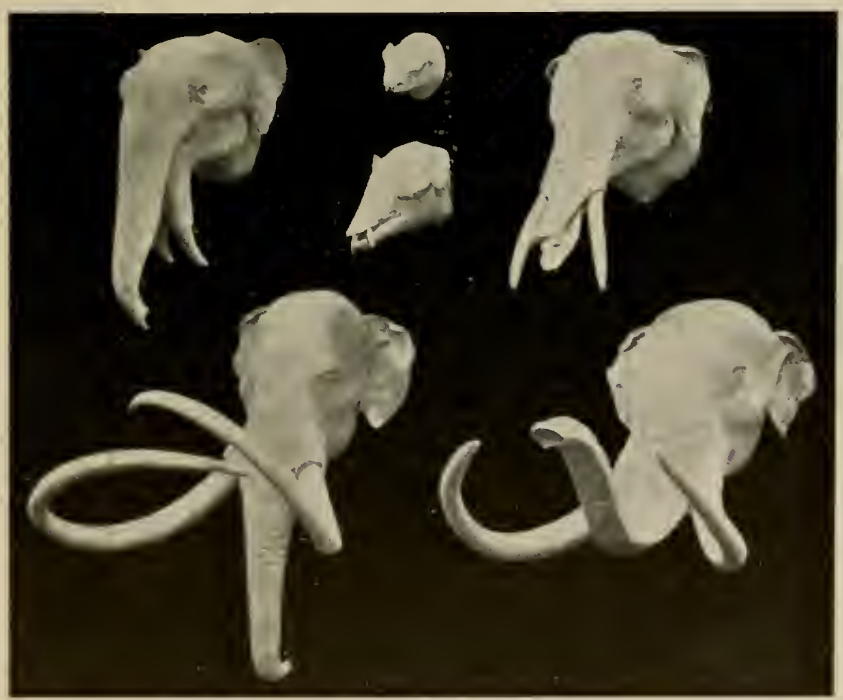

I'IG. 94. Erohution of elephant's trunk. (After I.ull.)

that has a bencficial influence on the individual, the chance that the individual will survive is increased, not only for itself. but for all of its 
descendants that come to inherit this character. It is this increase in the number of individuals possessing a particular character, that might have an influence on the course of evolution. 'This gives a better chance for improvement by several successive steps; but not because the species is more likely to mutate again in the same direction. An imaginary example will illustrate how this happens: When elephants had trumks less than a foot long, the chance of getting trunks more than one foot long was in proportion to the length of trunks already present and to the number of individuals; but increment in trunk length is no more likely to occur from an animal having a trunk more than one foot long than from an animal with a shorter trunk.

The case is analogous to tossing pennies. At any stage in the game the chance of accumulating a hundred heads is in proportion to the number of heads already obtained, and to the number of throws still to be made. But the number of heads obtained has no influence on the number of heads that will appear in the next throw. 

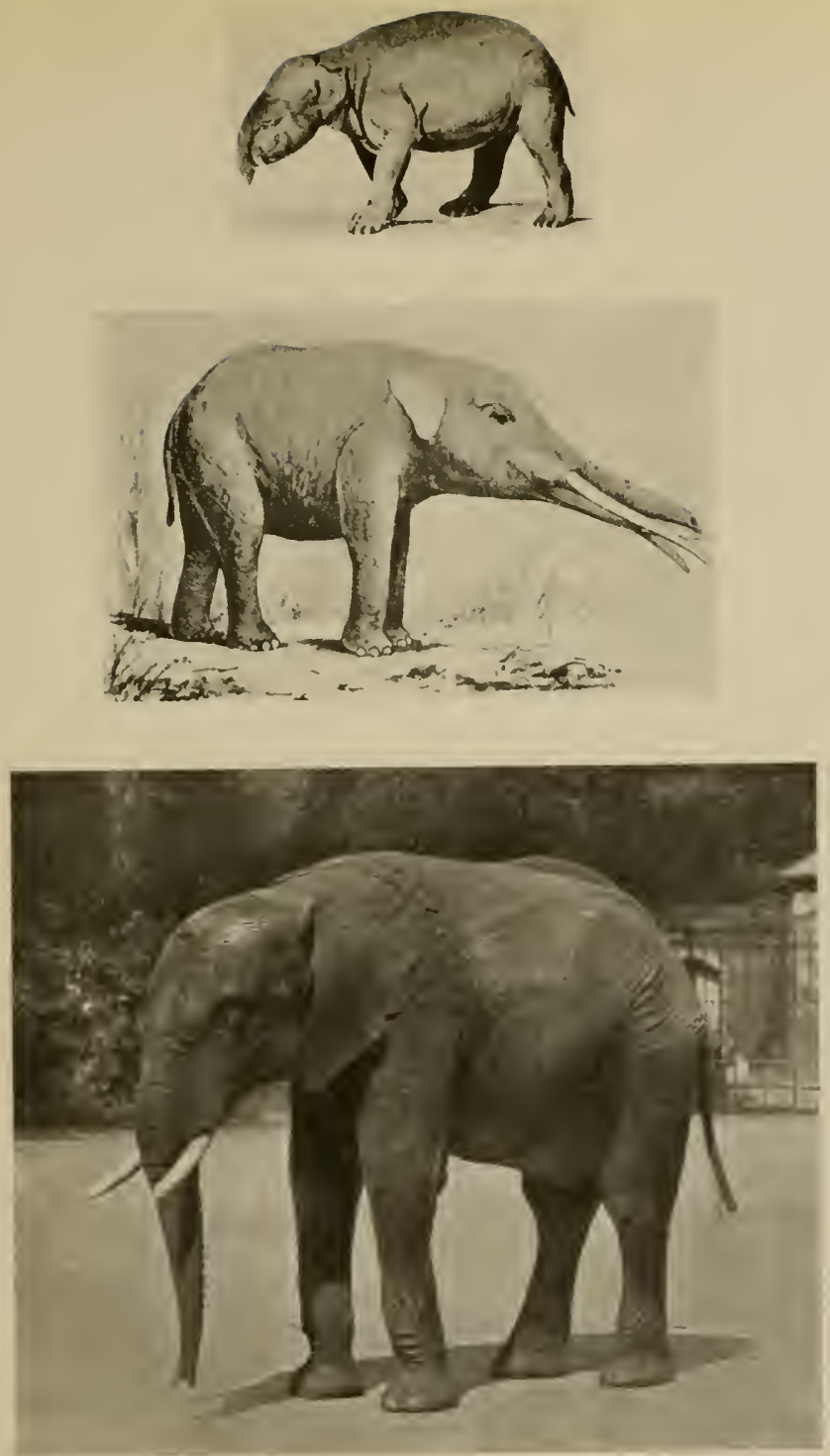

Fig. 95. Evolution of elephant's trunk: above Maeritherimu, in the middle Tetrabelorlon ( $\triangle$ fter I ancaster); helow $\triangle$ frican elephants (.Ifter (iamhier Bolton). 
Owing then to this property of the germ plasm to duplicate itself in a large number of samples not only is an opportunity furnished to an advantageous variation to become extensively multiplied, but the presence of a large number of individuals of a given sort prejudices the probable future result.

'The question may be raised as to whether it is desirable to call selection a creative process. 'There are so many supernatural and mystical implications that hang around the term creative that one can not be too careful in stating in what sense the term is to be used. If by creative is meant that something is made out of nothing, then of course there is no need for the scientist to try to answer such a question. But if by a creative process is meant that something is made out of something else, then there are two alternatives to be reckoned with.

First, if it were true that selection of an individual of a certain kind determines that new variations in the same direction occur as a consequence of the selection, then selection would certainly be creative. How this could occur might be quite unintelligible, but of course it 
might be claimed that the point is not whether we can explain how creation takes place, but whether we can get rerifiable evidence that such a kind of thing happens. 'This possibility is disposed of by the fact that there is no evidence that selection determines the direction in which variation occurs.

Second, if you mean by a creative process that by picking out a certain kind of individual and multiplying its numbers a better chance is furnished that a certain end result will be oltained, such a process may be said to be creative. 'This is, I think, the proper use of the term creative in a mechanistic sense.

\section{Concluesions}

In reviewing the evidence relating to selection I have tried to handle the problem as objectively as I could.

The evidence shows clearly that the characters of wild animals and plants. as well as those of domesticated races, are inherited both in the wild and in the domesticated forms according to Mendel's Law.

'The causes of the mutations that give rise 
to new character's we do not know, although we hare no reason for supposing that they are due to other than natural processes.

Erolution has taken place by the incorporation into the race of those mutations that are beneficial to the life and reproduction of the organism. Natural selection as here defined means both the increase in the number of individuals that results after a beneficial mutation has occurred (owing to the ability of living matter to propagate) and also that this preponderance of certain kinds of individuals in a population makes some further results more probable than others. Nore than this, natural selection can not mean, if factors are fixed and are not changed by selection. 


\section{INDEX}

Abmormal abdomen 109

Ibraxas $78-81$

Nllantois 17

Allelomorphs $83-84$

Nitenburg 11?

Imnion 16-17

Indalusian fowl 45,46

Anuelids 2:2

Antlered wing 111

Apterous wing 11

Arc wing 111

Aristae 104

Bar eye 6\%, 108, 169

Bateson 18, 34, 36

Beaded wing 11, 115

Beans $1+\gamma-149,15 \tau$

Belgian hare 171

Bent wing 116

Bergson 30, 31

Bildungstrich 34

Biogenetic law 15, 18, 19, 21

Biometricians 156

Bird 21,23

Bithorax 6.5, 112, 113 ,

Black body (olor 111, 133

Blakeslee 1.5:

Briclgen 114, 143, 163

British Association 36

Briinn 10

Buff eye color 109

I3ufon $\approx \gamma$

Castle 176-180

Cat 33

Cell 90,91

Chance variations $3 \gamma$

Chick 16, 17, 20

Chromatin 18t
Chromosome gromp of Drosophila 102

Chromosomes 91, 95, 96, 98, 130, 131, 132

Clearage 21, 22, 94

Clover butterfly 62

Club wing $69,80,108$

Colias philodice 6:2

Color blindness $7 \%, 125$

Comb of Drosophila 103

Combs of fowls 33,54

Comparative anatomy $7,8,9$. 14

Corn 150, 153, 17\%

Correns 41

Cosmogonies 27

Cream eve color 163, 164

Crepidula 22

Criss-cross inherilance is

Crossing over 131-133

Cuénot 178

Curled wing 115

Curved wing 111

Corve of probability 149

Cut wing 11, 101.

Dachs legs 112

Dahlgren 6:

Darwin $15,24,28,3 \%, 35-36,64$, $145,146,152,15+-156$

Dendy 189

I) Vries $18,11 \%, 1.56$

Dexter 170

Dichaele 11 t.

1)ithugia 184-187

Discontinuous variation 13

Jisuse 31

1) rosophila ampelophila 10, 1:, 
13, 48-50, 60, 75, 84, 85, 93, Hoge 66

$100,103,119,155,163,169$ Horse, evolution of, 6

Drosophila repleta 76

Duplication of legs 109

Dwarf 114

East 170,172

Eliony 50, 55, 56, 115

E.g. 91,94

Elephant 191

Elephants' skulls 188

Elephants' trumks 190

Embryology 13-93

Emerson 172

Enviromment 27

Eosin eye color 61, 107, 163

Erclmanin 183

Evolution Creatrice 30

Evolution-three kinds of$1,2,1$

Eye color 13

Eyeless 66,115

Factorial theory 89

Factors of Drosophila 143

Fantails 172,175

Fertilization 91

Fish 16, 20,21

Flatworms 22

Fluctuations 1?

Forked bristles 106

Fowl 77

Fused reins 10\%, 108

Galton 154

Geneticist 26

Germ-plasm 1+2

Geoffroy St. Hiliare 27

Giant 114

Gill-slits $20,21,23$

Grotips I, II, I I , IV, 100-118

\section{Haeckel 15}

Hamophilia 77

J leliotropism 106, 107

llimalyan rabbits 83

I'istory 1, 6

Indian corn 179,173

Interference 137,138

Janssens 132

Jaunty wing 111

Jemnings $161,181-184,186$

Johannsen 156, 15\%, 159-161 166,18 ?

l.amarck 31-34

l.allgshan 77

Leaves 147

L.eidy 186

I.ethal 105

Linkage groups 103

lizard 23

Jocalization of factors 118

MacDowell 155, 170, 171

Maeritherim 191

Mammal 16, 21, 93

Man $20,77,125,126$

Mlap of Chromosomes 136

Maroon eye color 114

Mendel $40,41,52,89$

Mendelian heredity 39

Mendel's law $41-59,64,124$

Mendel's second law 52

Mesenchyme cells 22

Mesoclerin cells 22

Metaphysician 30

Mice 33,178

Micklleton 183

Miniature wing 108

Mirabilis 12

Modifiers 163, 164, 170, 171

Molluses 2.2

Mouse 83

Muller 112, 167

Mutations 3.5, 39, 84

Nägeli 34, 35

Natural Selection 36, 145, 146, $18 \%-194$ 
Nisus formativus 31

Non-disjunction 139-14?

Notch wing 104-106

Nurclens 91

Origin of Species 35,145

Urthogenesis 31

Paleontology 24-27

Papilio polytes 63

Papilio turmos 63

Paramecium 151, 182

Paratettix S1

Peach eve color 111 .

Pea comb st

Pearl 161

Peas 47

Pigeons 17\%, 174, 175

Pink eve color 114, 115

Planarian g?

Plimouth Rock $\tau$ \%

Podarke ?2:

Polar bodies 1:6

Pole arms $j$

Protozoa 181

Psendo-parthenogenesis 183

Purple eye color 109

Prirpone 1

Rabbits 83, 170

Rats $176-180$

Reduction division 1A?

Reproductive cells 96

Ruby eye color 106

Rudimentary organ 116

Rudimentary wing $\gamma 0, \tau 1,10 \tau$

Sable body color 105

science, definition of, 6

secrregation 11

selenka 94

Sepia eve color 13, 114

sex chromosomes 118

sex linked inheritance is, 11 - 130

Sixual dimorphism 6:2

Sheep 33
Single comb 51

Sooty body color 50, 111,11 ;

speck $68,69,111$

spencer 145

Spermatozoön 91, 9s

Stars, erolution of, $(i$

St. Hiliare $27-30$

Stral) wing 110, 111

Stmmpy wing 11

Sturterant $\tau 6, \quad 1+3$

Stylonychia 183

Sirrival of the fittent 146

Systematist 85

Tails 33

'Tan flies 106,107

Tetrabelodon 191

Trefoil 111

Truncate wing 111, 112, 16\%, 168

Enfolding principle 34

Unio 2:2

Unit character 71,75

Use 31

Variation, discontinuous 13

Vermilion eye color 108, 163

Vestigial wing 11, 55, 56, 109, 133

Vital force 31.

Wrallace 36

Walnut comb jt

Weismamn 17, 31-33

Wilion, E. 13. 12j

Wingless $6 i$

Winiwarter 1:36

White eye color 13, 7.5, 119-130

Whiting eye color 163,164

Woodruff 183

Yellow body rolor 108, 133

Yolk sac $1 \dot{6}, 17$

Zeleny 169 




s

1 a

(1) 